\title{
Universal Access to Protease Chemiluminescent Probes through Solid-Phase Synthesis
}

\author{
Maria Ponomariov ${ }^{\mathrm{a}}$, Doron Shabat ${ }^{\mathrm{a} *}$ and Ori Green ${ }^{\mathrm{a} *}$

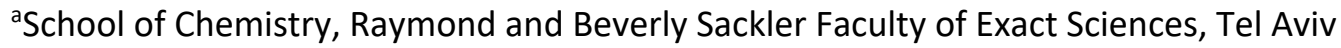 \\ University, Tel Aviv 69978 Israel.
}

\section{Supporting Information}

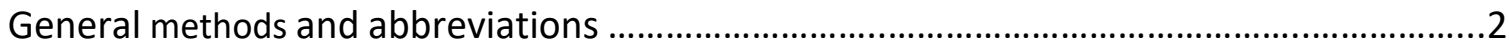

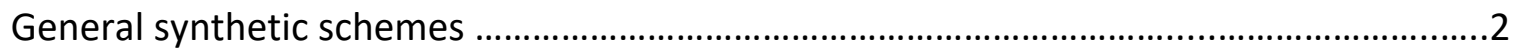

Compatibility of Met and Trp towards oxidation with singlet oxygen..................................3

Experimental procedures for the synthesis of compounds $1 \mathrm{a}-\mathbf{3 a}$.....................................8

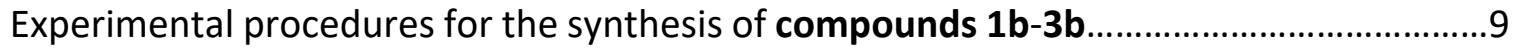

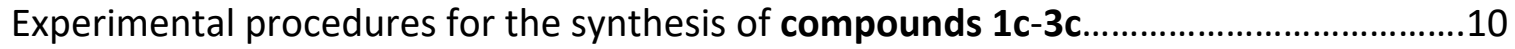

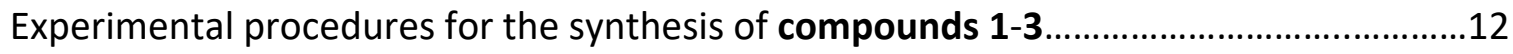

Experimental procedures for the synthesis of Resin 1-3 (Resin loading)............................15

Experimental procedures for the synthesis of Enol-ether 1-3 (Fmoc SPPS).......................16

Experimental procedures for the synthesis of APCP, CBCP and PSACL...........................21

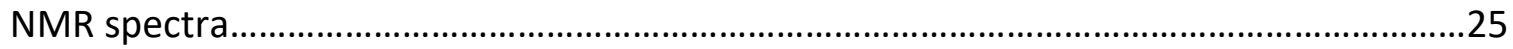




\section{General methods}

All reactions were carried out at room temperature unless stated otherwise. Chemicals and solvents were either A.R. grade or purified by standard techniques. Thin layer chromatography (TLC): silica gel plates Merck 60 F254: compounds were visualized by irradiation with UV light. Column chromatography (FC): silica gel Merck 60 (particle size 0.040-0.063 mm), eluent given in parentheses. Reverse-phase high pressure liquid chromatography (RP-HPLC): C18 5u, 250x4.6mm, eluent ACN and water with 0.1\% TFA, gradient given in parentheses. Preparative RPHPLC: $\mathrm{C} 185 \mathrm{u}, 250 \times 21 \mathrm{~mm}$, eluent ACN and water with $0.1 \%$ TFA, gradient given in parentheses. ${ }^{1} \mathrm{H}-\mathrm{NMR}$ spectra were recorded using Bruker Avance operated at $400 \mathrm{MHz}$ or $500 \mathrm{MHz} .{ }^{13} \mathrm{C}-\mathrm{NMR}$ spectra were recorded using Bruker Avance operated at $100 \mathrm{MHz}$ or $126 \mathrm{MHz}$. Chemical shifts were reported in ppm on the $\delta$ scale relative to a residual solvent $\left(\mathrm{CDCl} 3: \delta=7.26\right.$ for ${ }^{1} \mathrm{H}-\mathrm{NMR}$ and 77.16 for ${ }^{13} \mathrm{C}-\mathrm{NMR}$, DMSO-d6: $\delta=2.50$ for ${ }^{1} \mathrm{H}-\mathrm{NMR}$ and 39.52 for $13 \mathrm{C}-\mathrm{NMR}$ ). Mass spectra were measured on Waters Xevo TQD. Chemiluminescence was recorded on Molecular Devices Spectramax i3x.

Abbreviations: AcOH - Acetic acid, ACN - Acetonitrile, DCC - N,N'-Dicyclohexylcarbodiimide, DCM - Dichloromethane, DIPEA - Diisopropylethylamine, DMAP - 4-Dimethylaminopyridine, DMBA 1,3-Dimethylbarbituric acid, DMF - N,N'-Dimethylformamide, EEDQ - 2-Ethoxy-1-ethoxycarbonyl1,2-dihydroquinoline, EtOAc - Ethyl acetate, Hex - Hexanes, MeOH - Methanol, TFA Trifluoroacetic acid, TMS-Cl - Trimethylsilyl chloride, SPPS - Solid phase peptide synthesis.

\section{General Synthetic schemes}
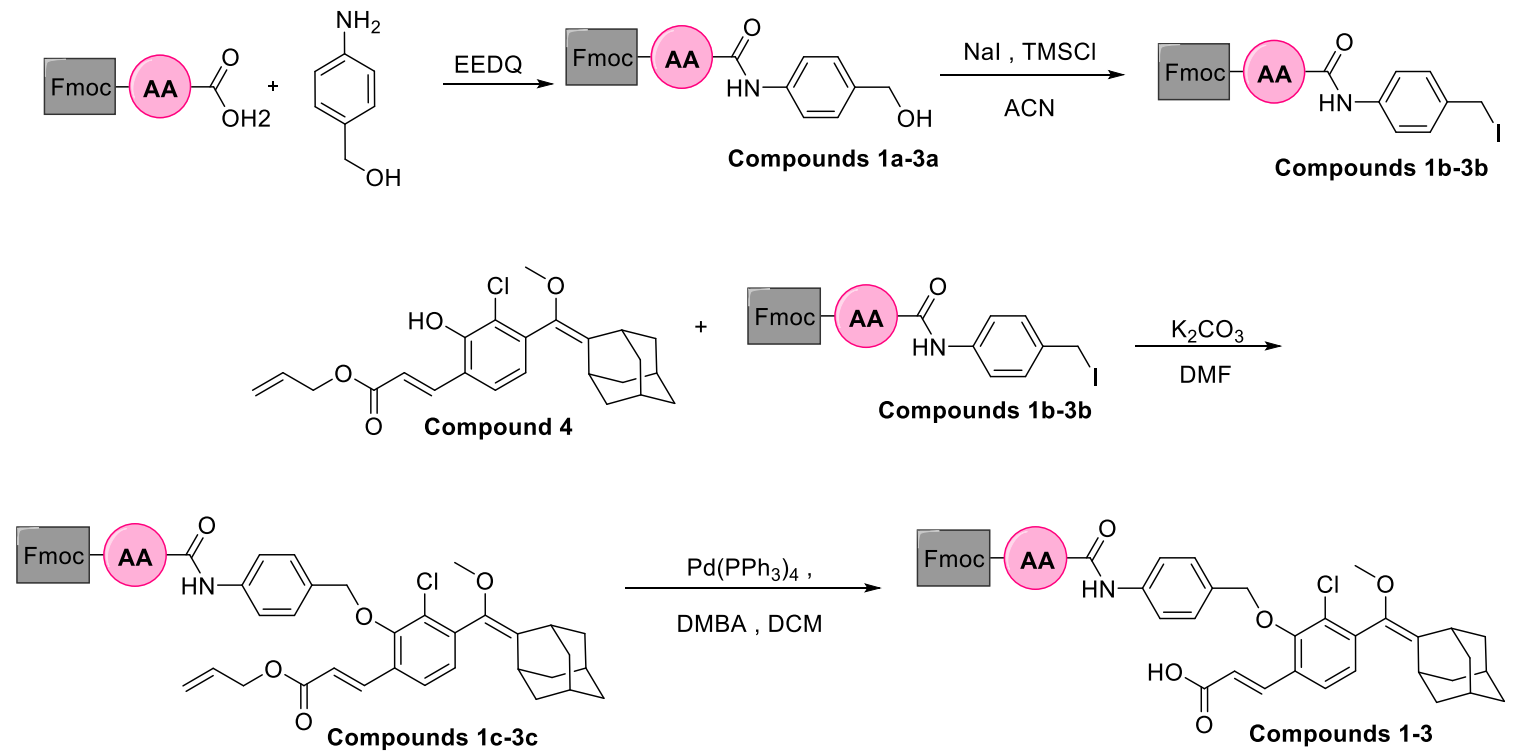

Figure S1. General synthetic scheme for compounds 1-3; Enol-ether protected with Fmoc-AA. 


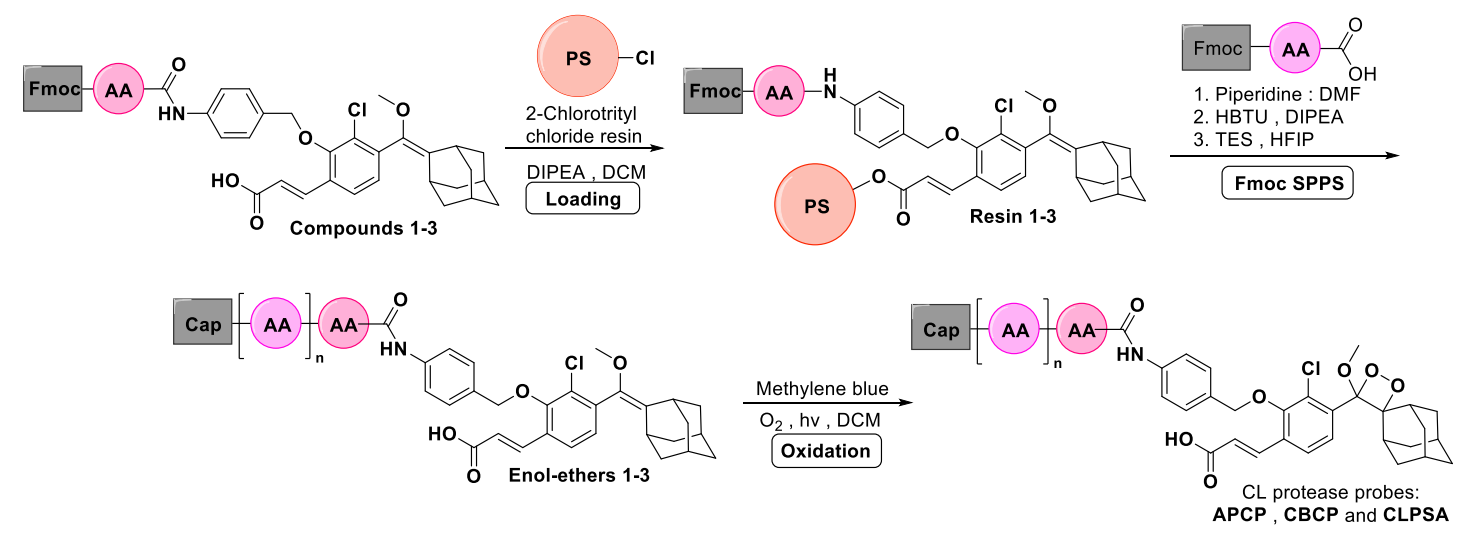

Figure S2. General synthetic scheme for preparing the protease probes APCP, CBCP and CLPSA using SPPS.

\section{Compatibility of Met and Trp towards oxidation with singlet oxygen}

The compatibility of the oxidation with the amino acids Met and Trp was tested by performing Fmoc SPPS with a single amino acid (either Fmoc-Met-OH or Fmoc-Trp(Boc)$\mathrm{OH}$ ) on resin 1, after which the oxidation was performed (as shown in Figure S2). The results are presented below.

\section{Tryptophan:}

Coupling:

Resin 1

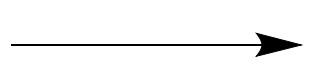<smiles>COC(=C1C2CC3CC(C2)CC1C3)c1ccc(/C=C/C(=O)O)c(OCc2ccc(NC(=O)C(C)NC(=O)C(Cc3cn(C(=O)OC(C)(C)C)c4ccccc34)NC(F)(F)F)cc2)c1Cl</smiles>

MS (ES+): $\mathrm{m} / \mathrm{z}$ calculated for $\mathrm{C}_{62} \mathrm{H}_{63} \mathrm{ClN}_{4} \mathrm{O}_{10}: 1058.4$; found: $1081.7[\mathrm{M}+\mathrm{Na}]^{+}$. 

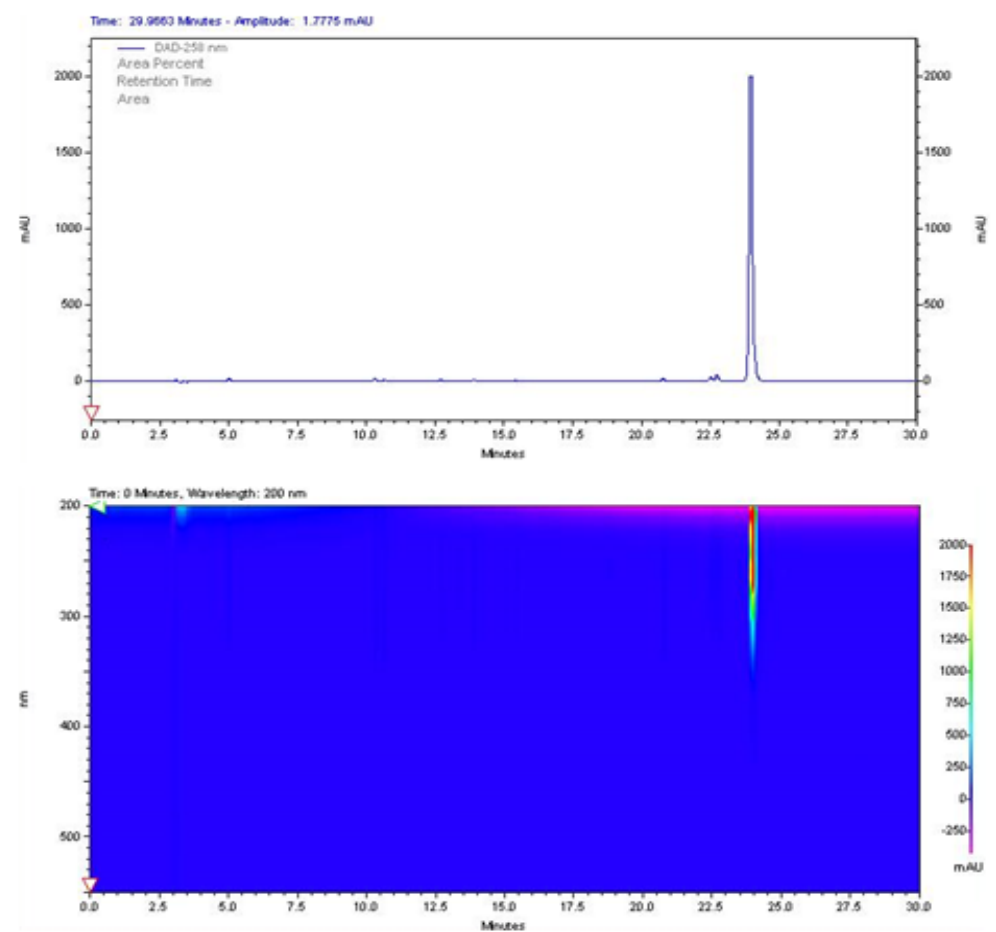

Figure S3. HPLC 2D and 3D chromatogram of Test-1a (50-100\% $A C N: \mathrm{H}_{2} \mathrm{O}, \mathrm{RT}=24$ minutes).

Oxidation:

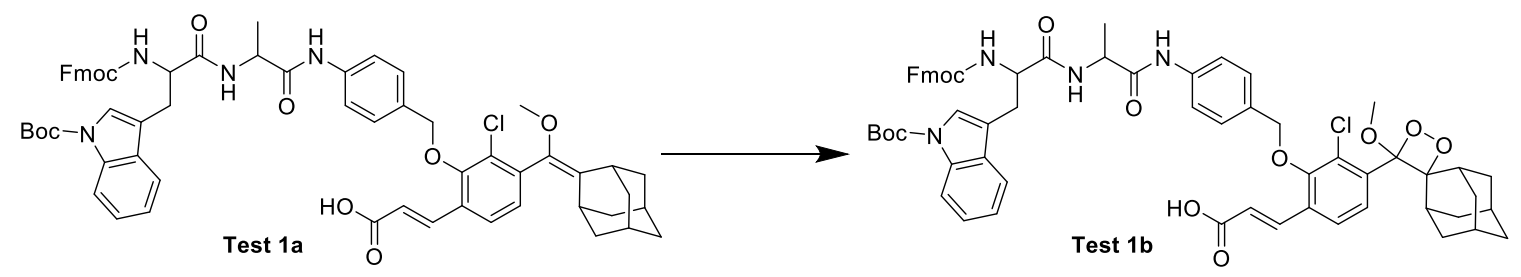

MS (ES+): $\mathrm{m} / \mathrm{z}$ calculated for $\mathrm{C}_{62} \mathrm{H}_{63} \mathrm{ClN}_{4} \mathrm{O}_{12}: 1090.4$; found: $1113.7[\mathrm{M}+\mathrm{Na}]^{+}$. 

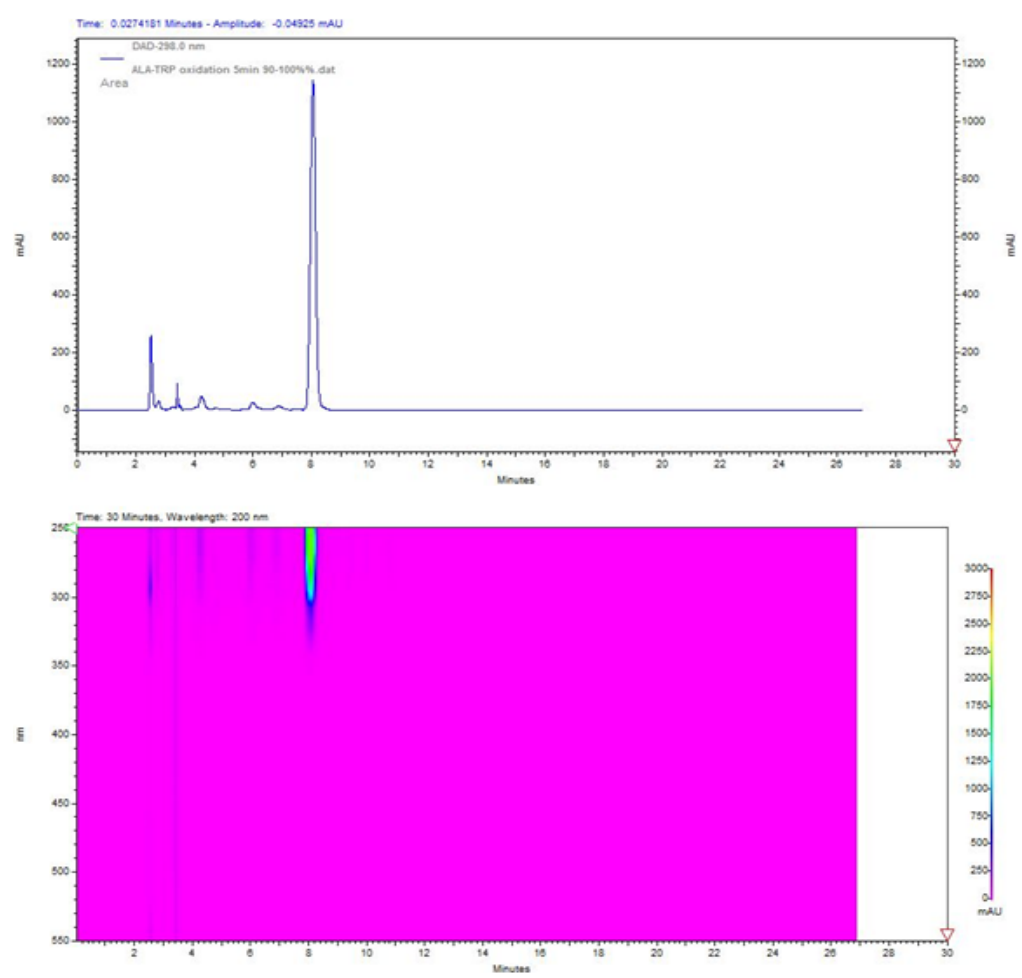

Figure S4. HPLC 2D and 3D chromatogram of Test-1b (90-100\% ACN: $\mathrm{H}_{2} \mathrm{O}, \mathrm{RT}=8$ minutes).

\section{Methionine:}

Coupling:

Resin 1<smiles>COC(=O)NC(CCSC)C(=O)NC(C)C(=O)Nc1ccc(COc2c(/C=C/C(=O)O)ccc(C(OC)=C3C4CC5CC(C4)CC3C5)c2Cl)cc1</smiles>

MS (ES+): $\mathrm{m} / \mathrm{z}$ calculated for $\mathrm{C}_{51} \mathrm{H}_{54} \mathrm{ClN}_{3} \mathrm{O}_{8} \mathrm{~S}:$ 903.3; found: $926.6[\mathrm{M}+\mathrm{Na}]^{+}$. 

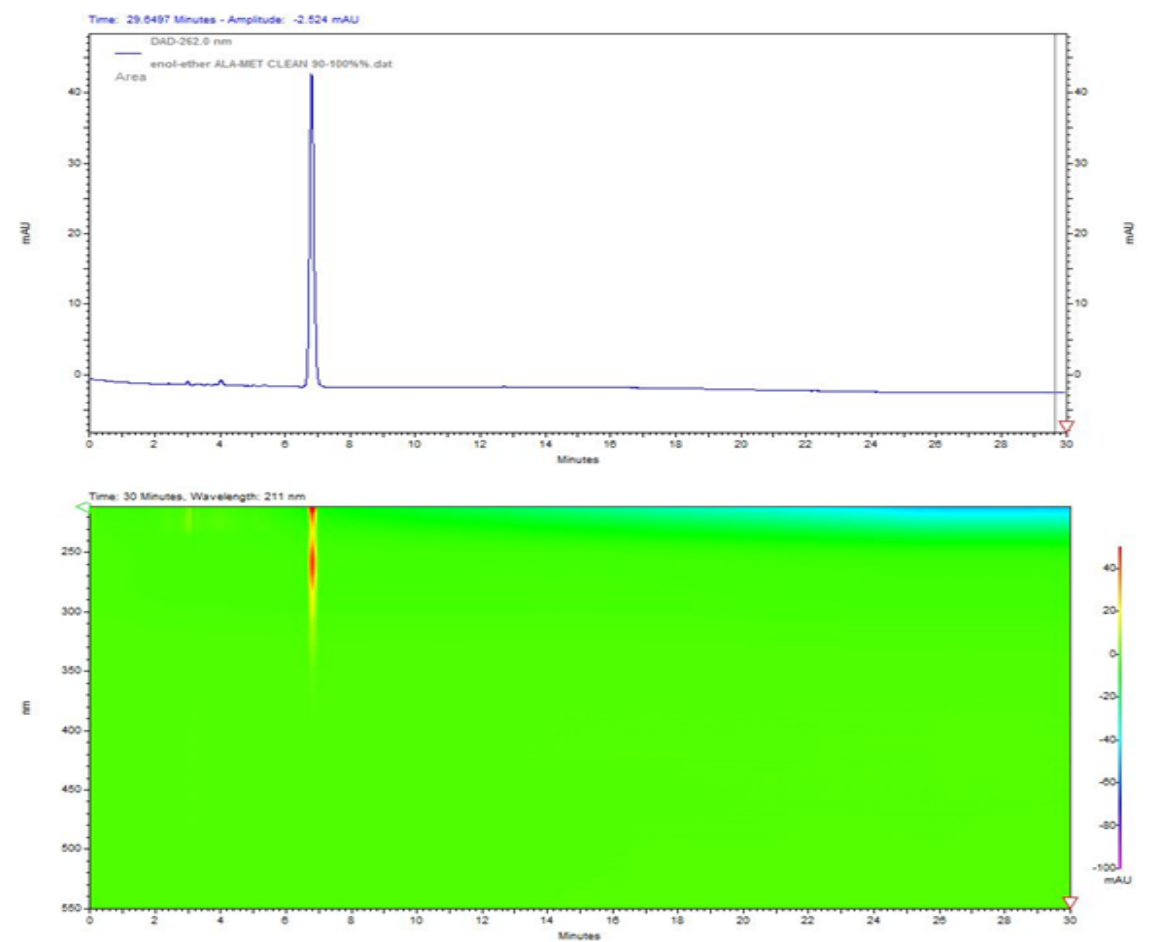

Figure S5. HPLC 2D and 3D chromatogram of Test-2a (90-100\% $\mathrm{ACN}: \mathrm{H}_{2} \mathrm{O}, \mathrm{RT}=6.8$ minutes).

\section{Oxidation:}

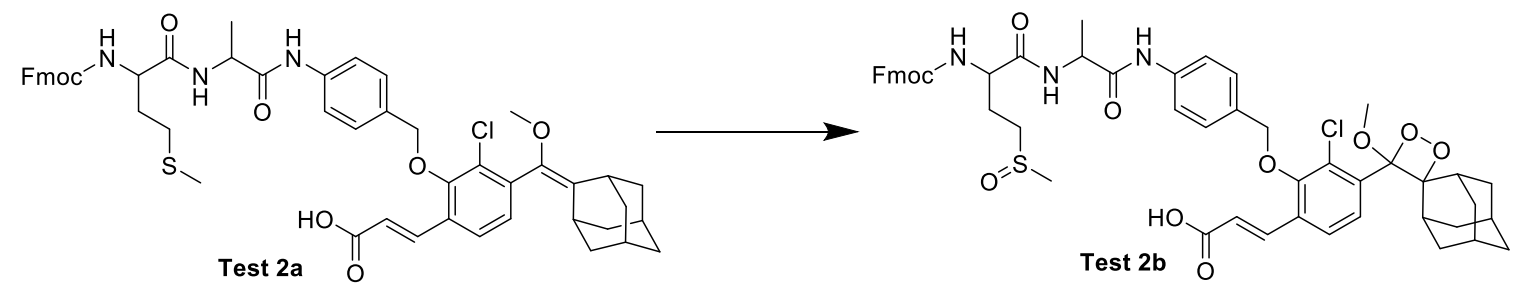

MS (ES+): $\mathrm{m} / \mathrm{z}$ calculated for $\mathrm{C}_{51} \mathrm{H}_{54} \mathrm{ClN}_{3} \mathrm{O}_{11} \mathrm{~S}$ : 951.3; found: $974.6[\mathrm{M}+\mathrm{Na}]^{+}$. 

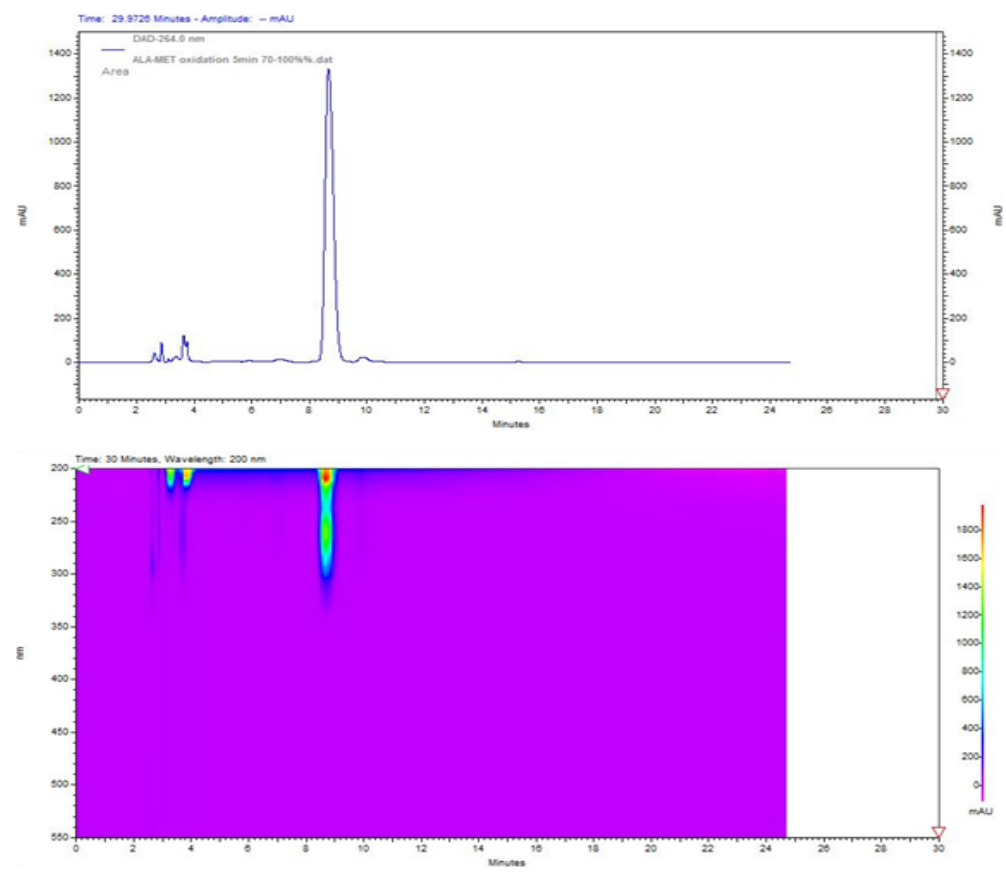

Figure S6. HPLC 2D and 3D chromatogram of Test-2b (70-100\% ACN: $\mathrm{H}_{2} \mathrm{O}, \mathrm{RT}=8.7$ minutes).

In addition to the coupling tests, Fmoc-Trp-OH was exposed to the oxidation conditions to see whether or not the side-chain nitrogen is oxidized by singlet oxygen:
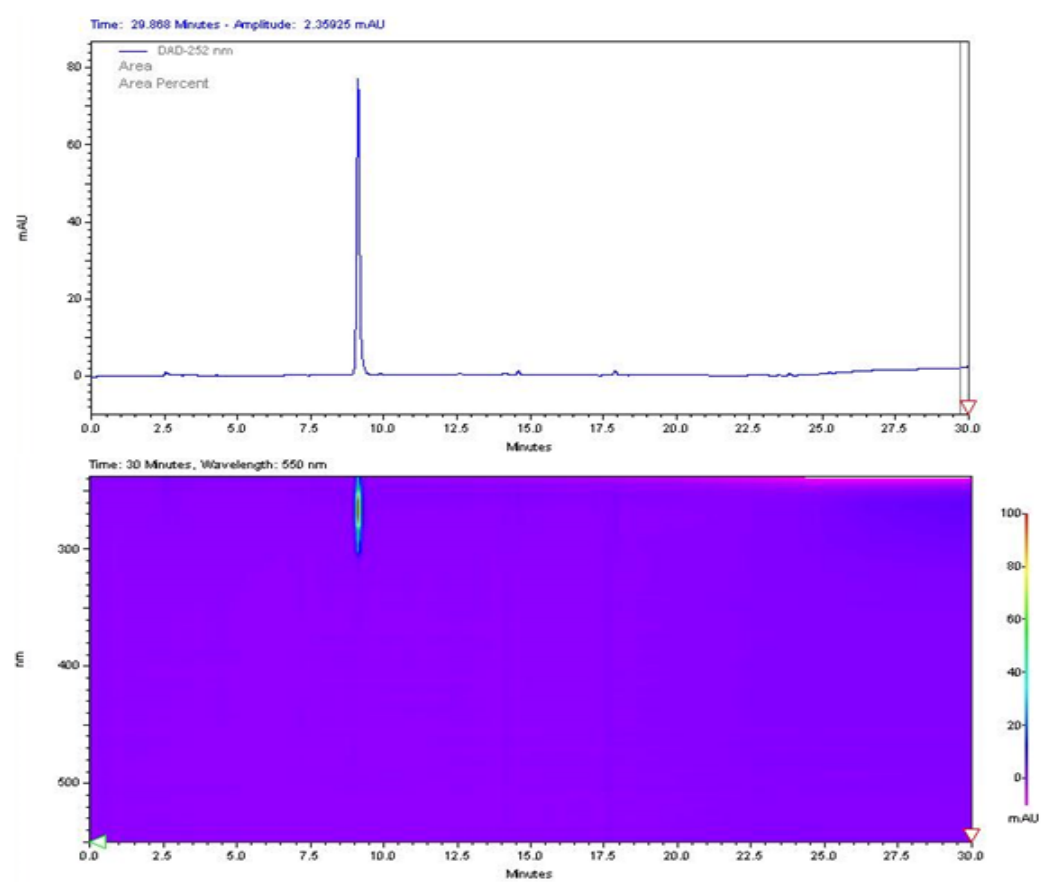

Figure S7. HPLC 2D and 3D chromatogram of Fmoc-Trp-OH (50-100\% ACN: $\mathrm{H}_{2} \mathrm{O}, \mathrm{RT}=9.1$ minutes). 

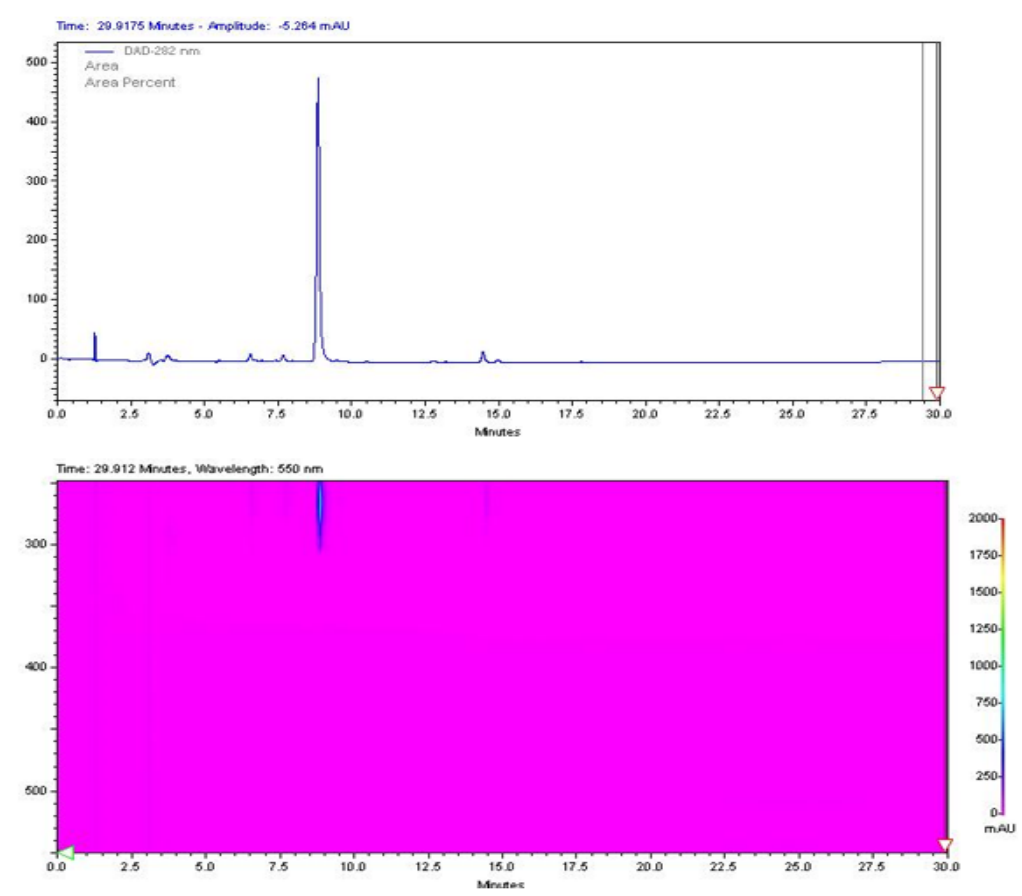

Figure S8. HPLC 2D and 3D chromatogram of Fmoc-Trp-OH after being exposed to singlet oxygen for 5 minutes (50-100\% ACN: $\mathrm{H}_{2} \mathrm{O}, \mathrm{RT}=9.1$ minutes).

\section{Experimental procedures}

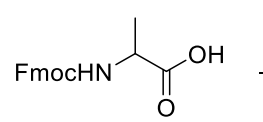

OH

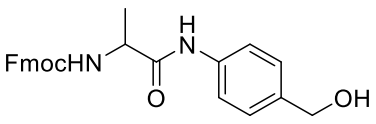

$82 \%$

Compound 1a

\section{Compound 1a}

Fmoc-Ala-OH (1.05 gr, $3.38 \mathrm{mmol}, 1 \mathrm{eq}), p$-aminobenzyl alcohol (624 mg, $5.06 \mathrm{mmol}, 1.5 \mathrm{eq})$ and EEDQ (1.67 gr, $6.75 \mathrm{mmol}$, 2eq) were dissolved in THF. The reaction was allowed to stir overnight. Completion of the reaction was confirmed by TLC monitoring (Hex:EtOAc 50:50). Next, the solvent was evaporated under reduced pressure and the crude was triturated with diethyl ether. The solvent was decanted off to afford compound $1 \mathrm{a}$ as a white solid $(1.15 \mathrm{gr}, 82 \%) .{ }^{1} \mathrm{H} \mathrm{NMR}(400 \mathrm{MHz}$, DMSO) $\delta 9.96(\mathrm{~s}, 1 \mathrm{H}), 7.86(\mathrm{~d}, J=5.6 \mathrm{~Hz}, 2 \mathrm{H}), 7.74(\mathrm{~s}, 2 \mathrm{H}), 7.67(\mathrm{~d}, J=5.6 \mathrm{~Hz}, 1 \mathrm{H}), 7.59(\mathrm{~d}, J=6.7 \mathrm{~Hz}, 2 \mathrm{H})$, $7.40(\mathrm{~s}, 2 \mathrm{H}), 7.35-7.20(\mathrm{~m}, 4 \mathrm{H}), 5.12(\mathrm{~s}, 1 \mathrm{H}), 4.46(\mathrm{~s}, 2 \mathrm{H}), 4.36-4.11(\mathrm{~m}, 4 \mathrm{H}), 1.33(\mathrm{~d}, J=4.5 \mathrm{~Hz}, 3 \mathrm{H}) .{ }^{13} \mathrm{C}$ NMR (101 MHz, DMSO) $\delta$ 171.50, 155.87, 143.93, 143.83, 140.76, 137.69, 137.45, 127.66, 127.09, 126.94, 125.33, 120.11, 118.98, 65.68, 50.81, 46.70, 18.14. MS (ES+): $\mathrm{m} / \mathrm{z}$ calculated for $\mathrm{C}_{25} \mathrm{H}_{24} \mathrm{~N}_{2} \mathrm{O}_{4}$ : 416.5; found: $417.5[\mathrm{M}+\mathrm{H}]^{+}$. 


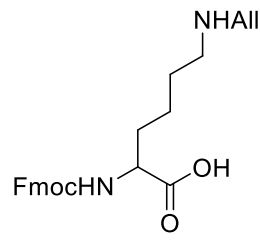

OOH

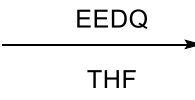

$82 \%$

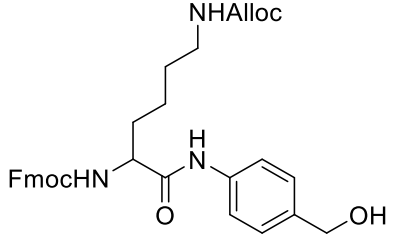

Compound 2a

\section{Compound 2a}

Fmoc-Lys(Alloc)-OH (420 mg, $0.93 \mathrm{mmol}, 1 \mathrm{eq}$ ), $p$-aminobenzyl alcohol (229 mg, $1.86 \mathrm{mmol}$, 2eq) and EEDQ (459 mg, $1.86 \mathrm{mmol}$, 2eq) were dissolved in THF. The reaction was allowed to stir overnight. Completion of the reaction was confirmed by TLC monitoring (Hex:EtOAc 50:50). Next, the solvent was evaporated under reduced pressure and the crude was triturated with diethyl ether. The solvent was decanted off to afford compound $2 \mathrm{a}$ as a white solid $(415 \mathrm{mg}, 82 \%) .{ }^{1} \mathrm{H}$ NMR (400 MHz, DMSO) $\delta 9.98(\mathrm{~s}, 1 \mathrm{H}), 7.85(\mathrm{~s}, 2 \mathrm{H}), 7.73(\mathrm{~s}, 2 \mathrm{H}), 7.66-7.57(\mathrm{~m}, 3 \mathrm{H}), 7.39-7.18(\mathrm{~m}, 6 \mathrm{H})$, $5.87(\mathrm{~s}, 1 \mathrm{H}), 5.24(\mathrm{~d}, J=17.1 \mathrm{~Hz}, 1 \mathrm{H}), 5.13(\mathrm{~s}, 1 \mathrm{H}), 4.45(\mathrm{~s}, 3 \mathrm{H}), 4.36-4.02(\mathrm{~m}, 4 \mathrm{H}), 3.43(\mathrm{~s}, 3 \mathrm{H}), 3.00(\mathrm{~s}, 2 \mathrm{H})$, $1.68(\mathrm{~s}, 2 \mathrm{H}), 1.50-1.18(\mathrm{~m}, 4 \mathrm{H}) .{ }^{13} \mathrm{C}$ NMR $(101 \mathrm{MHz}$, DMSO) $\delta 171.09,156.19,156.02,143.85,140.78$, 137.65, 137.52, 133.89, 127.70, 127.12, 126.98, 125.38, 120.14, 119.07, 116.89, 65.74, 64.20, 62.71, 55.49, 46.75, 40.13, 31.65, 29.20, 23.00. MS (ES+): $\mathrm{m} / \mathrm{z}$ calculated for $\mathrm{C}_{32} \mathrm{H}_{35} \mathrm{~N}_{3} \mathrm{O}_{6}$ : 557.6; found: 558.6 $[\mathrm{M}+\mathrm{H}]^{+}$.
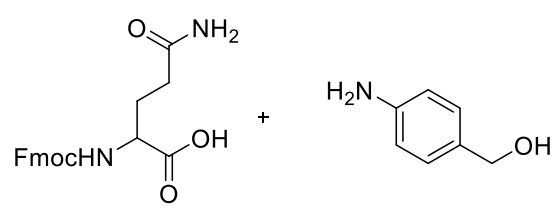

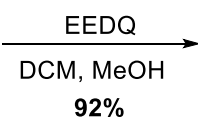

$92 \%$

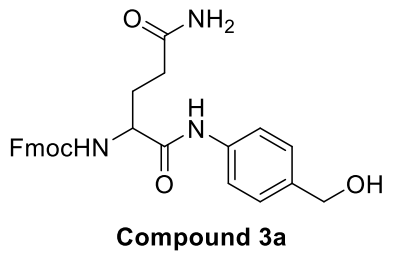

Compound 3 a

\section{Compound 3a}

Compound 3a was synthesized according to previously reported procedure ${ }^{2}$.

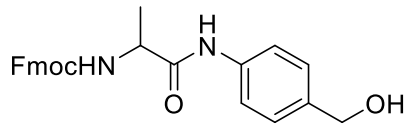

Compound 1a

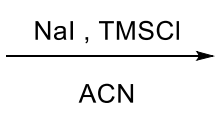

$98 \%$

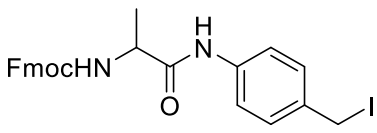

Compound $1 \mathrm{~b}$

\section{Compound 1b}

Benzyl alcohol compound 1a (1.2 gr, $2.9 \mathrm{mmol}, 1 \mathrm{eq})$ and $\mathrm{Nal}$ (1.3 gr, $8.6 \mathrm{mmol}$, 3eq) were dissolved in $\mathrm{ACN}$ and cooled to $0^{\circ} \mathrm{C}$ in an ice bath. $\mathrm{TMSCl}(1.1 \mathrm{ml}, 8.6 \mathrm{mmol}, 3 \mathrm{eq})$ was added and the reaction was brought to RT. The reaction was stirred for 30 minutes and monitored by TLC (EtOAC). Upon completion, the solvent was evaporated under reduced pressure. The residue was triturated with diethyl ether and the liquid was decanted off. The product was obtained as an orange solid (1.5 gr, 98\%). ${ }^{1} \mathrm{H}$ NMR $\left(500 \mathrm{MHz}, \mathrm{CDCl}_{3}\right) \delta 8.56(\mathrm{~s}, 1 \mathrm{H}), 7.75(\mathrm{~d}, J=7.2 \mathrm{~Hz}, 1 \mathrm{H}), 7.56(\mathrm{t}, J=8.2 \mathrm{~Hz}, 1 \mathrm{H})$, $7.43(\mathrm{~d}, J=8.1 \mathrm{~Hz}, 1 \mathrm{H}), 7.39(\mathrm{t}, J=7.3 \mathrm{~Hz}, 1 \mathrm{H}), 7.27(\mathrm{~d}, J=7.3 \mathrm{~Hz}, 1 \mathrm{H}), 5.64(\mathrm{~s}, 1 \mathrm{H}), 4.43(\mathrm{~s}, 2 \mathrm{H})$, $4.19(\mathrm{t}, J=6.7 \mathrm{~Hz}, 1 \mathrm{H}), 1.47(\mathrm{~d}, J=5.9 \mathrm{~Hz}, 1 \mathrm{H}) .{ }^{13} \mathrm{C} \mathrm{NMR}\left(126 \mathrm{MHz}, \mathrm{CDCl}_{3}\right) \delta$ 170.29, 143.27, 141.01, 
134.94, 129.12, 127.53, 126.85, 124.68, 119.90, 119.75, 67.09, 50.97, 46.77, 30.04, 29.39, 17.93, 5.29. MS (ES+): $\mathrm{m} / \mathrm{z}$ calculated for $\mathrm{C}_{25} \mathrm{H}_{23} \mathrm{IN}_{2} \mathrm{O}_{3}$ : 526.1; found: $527.4[\mathrm{M}+\mathrm{H}]^{+}$.

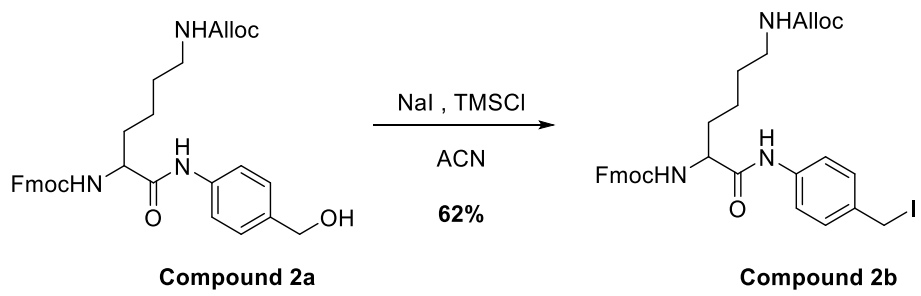

\section{Compound $\mathbf{2 b}$}

Benzyl alcohol compound 2b (269 mg, $0.48 \mathrm{mmol}, 1 \mathrm{eq}$ ) and $\mathrm{Nal}$ (217 mg, $1.45 \mathrm{mmol}$, 3eq) were dissolved in ACN and cooled to $0^{\circ} \mathrm{C}$ in an ice bath. TMSCl (184 $\mu \mathrm{l}, 1.45 \mathrm{mmol}$, 3eq) was added and the reaction was brought to RT. The reaction was stirred for 30 minutes and monitored by TLC (Hex:EtOAc 50:50). Upon completion, the solvent was evaporated under reduced pressure. The residue was triturated with diethyl ether and the liquid was decanted off. The product was obtained as an orange solid (198 mg, 62\%). ${ }^{1} \mathrm{H} \mathrm{NMR} \mathrm{(400} \mathrm{MHz,} \mathrm{DMSO)} \delta 10.08(\mathrm{~s}, 1 \mathrm{H}), 7.89$ (d, $J=$ $7.2 \mathrm{~Hz}, 2 \mathrm{H}), 7.77-7.70(\mathrm{~m}, 2 \mathrm{H}), 7.63(\mathrm{~d}, J=7.7 \mathrm{~Hz}, 1 \mathrm{H}), 7.54(\mathrm{~d}, J=8.2 \mathrm{~Hz}, 1 \mathrm{H}), 7.37(\mathrm{~m}, 6 \mathrm{H}), 7.19$ $(\mathrm{s}, 1 \mathrm{H}), 5.95-5.82(\mathrm{~m}, 1 \mathrm{H}), 5.25(\mathrm{~d}, J=16.9 \mathrm{~Hz}, 1 \mathrm{H}), 5.15(\mathrm{~d}, J=10.3 \mathrm{~Hz}, 1 \mathrm{H}), 4.62(\mathrm{~s}, 2 \mathrm{H}), 4.44$ (d, $J=3.8 \mathrm{~Hz}, 2 \mathrm{H}), 4.28(\mathrm{~d}, J=5.1 \mathrm{~Hz}, 2 \mathrm{H}), 4.23(\mathrm{~d}, J=6.8 \mathrm{~Hz}, 1 \mathrm{H}), 4.16-4.07(\mathrm{~m}, 1 \mathrm{H}), 2.98(\mathrm{~d}, J=4.8$ $\mathrm{Hz}, 2 \mathrm{H}), 1.65$ (s, 2H), $1.52-1.12(\mathrm{~m}, 7 \mathrm{H}) .{ }^{13} \mathrm{C}$ NMR (101 MHz, DMSO) $\delta 171.81,156.51,144.39$, 141.31, 138.99, 134.95, 134.45, 132.98, 130.04, 128.23, 127.65, 125.91, 120.70, 119.93, 117.44, $66.25,64.71,56.03,47.26,32.06,29.73,23.52,8.88$. MS (ES+): $\mathrm{m} / \mathrm{z}$ calculated for $\mathrm{C}_{32} \mathrm{H}_{34} \mathrm{IN}_{3} \mathrm{O}_{5}$ : 667.2; found: $668.5[\mathrm{M}+\mathrm{H}]^{+}$.
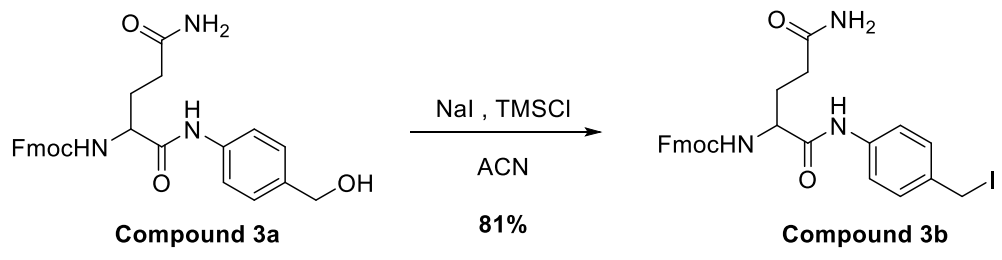

\section{Compound 3b}

Compound $\mathbf{3 b}$ was synthesized according to previously reported procedure ${ }^{2}$.

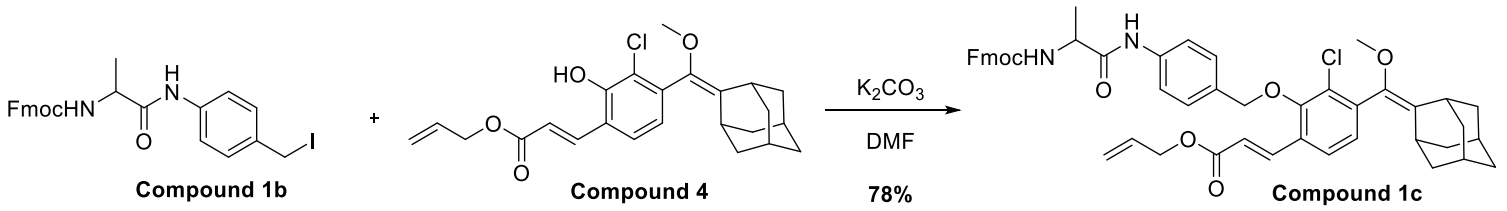

\section{Compound 1c}

Phenol enol-ether $\mathbf{4}^{1}$ (410 $\left.\mathrm{mg}, 0.99 \mathrm{mmol}, 1 \mathrm{eq}\right)$ was dissolved in anhydrous DMF and cooled to $0^{\circ} \mathrm{C}$ in an ice bath. Potassium carbonate (164 mg, $1.19 \mathrm{mmol}, 1.2 \mathrm{eq}$ ) was added, and the mixture 
stirred for several minutes at $0^{\circ} \mathrm{C}$. Next, benzyl iodide compound $\mathbf{1 b}$ (780 $\mathrm{mg}, 1.48 \mathrm{mmol}$, 1.5eq) was added and the reaction was brought to RT. The reaction was stirred overnight and monitored by TLC (Hex:EtOAc 50:50). Upon completion, the reaction mixture was diluted with EtOAc and washed with $\mathrm{NH}_{4} \mathrm{Cl}$ solution and brine. The organic layer was dried over $\mathrm{Na}_{2} \mathrm{SO}_{4}$ and evaporated under reduced pressure. The product was purified via column chromatography (Hex:EtOAc 50:50) to afford compound $1 \mathrm{c}$ as a yellow solid (629 mg, 78\%). ${ }^{1} \mathrm{H} \mathrm{NMR}\left(400 \mathrm{MHz}, \mathrm{CDCl}_{3}\right) \delta 8.41(\mathrm{~s}, 1 \mathrm{H})$, $7.95(\mathrm{~d}, J=16.1 \mathrm{~Hz}, 1 \mathrm{H}), 7.75(\mathrm{~d}, J=7.3 \mathrm{~Hz}, 2 \mathrm{H}), 7.56(\mathrm{~d}, J=6.5 \mathrm{~Hz}, 2 \mathrm{H}), 7.52(\mathrm{~d}, J=7.9 \mathrm{~Hz}, 2 \mathrm{H})$, $7.39(\mathrm{dd}, J=15.6,7.1 \mathrm{~Hz}, 4 \mathrm{H}), 7.31-7.25(\mathrm{~m}, 2 \mathrm{H}), 7.07(\mathrm{~d}, J=7.9 \mathrm{~Hz}, 1 \mathrm{H}), 6.46(\mathrm{~d}, J=16.2 \mathrm{~Hz}, 1 \mathrm{H})$, $6.03-5.91(\mathrm{~m}, 1 \mathrm{H}), 5.55(\mathrm{~s}, 1 \mathrm{H}), 5.36(\mathrm{~d}, J=17.1 \mathrm{~Hz}, 1 \mathrm{H}), 5.27(\mathrm{~d}, J=10.4 \mathrm{~Hz}, 1 \mathrm{H}), 4.96(\mathrm{~s}, 2 \mathrm{H})$, $4.70(\mathrm{~d}, J=5.0 \mathrm{~Hz}, 2 \mathrm{H}), 4.45(\mathrm{~d}, J=6.1 \mathrm{~Hz}, 2 \mathrm{H}), 4.21(\mathrm{t}, J=6.4 \mathrm{~Hz}, 1 \mathrm{H}), 3.32(\mathrm{~s}, 3 \mathrm{H}), 3.28(\mathrm{~s}, 1 \mathrm{H})$, $2.07(\mathrm{~s}, 1 \mathrm{H}), 1.99-1.68(\mathrm{~m}, 14 \mathrm{H}), 1.48(\mathrm{~d}, J=5.6 \mathrm{~Hz}, 3 \mathrm{H}) .{ }^{13} \mathrm{C} \mathrm{NMR}\left(101 \mathrm{MHz}, \mathrm{CDCl}_{3}\right) \delta 170.52$, $166.41,153.81,143.73,141.45,139.56,139.15,138.36,138.10,132.55,132.35,132.11,129.99$, 129.88, 129.80, 127.95, 127.27, 125.21, 125.11, 120.18, 120.10, 119.99, 118.39, 75.85, 67.47, $65.41,57.38,47.23,39.34,39.19,38.75,37.20,33.09,29.85,28.50,28.35,18.36 . M S(E S+): \mathrm{m} / \mathrm{z}$ calculated for $\mathrm{C}_{49} \mathrm{H}_{49} \mathrm{ClN}_{2} \mathrm{O}_{7}$ : 812.3; found: $813.7[\mathrm{M}+\mathrm{H}]^{+}$.

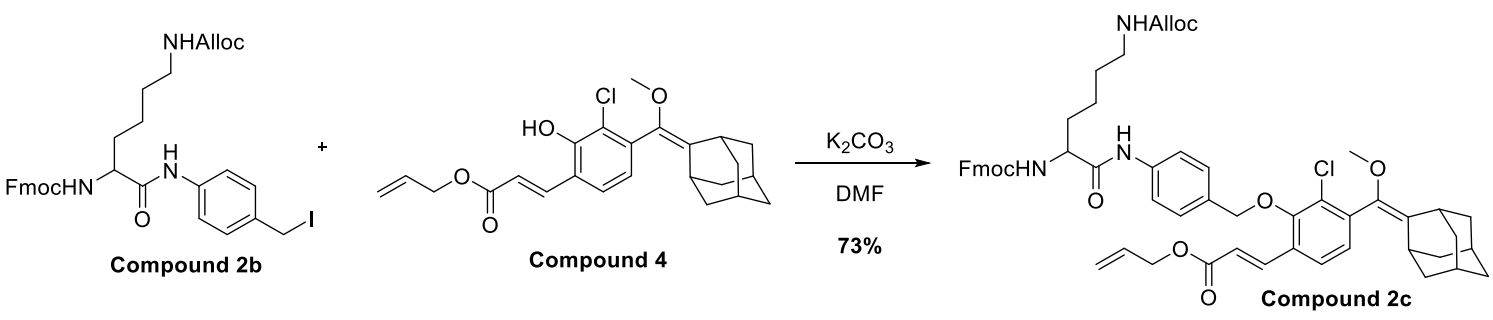

\section{Compound 2c}

Phenol enol-ether $4^{1}$ (106 mg, $0.26 \mathrm{mmol}, 1.5 \mathrm{eq}$ ) was dissolved in anhydrous DMF and cooled to $0^{\circ} \mathrm{C}$ in an ice bath. Potassium carbonate $(47 \mathrm{mg}, 0.34 \mathrm{mmol}, 2 \mathrm{eq})$ was added, and the mixture stirred for several minutes at $0^{\circ} \mathrm{C}$. Next, benzyl iodide compound $\mathbf{2 b}$ (111 $\left.\mathrm{mg}, 0.17 \mathrm{mmol}, 1 \mathrm{eq}\right)$ was added and the reaction was brought to RT. The reaction was stirred overnight and monitored by TLC (Hex:EtOAc 50:50). Upon completion, the reaction mixture was diluted with EtOAc and washed with $\mathrm{NH}_{4} \mathrm{Cl}$ solution and brine. The organic layer was dried over $\mathrm{Na}_{2} \mathrm{SO}_{4}$ and evaporated under reduced pressure. The product was purified via column chromatography (Hex:EtOAc 50:50) to afford compound $2 \mathrm{c}$ as a yellow solid (116 mg, 71\%). ${ }^{1} \mathrm{H} \mathrm{NMR}\left(400 \mathrm{MHz}, \mathrm{CDCl}_{3}\right) \delta 8.51(\mathrm{~s}, 1 \mathrm{H})$, $7.94(\mathrm{~d}, J=16.2 \mathrm{~Hz}, 1 \mathrm{H}), 7.75(\mathrm{~d}, J=7.3 \mathrm{~Hz}, 2 \mathrm{H}), 7.55(\mathrm{~d}, J=8.6 \mathrm{~Hz}, 4 \mathrm{H}), 7.40(\mathrm{dt}, J=15.3,7.7 \mathrm{~Hz}$, $5 \mathrm{H}), 7.31-7.23(\mathrm{~m}, 2 \mathrm{H}), 7.07(\mathrm{~d}, J=7.9 \mathrm{~Hz}, 1 \mathrm{H}), 6.45(\mathrm{~d}, J=16.2 \mathrm{~Hz}, 1 \mathrm{H}), 6.04-5.92(\mathrm{~m}, 1 \mathrm{H}), 5.87$ $(\mathrm{d}, J=5.6 \mathrm{~Hz}, 1 \mathrm{H}), 5.71(\mathrm{~s}, 1 \mathrm{H}), 5.36(\mathrm{~d}, J=17.2 \mathrm{~Hz}, 1 \mathrm{H}), 5.25(\mathrm{~d}, J=7.3 \mathrm{~Hz}, 1 \mathrm{H}), 5.17(\mathrm{~d}, J=10.4$ $\mathrm{Hz}, 1 \mathrm{H}), 4.95(\mathrm{~s}, 3 \mathrm{H}), 4.70(\mathrm{~d}, J=4.9 \mathrm{~Hz}, 2 \mathrm{H}), 4.53(\mathrm{~s}, 2 \mathrm{H}), 4.43(\mathrm{~d}, J=4.8 \mathrm{~Hz}, 2 \mathrm{H}), 4.31(\mathrm{~s}, 1 \mathrm{H}), 4.20$ $(\mathrm{t}, J=6.5 \mathrm{~Hz}, 1 \mathrm{H}), 3.32(\mathrm{~s}, 3 \mathrm{H}), 3.28(\mathrm{~s}, 1 \mathrm{H}), 3.19(\mathrm{~s}, 2 \mathrm{H}), 2.07(\mathrm{~s}, 1 \mathrm{H}), 1.97-1.67(\mathrm{~m}, 14 \mathrm{H}), 1.42(\mathrm{~d}$, $J=3.9 \mathrm{~Hz}, 1 \mathrm{H}), 1.26(\mathrm{~s}, 4 \mathrm{H}) .{ }^{13} \mathrm{C} \mathrm{NMR}\left(101 \mathrm{MHz}, \mathrm{CDCl}_{3}\right) \delta 170.25,166.42,156.85,153.81,143.79$, $141.44,139.56,139.14,138.35,132.99,132.54,132.35,132.10,129.99,129.85,127.91,127.25$, $125.19,125.14,120.15,120.09,120.03,118.40,117.79,75.85,67.35,65.74,65.41,57.38,55.56$, 47.27, 40.14, 39.33, 39.17, 38.74, 37.19, 33.08, 31.65, 31.56, 29.84, 29.46, 28.49, 28.35, 22.41. MS (ES+): $\mathrm{m} / \mathrm{z}$ calculated for $\mathrm{C}_{56} \mathrm{H}_{60} \mathrm{ClN}_{3} \mathrm{O}_{9}$ : 953.4; found: $954.9[\mathrm{M}+\mathrm{H}]^{+}$. 


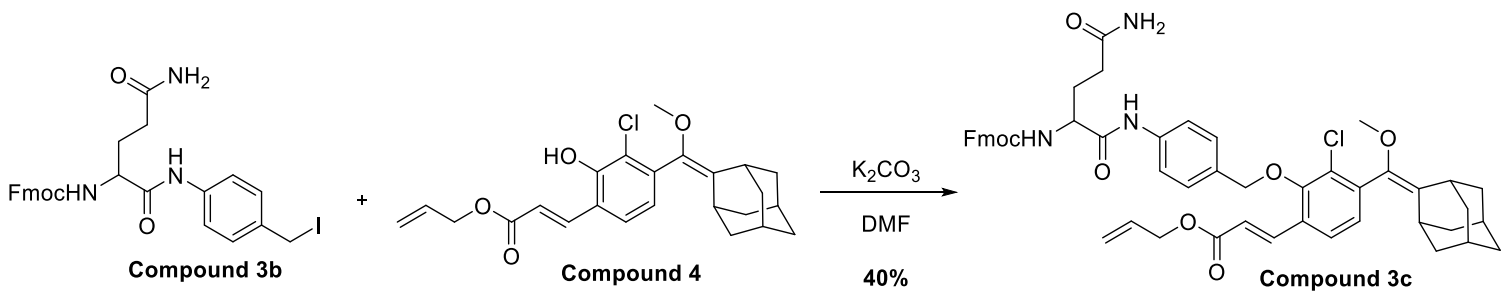

\section{Compound 3c}

Phenol enol-ether $4^{1}$ (95 mg, $0.23 \mathrm{mmol}$, 1eq) was dissolved in anhydrous DMF and cooled to $0^{\circ} \mathrm{C}$ in an ice bath. Potassium carbonate ( $38 \mathrm{mg}, 0.28 \mathrm{mmol}, 1.2 \mathrm{eq}$ ) was added, and the mixture stirred for several minutes at $0^{\circ} \mathrm{C}$. Next, benzyl iodide compound $3 \mathbf{b}^{2}$ (200 mg, $0.34 \mathrm{mmol}$, 1.5eq) was added and the reaction was brought to RT. The reaction was stirred overnight and monitored by TLC (EtOAc). Upon completion, the reaction mixture was diluted with EtOAc and washed with $\mathrm{NH}_{4} \mathrm{Cl}$ and brine. The organic layer was dried over $\mathrm{Na}_{2} \mathrm{SO}_{4}$ and evaporated under reduced pressure. The product was purified via column chromatography (EtOAc) to afford compound 3c as a yellow solid (80 mg, 40\%). ${ }^{1} \mathrm{H}$ NMR $\left(400 \mathrm{MHz}, \mathrm{CDCl}_{3}\right) \delta 9.40(\mathrm{~s}, 1 \mathrm{H}), 7.91(\mathrm{~d}, J=16.2 \mathrm{~Hz}, 1 \mathrm{H})$, $7.75(\mathrm{~d}, J=7.3 \mathrm{~Hz}, 2 \mathrm{H}), 7.58(\mathrm{~d}, J=7.3 \mathrm{~Hz}, 4 \mathrm{H}), 7.40(\mathrm{t}, J=8.5 \mathrm{~Hz}, 5 \mathrm{H}), 7.29(\mathrm{~s}, 1 \mathrm{H}), 7.06$ (d, J = 7.9 $\mathrm{Hz}, 1 \mathrm{H}), 6.42(\mathrm{~d}, J=16.2 \mathrm{~Hz}, 1 \mathrm{H}), 6.19(\mathrm{~d}, J=5.9 \mathrm{~Hz}, 1 \mathrm{H}), 6.09-5.91(\mathrm{~m}, 2 \mathrm{H}), 5.83(\mathrm{~s}, 1 \mathrm{H}), 5.36(\mathrm{~d}$, $J=17.1 \mathrm{~Hz}, 1 \mathrm{H}), 5.28(\mathrm{~d}, J=10.9 \mathrm{~Hz}, 1 \mathrm{H}), 4.96(\mathrm{~s}, 2 \mathrm{H}), 4.69(\mathrm{~d}, J=5.0 \mathrm{~Hz}, 2 \mathrm{H}), 4.41(\mathrm{~s}, 2 \mathrm{H}), 4.21(\mathrm{t}$, $J=6.6 \mathrm{~Hz}, 1 \mathrm{H}), 3.32(\mathrm{~s}, 3 \mathrm{H}), 3.28(\mathrm{~s}, 1 \mathrm{H}), 2.52(\mathrm{~s}, 1 \mathrm{H}), 2.41(\mathrm{~s}, 1 \mathrm{H}), 2.23(\mathrm{~s}, 1 \mathrm{H}), 2.06(\mathrm{~s}, 1 \mathrm{H}), 2.00-$ $1.62(\mathrm{~m}, 14 \mathrm{H}), 1.42(\mathrm{~d}, J=5.5 \mathrm{~Hz}, 1 \mathrm{H}) .{ }^{13} \mathrm{C} N M R\left(101 \mathrm{MHz}, \mathrm{CDCl}_{3}\right) \delta$ 169.78, 166.44, 153.76, 143.92, 143.76, 141.44, 139.56, 139.19, 138.34, 132.54, 132.34, 131.96, 129.96, 129.88, 127.91, 127.25, 125.23, 125.15, 120.16, 119.93, 118.42, 116.67, 75.92, 67.31, 65.42, 57.37, 54.66, 47.27, 39.17, 38.72, 37.19, 33.08, 29.82, 29.74, 28.49, 28.43, 28.32, 28.24. MS (ES+): $\mathrm{m} / \mathrm{z}$ calculated for $\mathrm{C}_{51} \mathrm{H}_{52} \mathrm{ClN}_{3} \mathrm{O}_{8}$ : 869.3; found: $870.8[\mathrm{M}+\mathrm{H}]^{+}$.

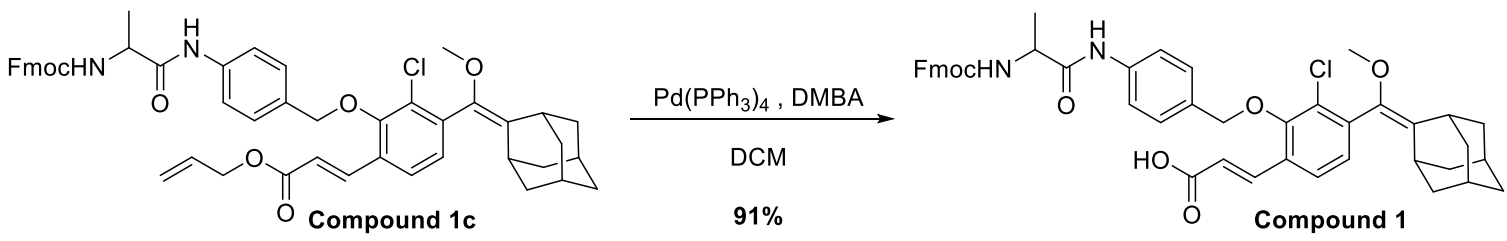

\section{Compound 1}

Compound 1c (527 mg, $0.65 \mathrm{mmol}, 1 \mathrm{eq}$ ) was dissolved in a minimal amount of DCM. DMBA (304 $\mathrm{mg}, 1.94 \mathrm{mmol}, 3 \mathrm{eq})$ and $\mathrm{Pd}\left(\mathrm{PPh}_{3}\right)_{4}(75 \mathrm{mg}, 0.07 \mathrm{mmol}, 0.1 \mathrm{eq})$ were added, and the reaction was heated to $35^{\circ} \mathrm{C}$. Reaction was stirred for 1 hour and monitored by TLC (Hex:EtOAc 50:50). Upon completion, the reaction mixture was diluted with $\mathrm{DCM}$ and washed with $\mathrm{NH}_{4} \mathrm{Cl}$ solution and brine. The organic layer was dried over $\mathrm{Na}_{2} \mathrm{SO}_{4}$ and evaporated under reduced pressure. The product was purified via column chromatography (Hex:EtOAc 50:50) to afford compound $\mathbf{1}$ as a yellow solid (456 mg, 91\%). ${ }^{1} \mathrm{H}$ NMR (400 MHz, CDCl $\left.{ }_{3}\right) \delta 9.08(\mathrm{~s}, 1 \mathrm{H}), 7.92(\mathrm{~d}, J=16.1 \mathrm{~Hz}, 1 \mathrm{H}), 7.81$ (s, 1H), 7.70 (d, J=7.1 Hz, 2H), 7.55 (d, J=7.4 Hz, 3H), 7.51 (d, $J=7.5 \mathrm{~Hz}, 1 \mathrm{H}$ ), 7.41 (d, $J=7.8 \mathrm{~Hz}$, $1 \mathrm{H}$ ), $7.33(\mathrm{t}, J=7.1 \mathrm{~Hz}, 3 \mathrm{H}$ ), $7.22(\mathrm{~s}, 2 \mathrm{H}), 7.07(\mathrm{~d}, J=7.8 \mathrm{~Hz}, 1 \mathrm{H}), 6.39$ (d, J=16.4 Hz, 1H), $4.92(\mathrm{~s}$, $2 \mathrm{H}), 4.52(\mathrm{~s}, 1 \mathrm{H}), 4.30(\mathrm{~s}, 2 \mathrm{H}), 4.13(\mathrm{~s}, 1 \mathrm{H}), 3.34(\mathrm{~s}, 3 \mathrm{H}), 3.30(\mathrm{~s}, 1 \mathrm{H}), 2.09(\mathrm{~s}, 1 \mathrm{H}), 2.01-1.64(\mathrm{~m}$, 14H), 1.47 (d, J = 5.6 Hz, 3H). ${ }^{13} \mathrm{C} \mathrm{NMR}\left(101 \mathrm{MHz}, \mathrm{CDCl}_{3}\right) \delta 171.93,170.91,156.88,153.90,143.87$, 
$143.65,141.38,140.63,139.53,138.59,138.20,132.74,132.15,129.97,129.83,129.73,127.97$, $127.90,127.27,125.29,125.22,120.32,120.11,119.58,75.95,67.59$, 57.43, 51.54, 47.07, 39.34, 38.77, 37.20, 33.12, 29.88, 28.36, 18.59, 1.99. MS (ES+): $\mathrm{m} / \mathrm{z}$ calculated for $\mathrm{C}_{46} \mathrm{H}_{45} \mathrm{ClN}_{2} \mathrm{O}_{7}$ : 772.3; found: $773.8[\mathrm{M}+\mathrm{H}]^{+}$.

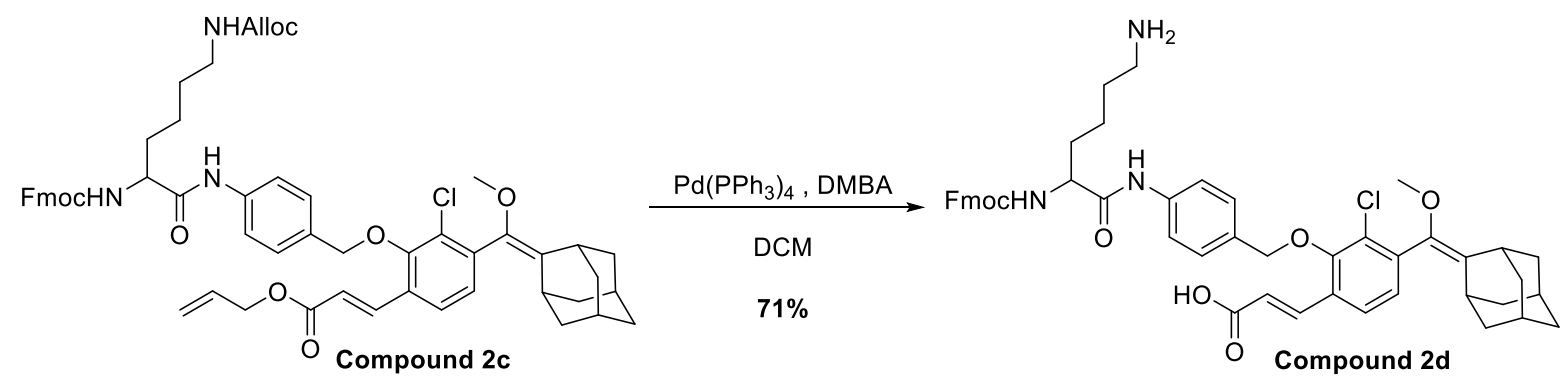

\section{Compound 2d}

Compound 2c (116 mg, $0.12 \mathrm{mmol}, 1 \mathrm{eq})$ was dissolved in a minimal amount of DCM. DMBA (114 $\mathrm{mg}, 0.73 \mathrm{mmol}, 6 \mathrm{eq})$ and $\mathrm{Pd}\left(\mathrm{PPh}_{3}\right)_{4}(14 \mathrm{mg}, 0.012 \mathrm{mmol}, 0.1 \mathrm{eq})$ were added, and the reaction was heated to $35^{\circ} \mathrm{C}$. Reaction was stirred for 1 hour and monitored by RP-HPLC (70-100\% ACN). Upon completion, the solvent was evaporated, and the crude was purified via PREP-RP-HPLC (70$100 \% \mathrm{ACN}$ ) to afford product compound $2 \mathrm{~d}$ as a white solid (71 $\mathrm{mg}, 71 \%) .{ }^{1} \mathrm{H} \mathrm{NMR} \mathrm{(400} \mathrm{MHz}$, $\left.\mathrm{CDCl}_{3}\right) \delta 9.34(\mathrm{~s}, 1 \mathrm{H}), 7.89-7.66(\mathrm{~m}, 4 \mathrm{H}), 7.59(\mathrm{~d}, J=6.2 \mathrm{~Hz}, 2 \mathrm{H}), 7.45(\mathrm{~s}, 3 \mathrm{H}), 7.30-7.17(\mathrm{~m}, 5 \mathrm{H})$, $7.12(\mathrm{~s}, 2 \mathrm{H}), 6.98(\mathrm{~d}, J=7.2 \mathrm{~Hz}, 1 \mathrm{H}), 6.47(\mathrm{~s}, 1 \mathrm{H}), 6.26-5.84(\mathrm{~m}, 4 \mathrm{H}), 4.82(\mathrm{~s}, 2 \mathrm{H}), 4.23(\mathrm{~s}, 3 \mathrm{H}), 4.02$ $(\mathrm{s}, 1 \mathrm{H}), 3.28(\mathrm{~s}, 4 \mathrm{H}), 2.92(\mathrm{~s}, 2 \mathrm{H}), 2.06(\mathrm{~s}, 1 \mathrm{H}), 1.98-1.54(\mathrm{~m}, 14 \mathrm{H}), 1.48-1.30(\mathrm{~m}, 2 \mathrm{H}) .{ }^{13} \mathrm{C} N M R$ $\left(101 \mathrm{MHz} \mathrm{CDCl}_{3}\right) \delta 171.48,169.96,157.11,153.73,143.65,141.26,140.22,139.53,138.44$, $137.91,132.74,132.33,129.96,129.82,129.71,127.93,127.83,127.19,125.11,120.62,120.01$, $119.45,75.95,67.47,57.38,46.98,39.82,39.18,38.74,37.19,33.10,31.72,29.84,28.46,28.33$, 26.72, 22.33. MS (ES+): $\mathrm{m} / \mathrm{z}$ calculated for $\mathrm{C}_{49} \mathrm{H}_{52} \mathrm{ClN}_{3} \mathrm{O}_{7}$ : 829.3; found: $830.7[\mathrm{M}+\mathrm{H}]^{+}$.
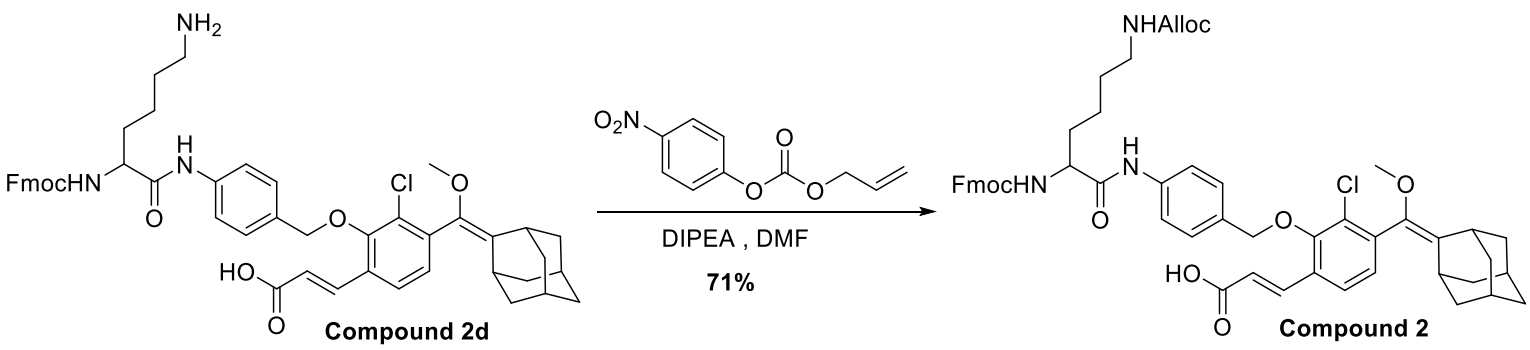

\section{Compound 2}

Compounds 2d (89 mg, $0.107 \mathrm{mmol}, 1 \mathrm{eq}$ ) and allyl-(4-nitrophenyl)-carbonate ( $34 \mathrm{mg}, 0.16 \mathrm{mmol}$, 1.5eq) were dissolved in a minimal amount of DMF and cooled to $0^{\circ} \mathrm{C}$. DIPEA ( $56 \mu \mathrm{l}, 0.32 \mathrm{mmol}$, 3eq) was added dropwise and the reaction was brought to RT and monitored by RP-HPLC (70$100 \%$ ACN). Upon completion, the crude was purified via PREP-RP-HPLC (70-100\% ACN) to afford compound 2 as a white solid (70 mg, 71\%). ${ }^{1} \mathrm{H}$ NMR (400 MHz, $\left.\mathrm{CDCl}_{3}\right) \delta 8.96(\mathrm{~s}, 1 \mathrm{H}), 7.72(\mathrm{~d}, \mathrm{~J}=$ 
$5.6 \mathrm{~Hz}, 2 \mathrm{H}), 7.54(\mathrm{~s}, 4 \mathrm{H}), 7.44-7.35(\mathrm{~m}, 5 \mathrm{H}), 7.25(\mathrm{~d}, J=6.6 \mathrm{~Hz}, 2 \mathrm{H}), 7.07(\mathrm{~d}, J=6.2 \mathrm{~Hz}, 1 \mathrm{H}), 5.44$ $-5.09(\mathrm{~m}, 7 \mathrm{H}), 4.95(\mathrm{~s}, 2 \mathrm{H}), 4.66-4.44(\mathrm{~m}, 3 \mathrm{H}), 4.35(\mathrm{~s}, 3 \mathrm{H}), 4.15(\mathrm{~s}, 1 \mathrm{H}), 3.34(\mathrm{~s}, 3 \mathrm{H}), 3.29(\mathrm{~s}, 1 \mathrm{H})$, $3.16(\mathrm{~s}, 2 \mathrm{H}), 2.09(\mathrm{~s}, 1 \mathrm{H}), 2.02-1.63(\mathrm{~m}, 14 \mathrm{H}), 1.49(\mathrm{~d}, \mathrm{~J}=30.4 \mathrm{~Hz}, 5 \mathrm{H}) .{ }^{13} \mathrm{C} \mathrm{NMR}\left(101 \mathrm{MHz}, \mathrm{CDCl}_{3}\right)$ $\delta 171.22,170.19,157.01,143.83,143.71,141.40,140.51,139.54,138.08,132.88,132.72,129.94$, $127.89,127.24,125.19,120.38,120.10,119.39,117.88,76.10,67.52,66.37,65.84,65.46,57.41$, $55.73,47.15,40.31,39.33,39.18,38.78,37.19,33.12,31.86,29.87,29.42,29.34,29.22,29.18$, 28.49, 28.34, 22.51. MS (ES+): $\mathrm{m} / \mathrm{z}$ calculated for $\mathrm{C}_{53} \mathrm{H}_{56} \mathrm{ClN}_{3} \mathrm{O}_{9}$ : 913.4; found: $914.8[\mathrm{M}+\mathrm{H}]^{+}$.

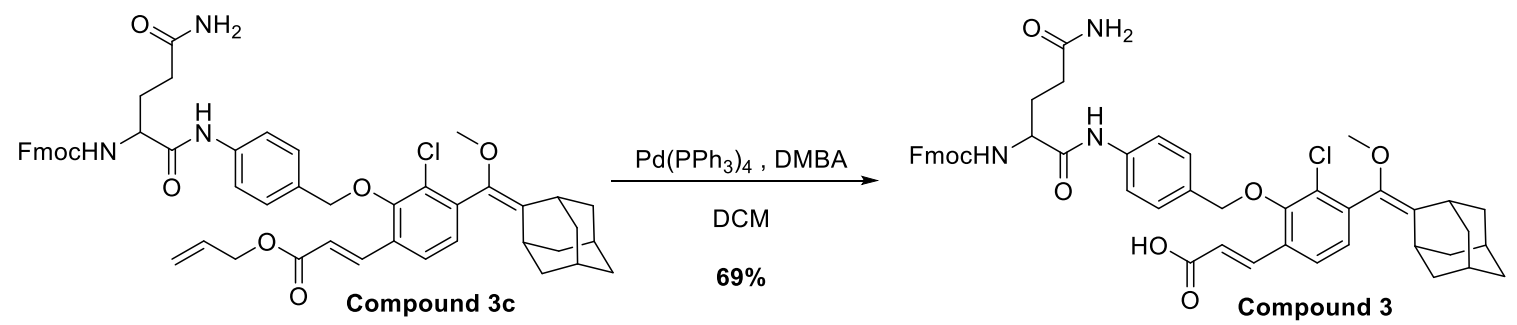

\section{Compound 3}

Compound $3 \mathrm{c}(80 \mathrm{mg}, 0.09 \mathrm{mmol}, 1 \mathrm{eq})$ was dissolved in a minimal amount of DCM. DMBA (43 $\mathrm{mg}, 0.28 \mathrm{mmol}, 3 \mathrm{eq})$ and $\mathrm{Pd}\left(\mathrm{PPh}_{3}\right)_{4}(10.6 \mathrm{mg}, 0.009 \mathrm{mmol}, 0.1 \mathrm{eq})$ were added, and the reaction was heated to $35^{\circ} \mathrm{C}$. Reaction was stirred for 1 hour and monitored by RP-HPLC (70-100\% ACN). Upon completion, the solvent was evaporated and the crude was purified via PREP-RP-HPLC (70$100 \% \mathrm{ACN}$ ) to afford Compound 3 as a white solid (51 mg, 69\%). ${ }^{1} \mathrm{H}$ NMR (400 MHz, $\left.\mathrm{CDCl}_{3}\right) \delta 9.52$ $(\mathrm{s}, 1 \mathrm{H}), 7.71(\mathrm{~d}, J=16.0 \mathrm{~Hz}, 1 \mathrm{H}), 7.64(\mathrm{~d}, J=7.0 \mathrm{~Hz}, 2 \mathrm{H}), 7.50(\mathrm{dd}, J=20.2,7.4 \mathrm{~Hz}, 4 \mathrm{H}), 7.32(\mathrm{~d}, J=$ $7.9 \mathrm{~Hz}, 1 \mathrm{H}), 7.30-7.20(\mathrm{~m}, 4 \mathrm{H}), 7.17(\mathrm{~s}, 2 \mathrm{H}), 7.02(\mathrm{~d}, J=7.8 \mathrm{~Hz}, 1 \mathrm{H}), 6.90(\mathrm{~s}, 1 \mathrm{H}), 6.77(\mathrm{~s}, 1 \mathrm{H}), 6.69$ $(\mathrm{s}, 1 \mathrm{H}), 6.21(\mathrm{~d}, J=16.1 \mathrm{~Hz}, 1 \mathrm{H}), 4.87(\mathrm{~s}, 2 \mathrm{H}), 4.49(\mathrm{~s}, 1 \mathrm{H}), 4.26(\mathrm{~s}, 2 \mathrm{H}), 4.07(\mathrm{~s}, 1 \mathrm{H}), 3.31(\mathrm{~s}, 3 \mathrm{H})$, $3.28(\mathrm{~s}, 1 \mathrm{H}), 2.39(\mathrm{~s}, 1 \mathrm{H}), 2.23(\mathrm{~s}, 1 \mathrm{H}), 2.08(\mathrm{~s}, 2 \mathrm{H}), 2.03-1.62(\mathrm{~m}, 14 \mathrm{H}) .{ }^{13} \mathrm{C} \mathrm{NMR}\left(101 \mathrm{MHz}, \mathrm{CDCl}_{3}\right)$ $\delta 177.22,170.72,170.05,157.08,153.85,143.83,143.64,141.31,140.17,140.07,139.57,138.37$, $138.19,132.64,132.12,130.13,130.02,129.79,127.85,127.22,125.21,125.04,120.34,120.06$, $119.59,116.55,76.18,67.46,57.40,55.09,47.08,39.31,38.80,37.21,33.11,29.86,28.35 . \mathrm{MS}$ (ES+): $\mathrm{m} / \mathrm{z}$ calculated for $\mathrm{C}_{48} \mathrm{H}_{48} \mathrm{ClN}_{3} \mathrm{O}_{8}$ : 829.3; found: $830.8[\mathrm{M}+\mathrm{H}]^{+}$. 

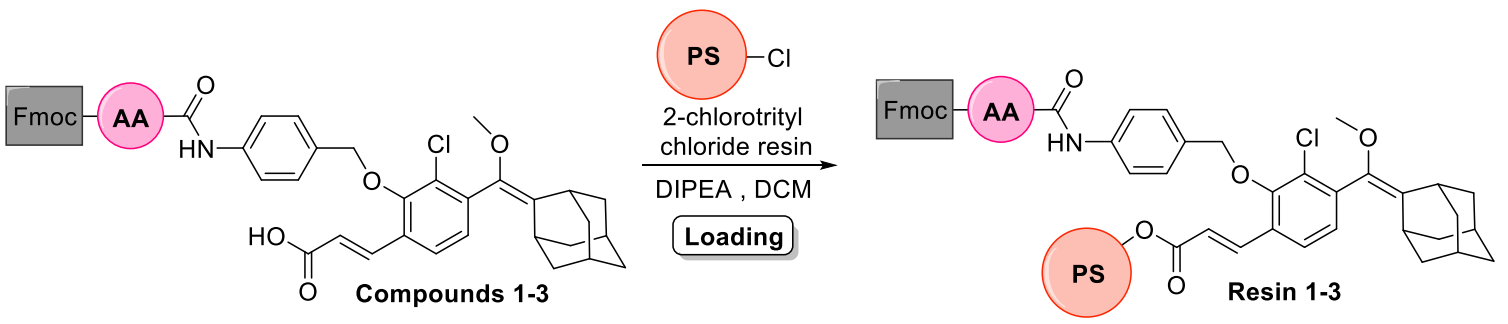

The resin 2-chlorotrityl chloride (5eq) was swelled by swirling in DCM for 2 hours. Next, a solution of ccompounds 1-3 (1eq) and DIPEA (6eq) in DCM were added to the resin and the reaction was swirled overnight. Then, the loading solution was removed, and the resin was washed with DCM three times. Next, the capping solution ( $9 \mathrm{ml} \mathrm{DCM}, 1 \mathrm{ml} \mathrm{MeOH}$ and $0.5 \mathrm{ml}$ DIPEA) was added to the resin and swirled for 1 hour. Then, the capping solution was removed, and the resin was washed with DCM three times to give Resin 1-3.

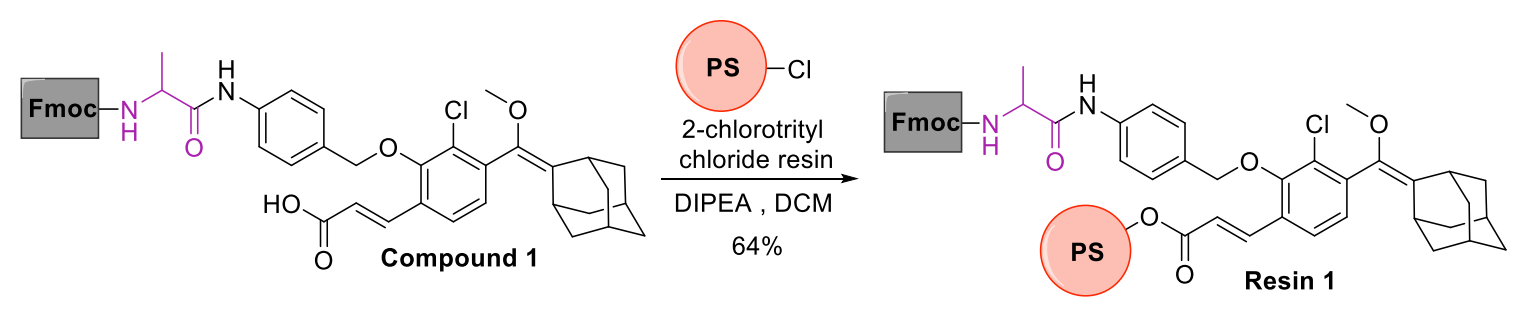

\section{Resin 1}

Resin 1 was prepared according to the general loading procedure on $0.65 \mathrm{mmol}$ scale, $64 \%$ yield.
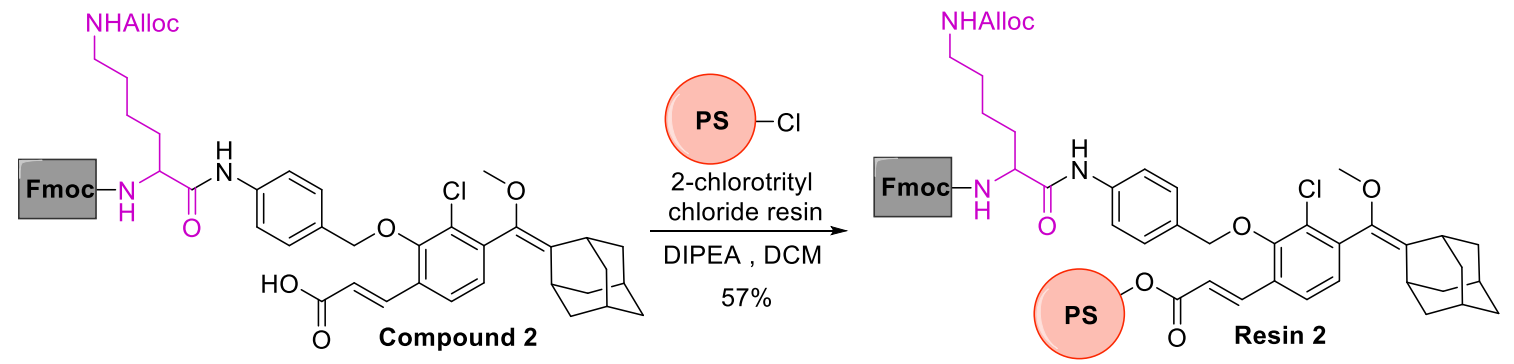

\section{Resin 2}

Resin 2 was prepared according to the general loading procedure on $0.08 \mathrm{mmol}$ scale, $57 \%$ yield. 

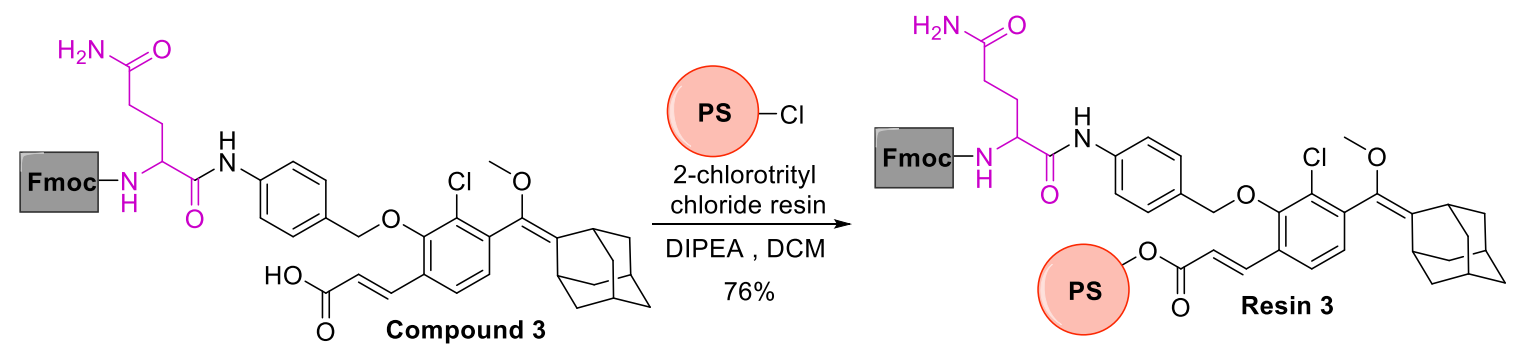

Resin 3

Resin 3 was prepared according to the general loading procedure on $0.15 \mathrm{mmol}$ scale, $76 \%$ yield.

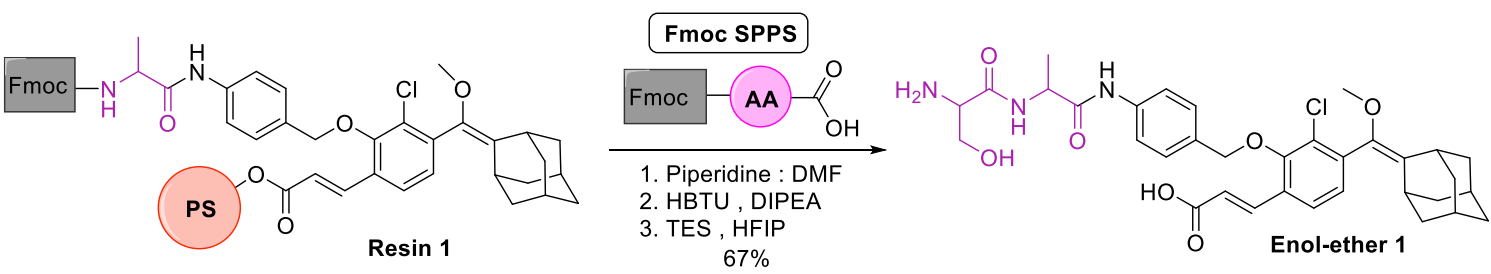

Enol-ether 1

Enol-ether 1 was synthesized via Fmoc-Solid Phase Peptide Synthesis. Resin 1 (250 mg, 0.046 mmol, 1eq) was swirled in DCM for $30 \mathrm{~min}$. Fmoc deprotection was conducted with $20 \%$ piperidine in DMF (15 minutes) followed by coupling of Fmoc-Ser(Trt)-OH (105 mg, 0.184 mmol, 4eq) using HBTU (70 mg, $0.184 \mathrm{mmol}, 4 \mathrm{eq}$ ) and DIPEA (48 $\mu \mathrm{l}, 0.276 \mathrm{mmol}, 6 \mathrm{eq})$ in DMF (30 minutes).Next, Fmoc deprotection of the serine was completed and to the resin was added the cleavage cocktail (HFIP/DCM/TES [50:45:5]) followed by swirling for 2 hours (also provided Trt deprotection). After filtration, the solvent was evaporated under reduced pressure, and the crude was triturated using diethyl ether followed by filtration to afford the title compound Enol-ether 1 as a white solid (19.6 mg, 67\%). MS (ES+): $\mathrm{m} / \mathrm{z}$ calculated for $\mathrm{C}_{34} \mathrm{H}_{40} \mathrm{ClN}_{3} \mathrm{O}_{7}$ : 637.3; found: 638.5 $[\mathrm{M}+\mathrm{H}]^{+}$. 


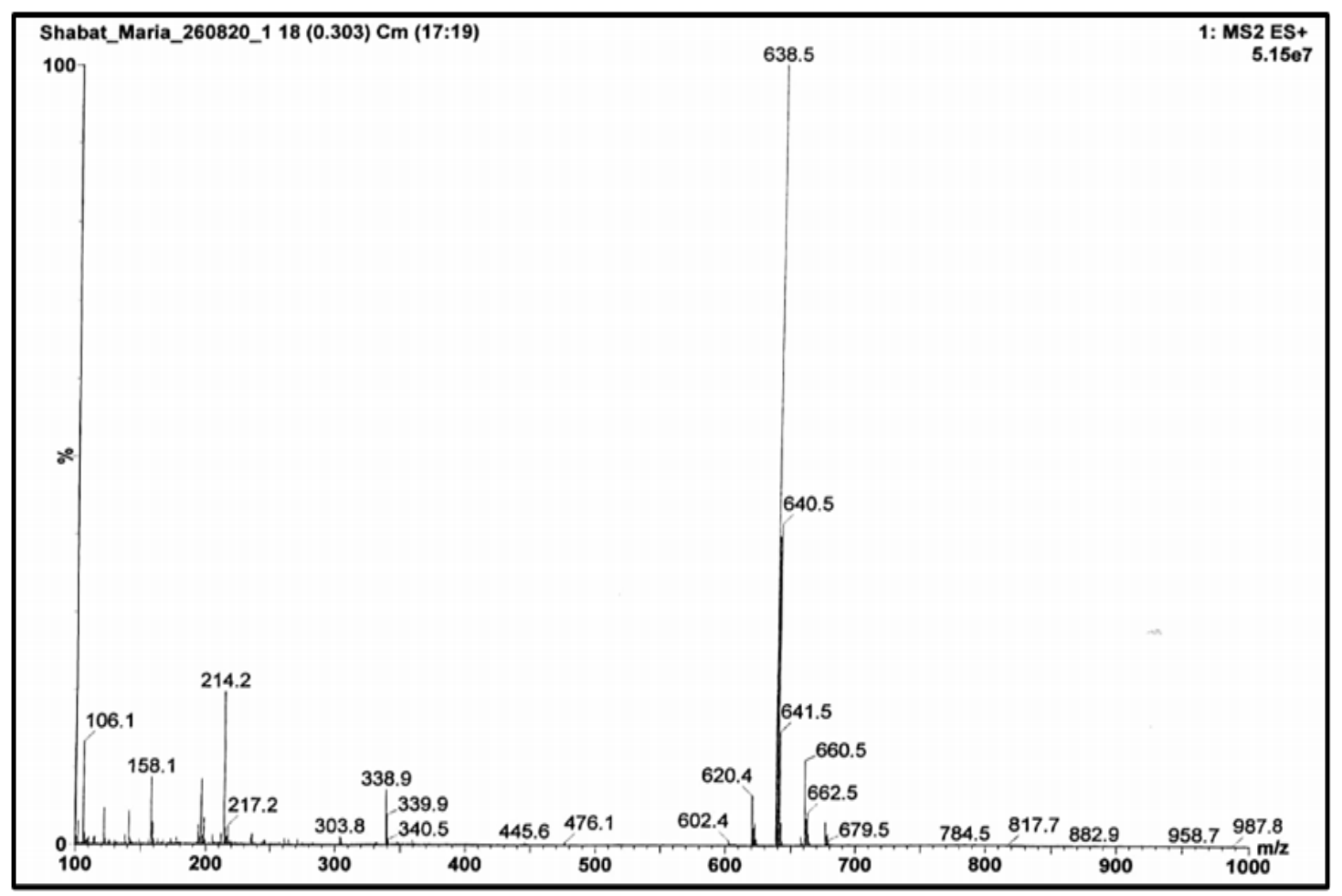

Figure S9. MS(+) spectra of Enol-ether 1.

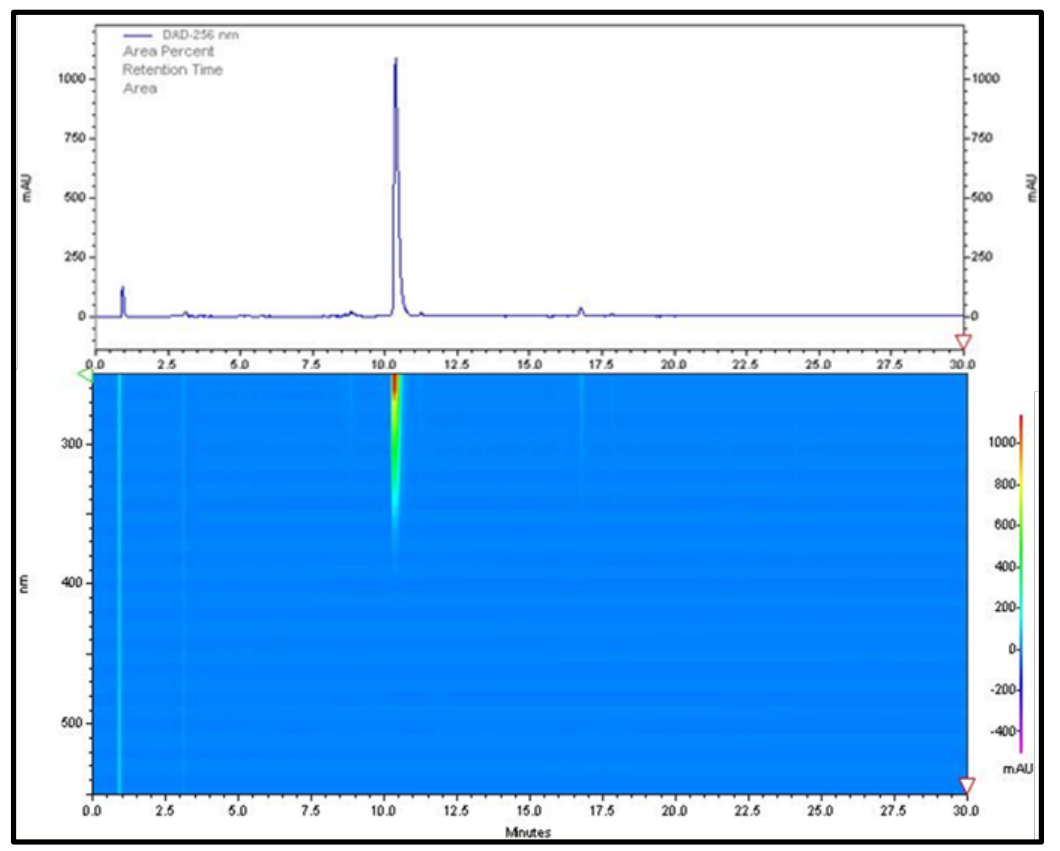

Figure S10. HPLC 2D and 3D chromatogram of Enol-ether 1 (50-100\% ACN: $\mathrm{H}_{2} \mathrm{O}, \mathrm{RT}=10.2$ minutes). 


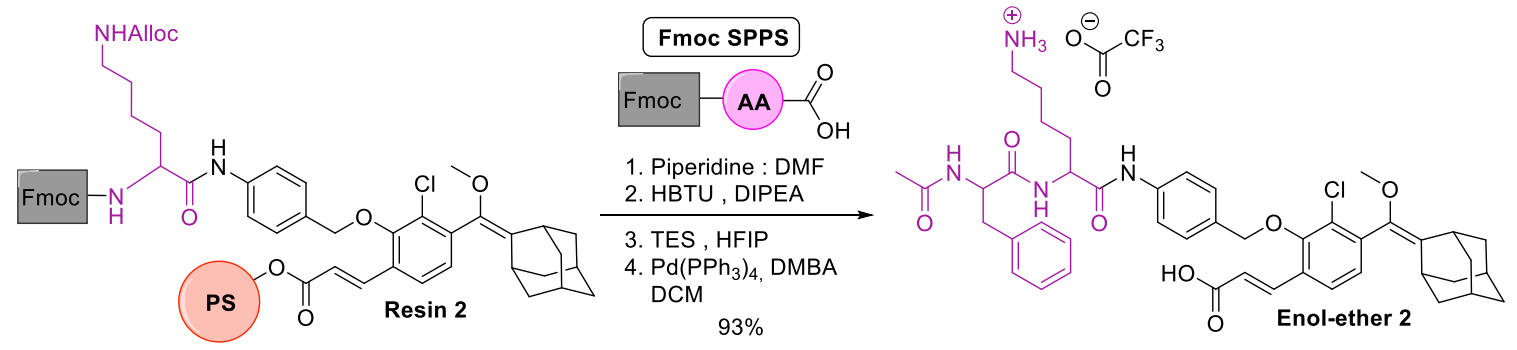

\section{Enol-ether 2}

Enol-ether 2 was synthesized via Fmoc-Solid Phase Peptide Synthesis. Resin 2 (225 mg, 0.025 mmol, 1 eq) was swirled in DCM for 30 min. Fmoc deprotection was conducted with $20 \%$ piperidine in DMF (15 minutes) followed by coupling of the Fmoc-Phe-OH ( $39 \mathrm{mg}, 0.1 \mathrm{mmol}, 4 \mathrm{eq}$ ) using HBTU (38 mg, $0.1 \mathrm{mmol}, 4 \mathrm{eq}$ ) and DIPEA ( $26 \mu \mathrm{l}, 0.15 \mathrm{mmol}, 6 \mathrm{eq})$ in DMF (30 minutes). Next, Fmoc deprotection of the phenylalanine was completed and the resin was subjected to caping using $\mathrm{Ac}_{2} \mathrm{O}$ ( $24 \mu \mathrm{L}, 0.25 \mathrm{mmol}, 10 \mathrm{eq}$ ) and DIPEA (65 $\mu \mathrm{L}, 0.38 \mathrm{mmol}, 15 \mathrm{eq}$ ). Next, the resin was added the cleavage cocktail (HFIP/DCM/TES [50:45:5]) and swirled for 1 hour. After filtration, the solvent was evaporated under reduced pressure, and the crude was triturated using diethyl ether followed by filtration of the solid. The crude was reacted without further purification with DMBA (12 mg, $0.075 \mathrm{mmol}, 3 e q)$ and $\mathrm{Pd}\left(\mathrm{PPh}_{3}\right)_{4}(3 \mathrm{mg}, 0.0025 \mathrm{mmol}, 0.1 \mathrm{eq}$ ) in DCM and monitored by HPLC (50-100\% ACN). Upon completion, the solvent was evaporated, and the compound was purified via PREP-RP-HPLC (50-100\% ACN) to afford Enol-ether 2 as a white solid (19 $\mathrm{mg}, 93 \%$ yield). $\mathrm{MS}$ (ES+): $\mathrm{m} / \mathrm{z}$ calculated for $\mathrm{C}_{45} \mathrm{H}_{53} \mathrm{ClN}_{4} \mathrm{O}_{7}$ : 796.4; found: $797.8[\mathrm{M}+\mathrm{H}]^{+}$.

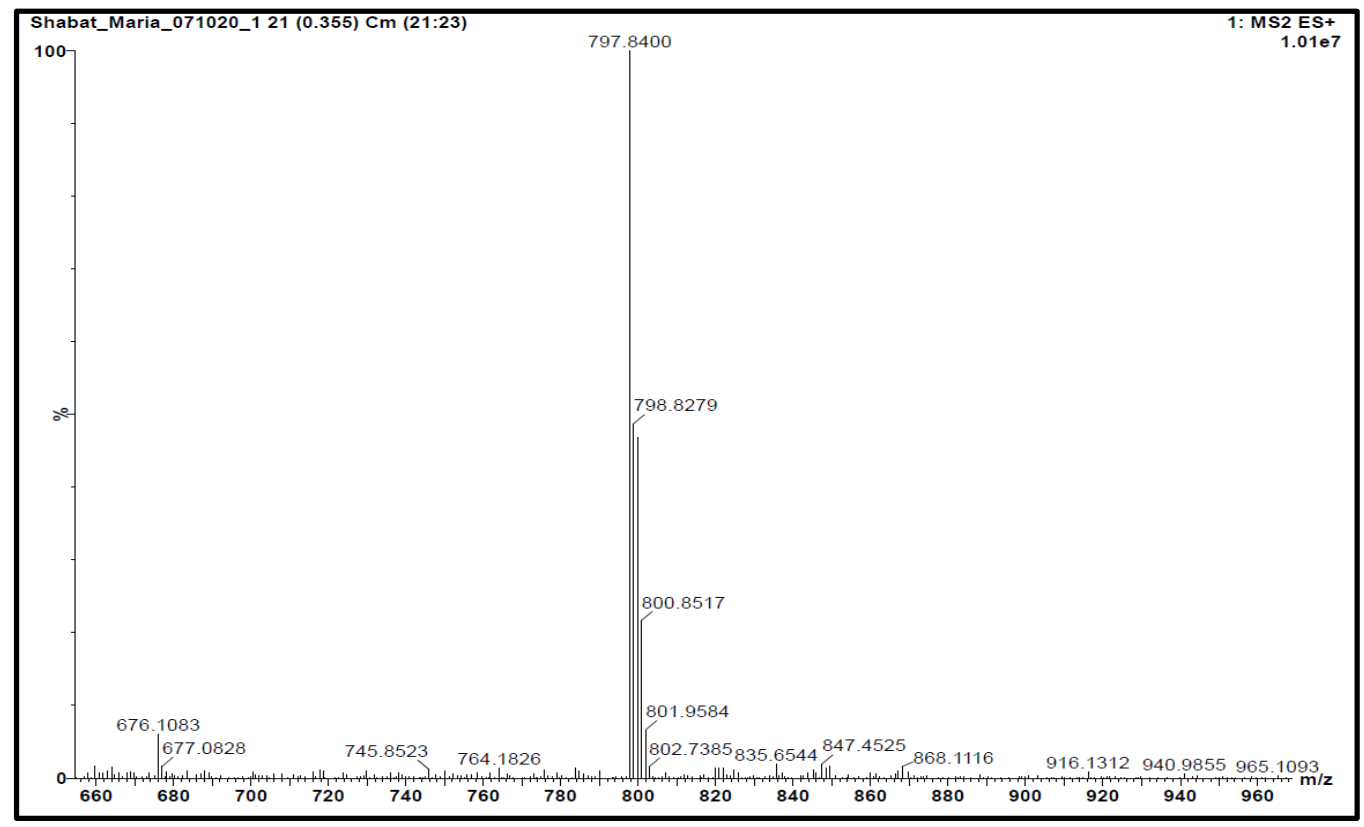

Figure S11. MS(+) spectra of Enol-ether 2. 


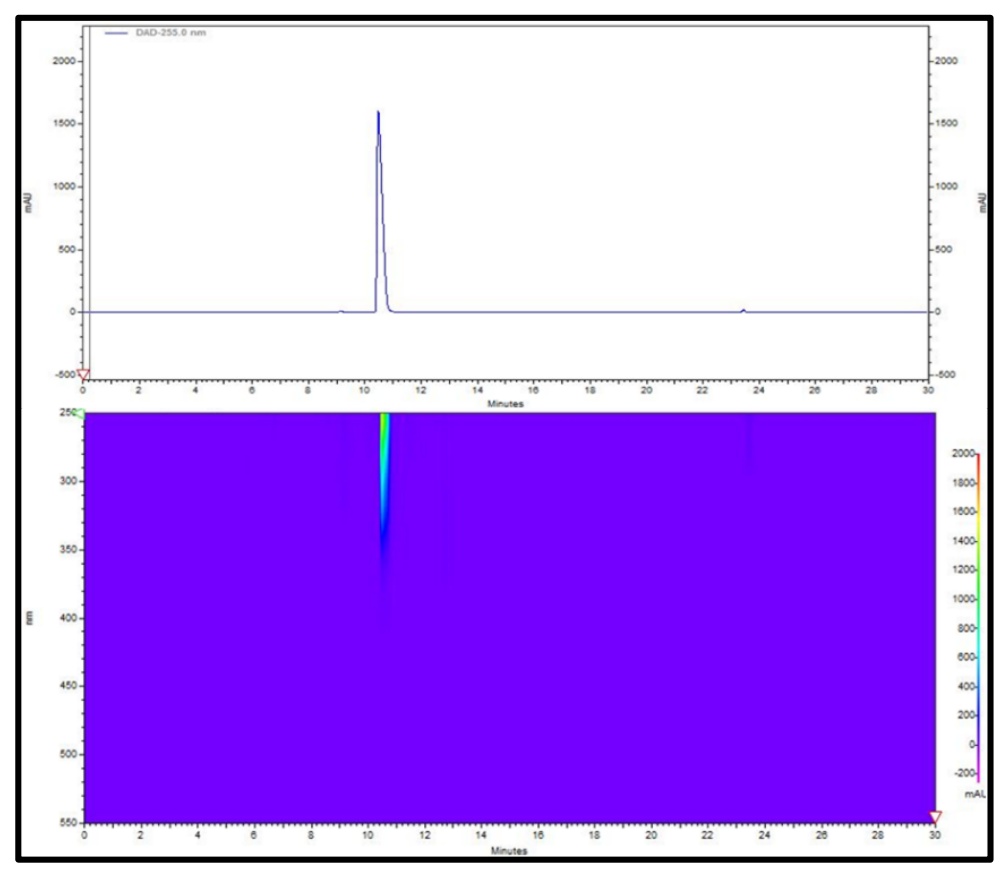

Figure S12. HPLC 2D and 3D chromatogram of Enol-ether 2 (50-100\% $A C N: \mathrm{H}_{2} \mathrm{O}, \mathrm{RT}=10.5$ minutes).
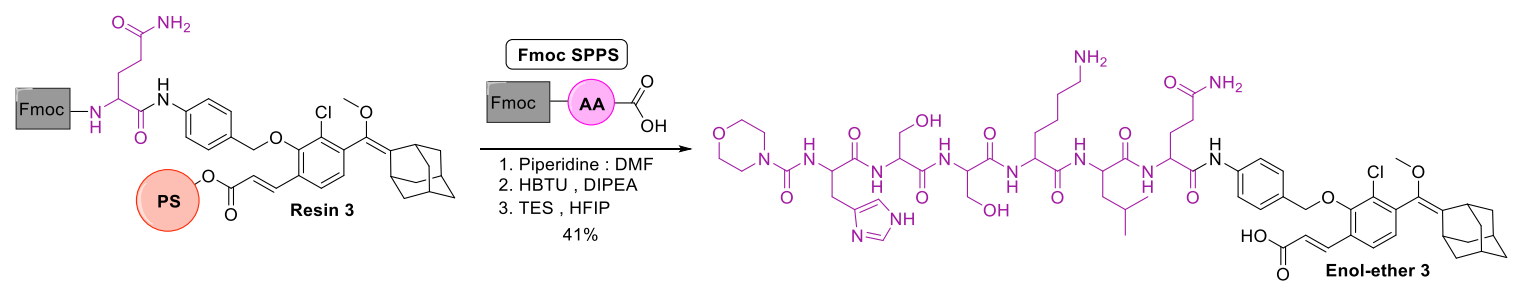

\section{Enol-ether 3}

Enol-ether 3 was synthesized via Fmoc-Solid Phase Peptide Synthesis. Resin 3 (215 mg, 0.063 $\mathrm{mmol}$, 1eq) was swirled in DCM for $30 \mathrm{~min}$. Fmoc deprotection was done with $20 \%$ piperidine in DMF (15 minutes) followed by coupling of the next amino acid (4 eq) using HBTU (4 eq) and DIPEA (6 eq) in DMF (30 minutes). These two steps were repeated until the sequence is completed. After Fmoc deprotection of the histidine was completed, the peptide was capped with 4morpholinecarbonyl chloride (110 $\mu \mathrm{l}, 0.95 \mathrm{mmol}, 15 \mathrm{eq})$ and DIPEA (329 $\mu \mathrm{l}, 1.89 \mathrm{mmol}, 30 \mathrm{eq})$ in DMF. Finally, Next, the resin was added the cleavage cocktail (HFIP/DCM/TES [50:45:5]), which also provided $\mathrm{Mmt}$ and Trt deprotection after swirling for 2 hours. After filtration, the solvent was evaporated under reduced pressure, and the crude was triturated using diethyl ether followed by filtration to afford the title compound Enol-ether 3 as a white solid (32.3 mg, 41\%). MS (ES-): m/z calculated for $\mathrm{C}_{62} \mathrm{H}_{85} \mathrm{ClN}_{12} \mathrm{O}_{15}$ : 1272.6; found: 1272.3. MS (ES+): $\mathrm{m} / \mathrm{z}$ calculated for $\mathrm{C}_{62} \mathrm{H}_{85} \mathrm{ClN}_{12} \mathrm{O}_{15}$ : 1272.6; found: 637.9.[(M+2H)/2z] $]^{+}$ 


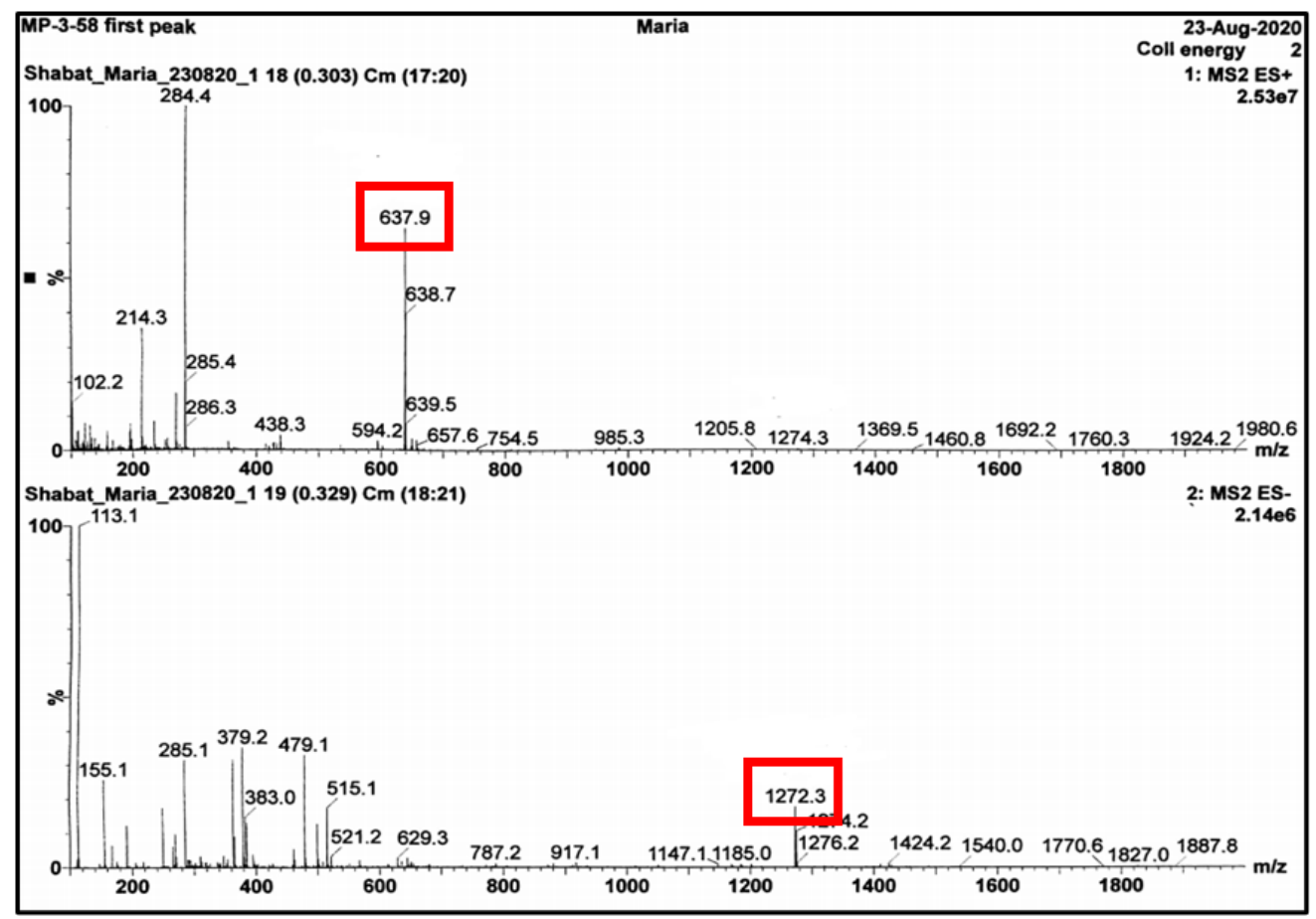

Figure S13. MS(+) spectra of Enol-ether 3.

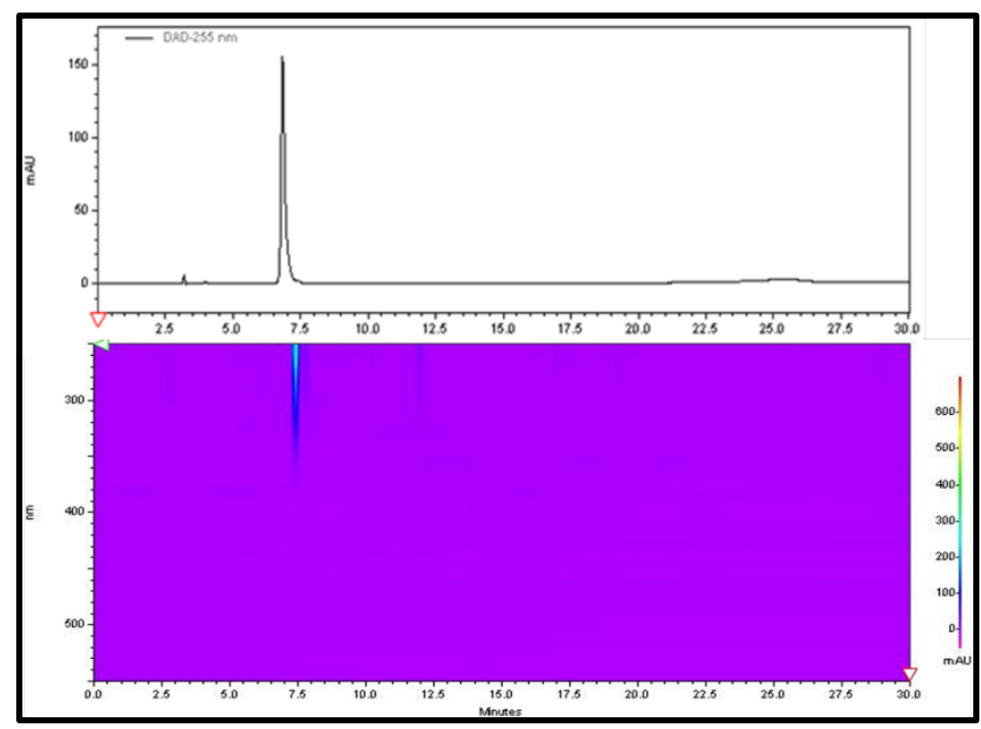

Figure S14. HPLC 2D and 3D chromatogram of Enol-ether 3 (50-100\% ACN: $\mathrm{H}_{2} \mathrm{O}, \mathrm{RT}=7.4$ minutes).<smiles>C/C=C(/C)NC(=O)C(C)NC(=O)C(N)CO</smiles><smiles>CCc1ccccc1</smiles><smiles>COC(=C1C2CC3CC(C2)CC1C3)c1ccc(C)c(Cl)c1Cl</smiles>
Methylene blue $\mathrm{HO}$ Enol-ether 1

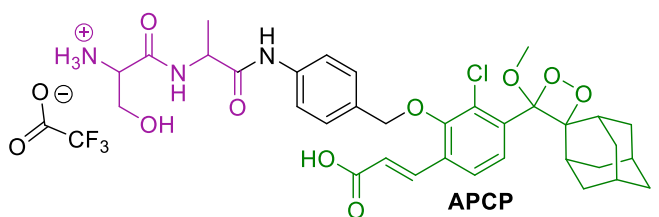


Enol-ether 1 ( $9.8 \mathrm{mg}, 0.015 \mathrm{mmol}$ ) and few milligrams of methylene blue were dissolved in $10 \mathrm{ml}$ of DMF. Oxygen was bubbled through the solution while irradiating with yellow light for 10 minutes. The reaction was monitored by RP-HPLC. After completion, the reaction mixture was purified by preparative RP-HPLC (50-100\% ACN). The product APCP was obtained as a white solid (9.4 mg, 91\%). MS (ES+): $\mathrm{m} / \mathrm{z}$ calculated for $\mathrm{C}_{34} \mathrm{H}_{40} \mathrm{ClN}_{3} \mathrm{O}_{9}$ : 669.2; found: $670.5[\mathrm{M}+\mathrm{H}]^{+}$.

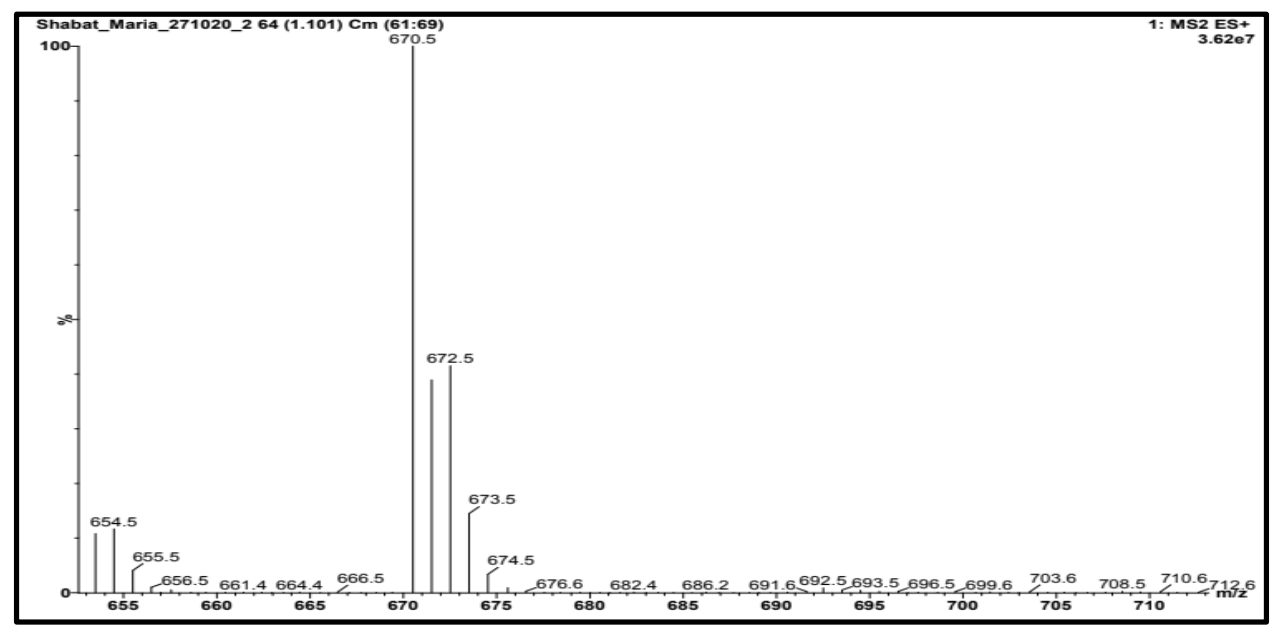

Figure S15. MS(+) spectra of APCP.

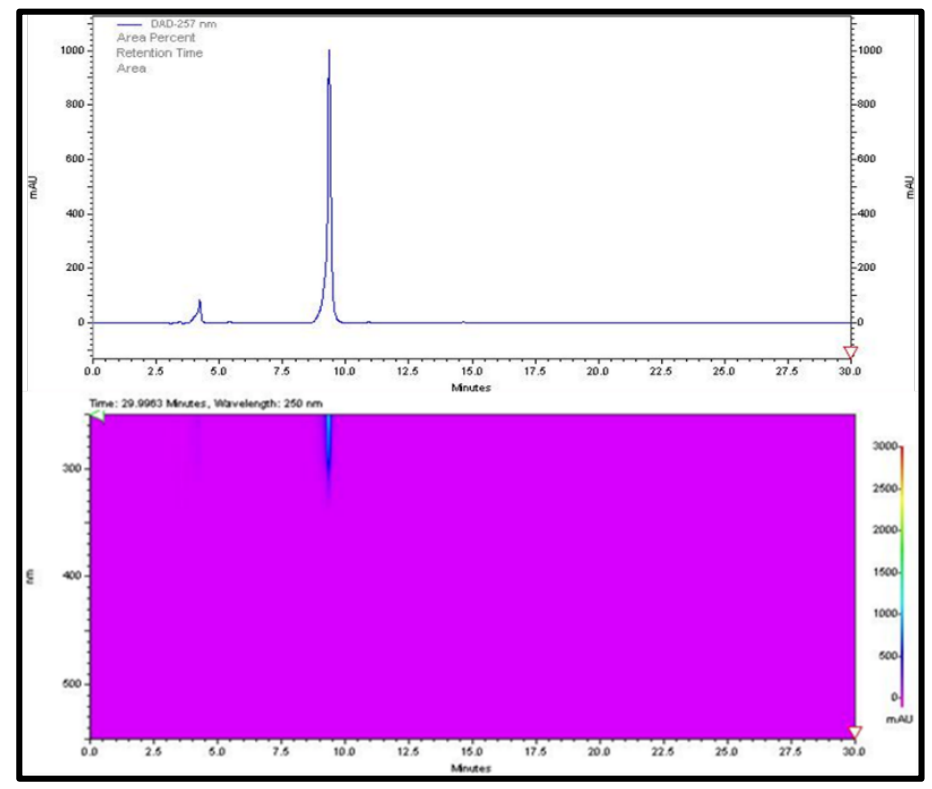

Figure S16. HPLC 2D and 3D chromatogram of APCP (50-100\% $\mathrm{ACN}: \mathrm{H}_{2} \mathrm{O}, \mathrm{RT}=9.3$ minutes). 


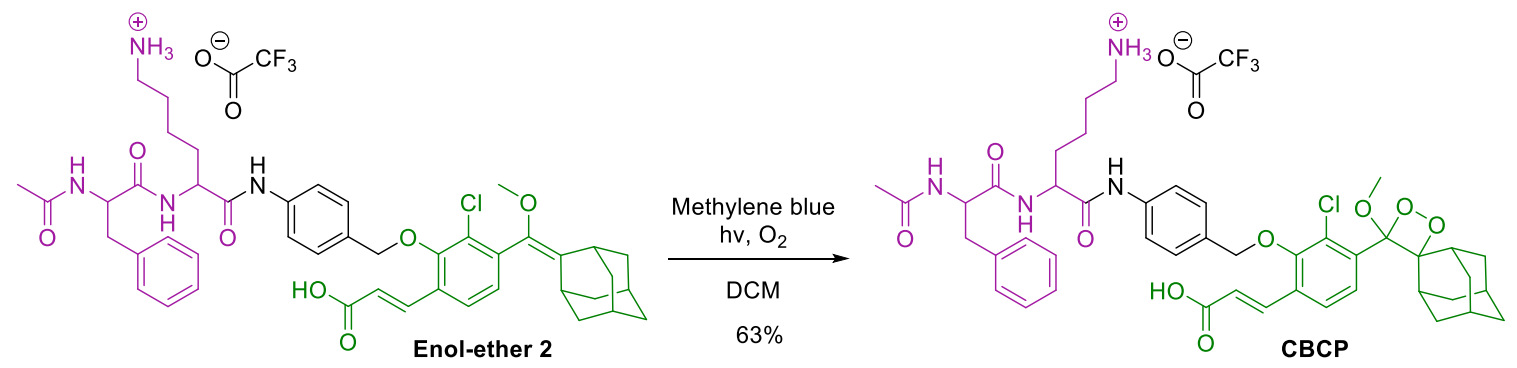

CBCP

Enol-ether 2 (9.1 mg, $0.011 \mathrm{mmol}$ ) and few milligrams of methylene blue were dissolved in $2 \mathrm{ml}$ of DMF. Oxygen was bubbled through the solution while irradiating with yellow light for 5 minutes. The reaction was monitored by RP-HPLC. Upon completion, the reaction mixture was purified by preparative RP-HPLC (50-100\% ACN). The product CBCP was obtained as a white solid (5.94 mg, 63\%). MS (ES+): $\mathrm{m} / \mathrm{z}$ calculated for $\mathrm{C}_{45} \mathrm{H}_{53} \mathrm{ClN}_{4} \mathrm{O}_{9}$ : 828.4; found: $829.7[\mathrm{M}+\mathrm{H}]^{+}$.

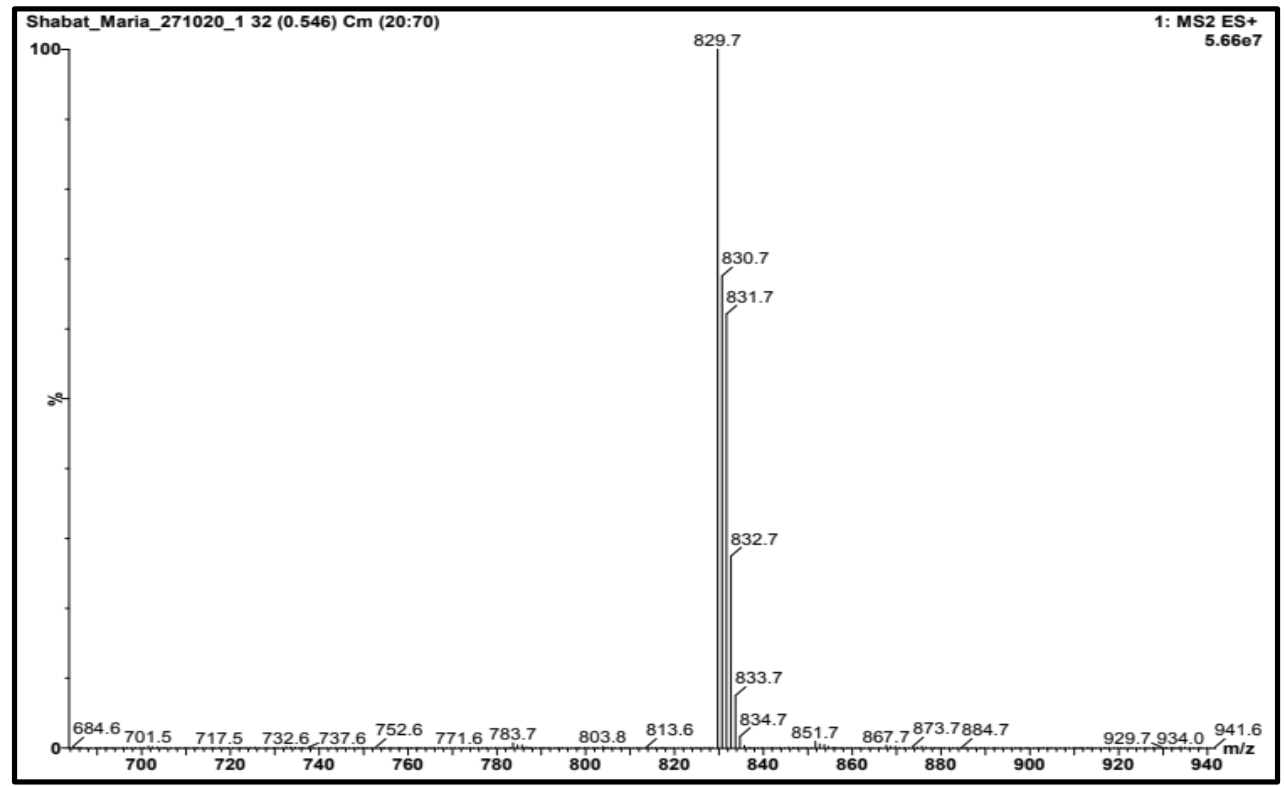

Figure S17. $\mathrm{MS}(+)$ spectra of CBCP. 


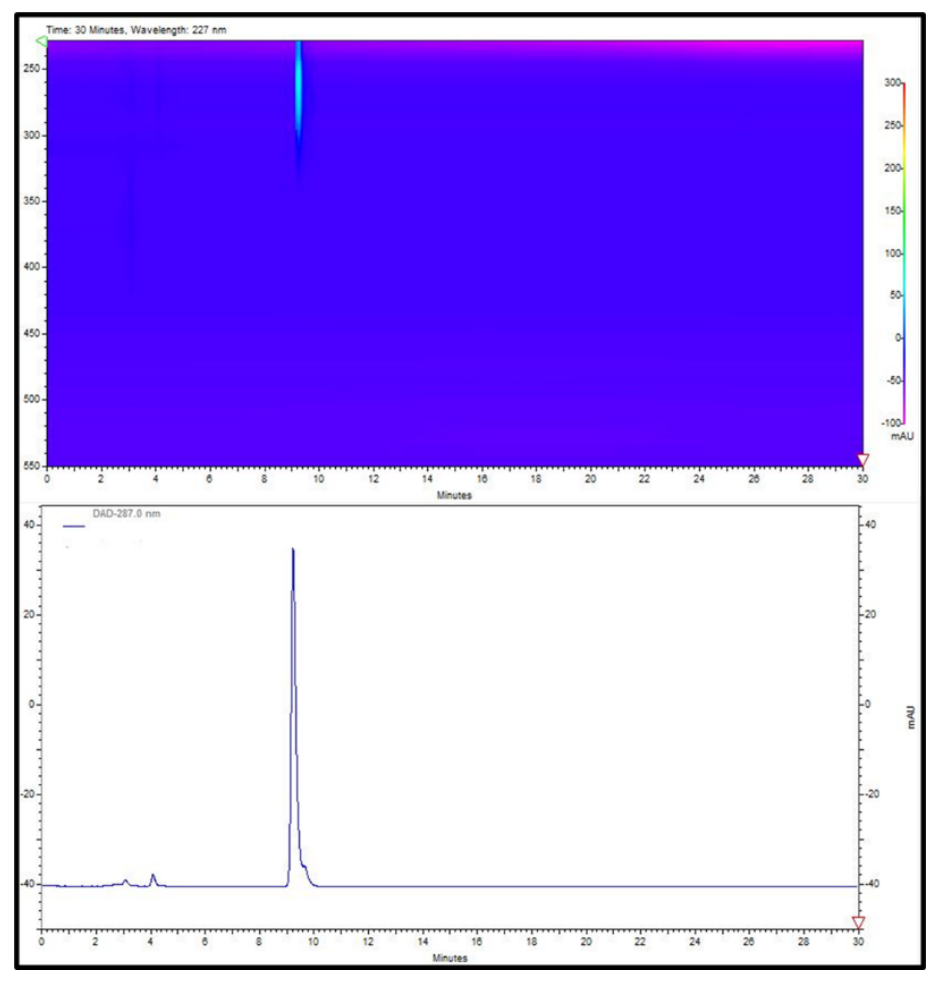

Figure S18. HPLC 2D and 3D chromatogram of CBCP (50-100\% ACN: $\mathrm{H}_{2} \mathrm{O}, \mathrm{RT}=14.6$ minutes).

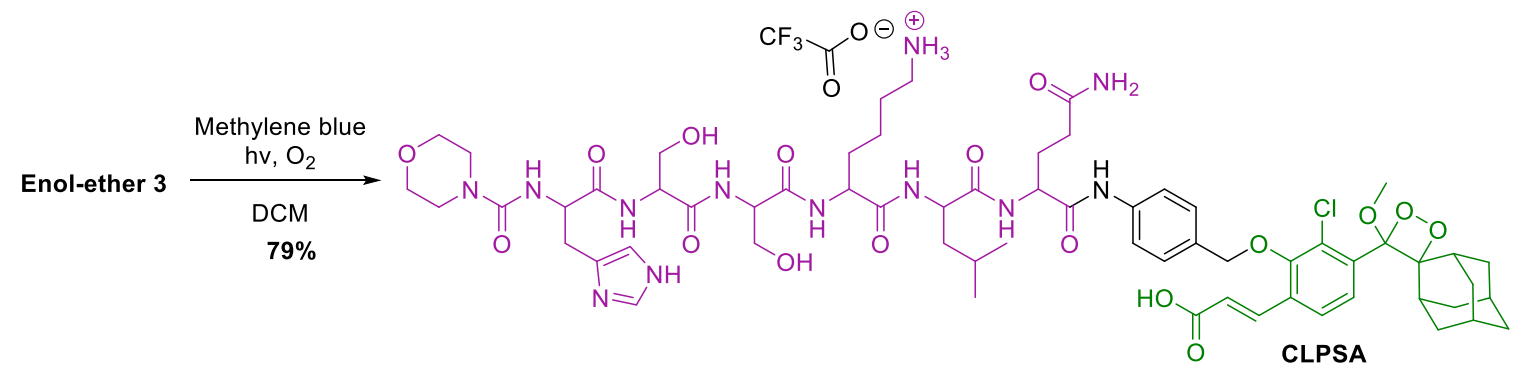

\section{CLPSA}

Compound CLSPA was synthesized according to a previously reported procedure ${ }^{2}$.

MS (ES+): $\mathrm{m} / \mathrm{z}$ calculated for $\left[\mathrm{C}_{62} \mathrm{H}_{86} \mathrm{ClN}_{12} \mathrm{O}_{17}\right]^{+}:$1304.6; found: $1304.2[\mathrm{M}]^{+}$. 


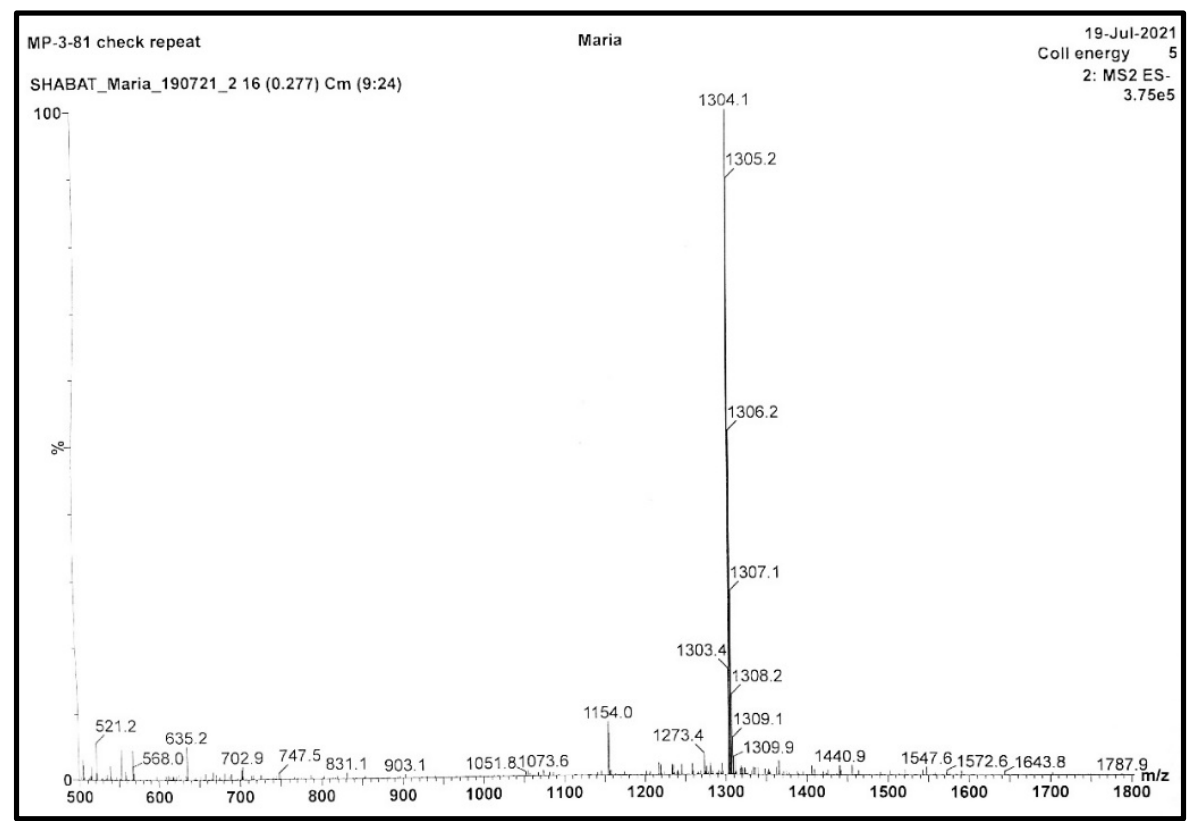

Figure S19. MS(+) spectra of CLPSA.

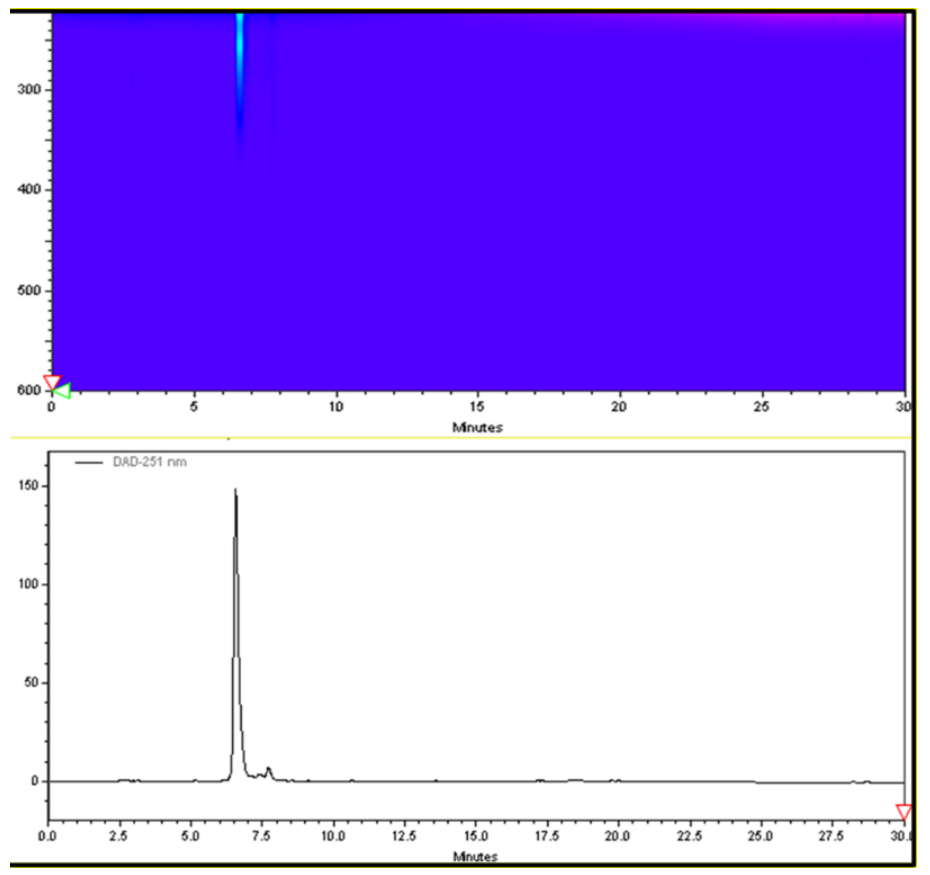

Figure S20. HPLC 2D and 3D chromatogram of CLPSA (50-100\% $A C N: \mathrm{H}_{2} \mathrm{O}, \mathrm{RT}=5.3$ minutes). 


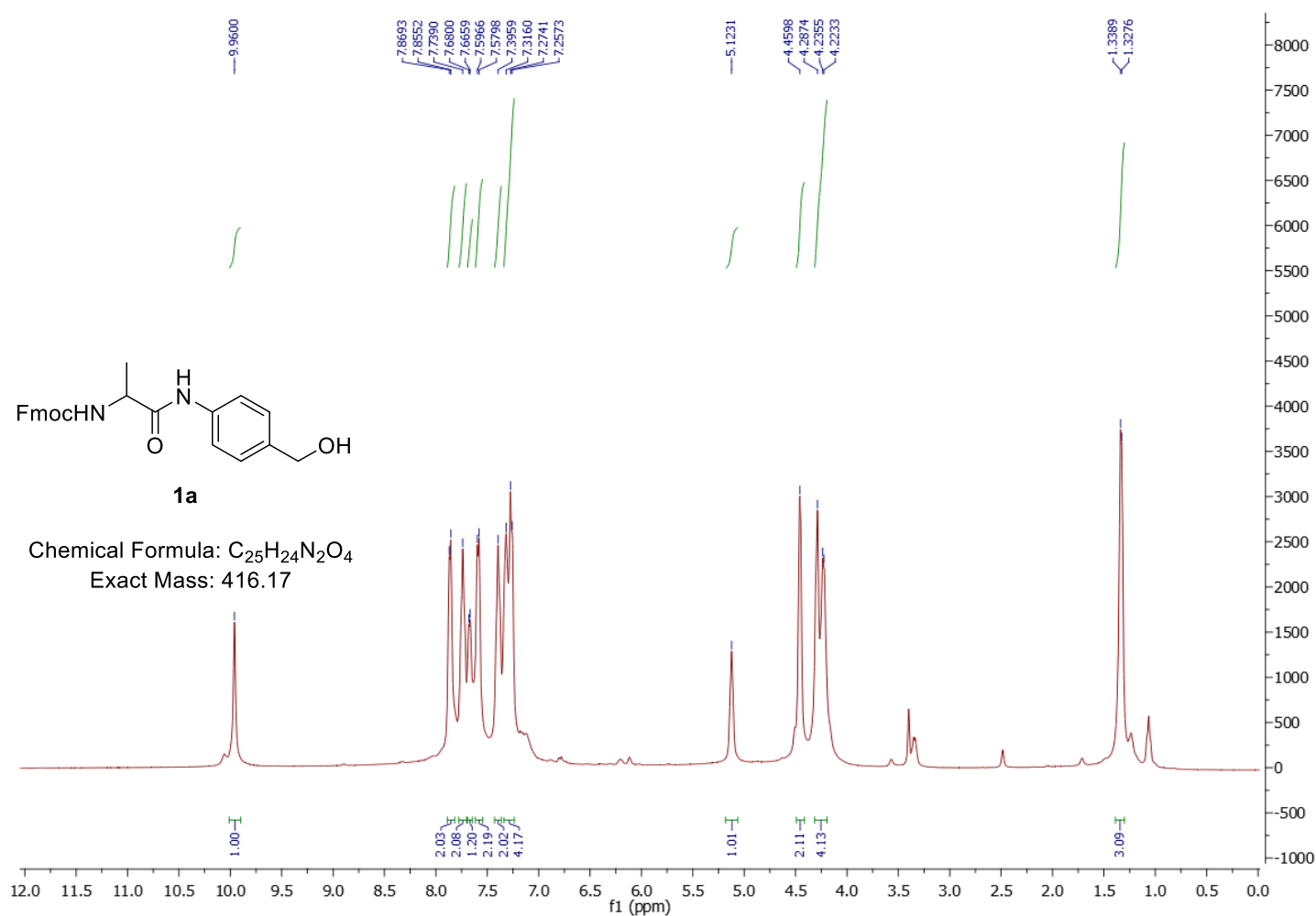

${ }^{1}$ HNMR spectrum of compound $\mathbf{1 a}$
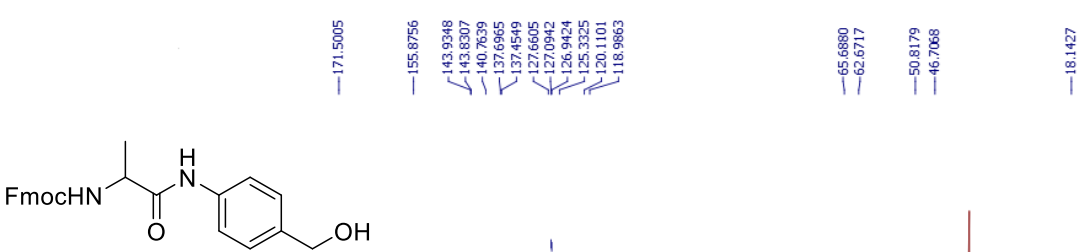

1a

Chemical Formula: $\mathrm{C}_{25} \mathrm{H}_{24} \mathrm{~N}_{2} \mathrm{O}_{4}$ Exact Mass: 416.17

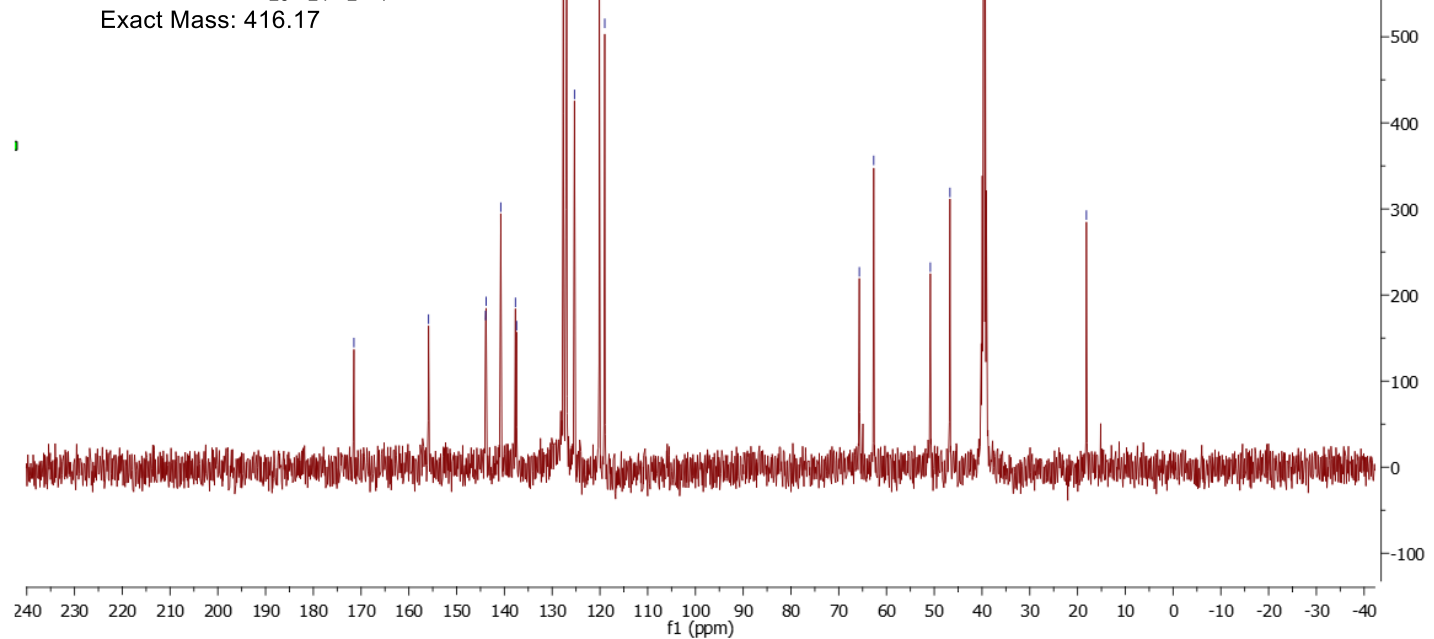

${ }^{13}$ CNMR spectrum of compound $\mathbf{1 a}$ 


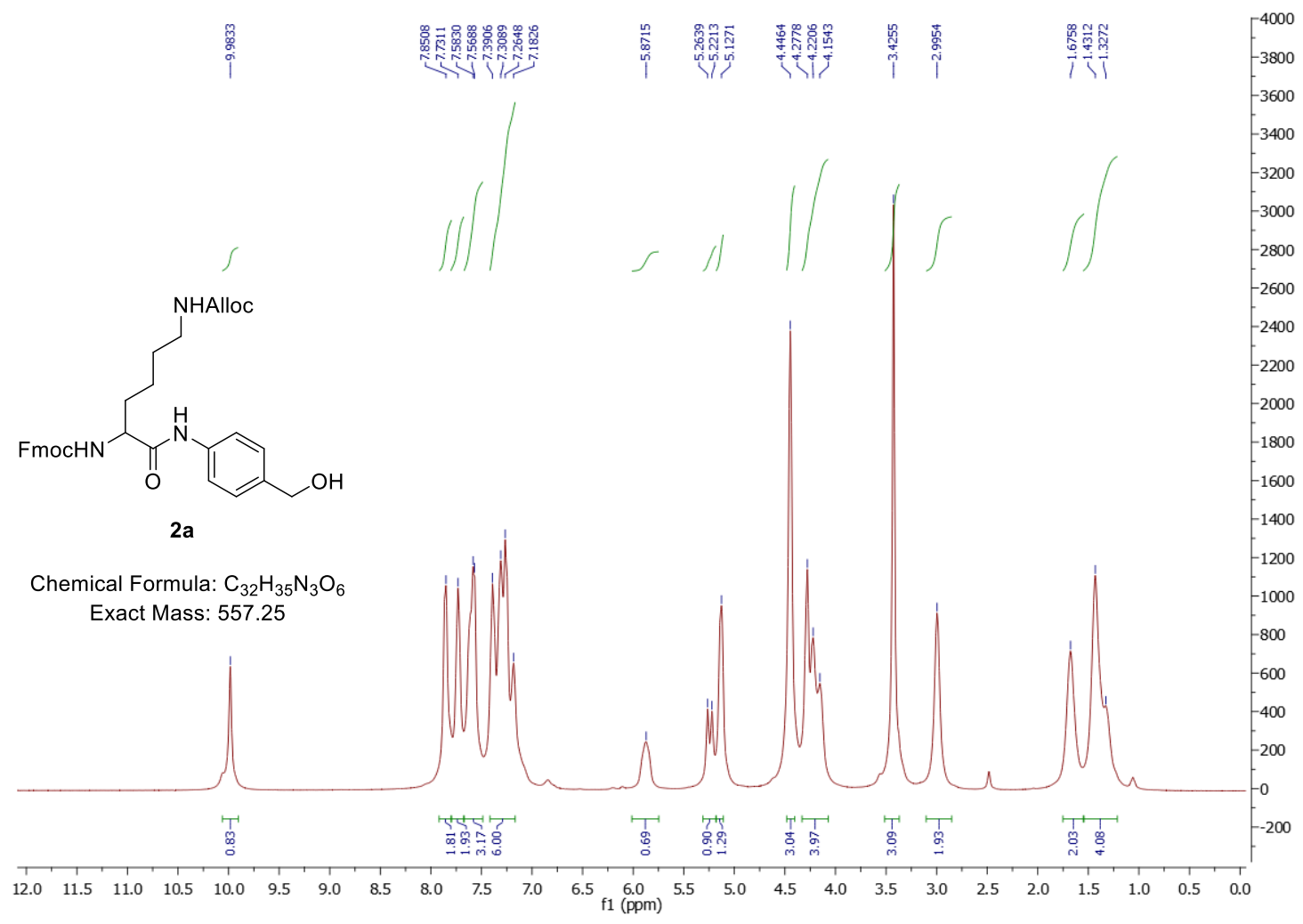

${ }^{1}$ HNMR spectrum of compound $2 a$

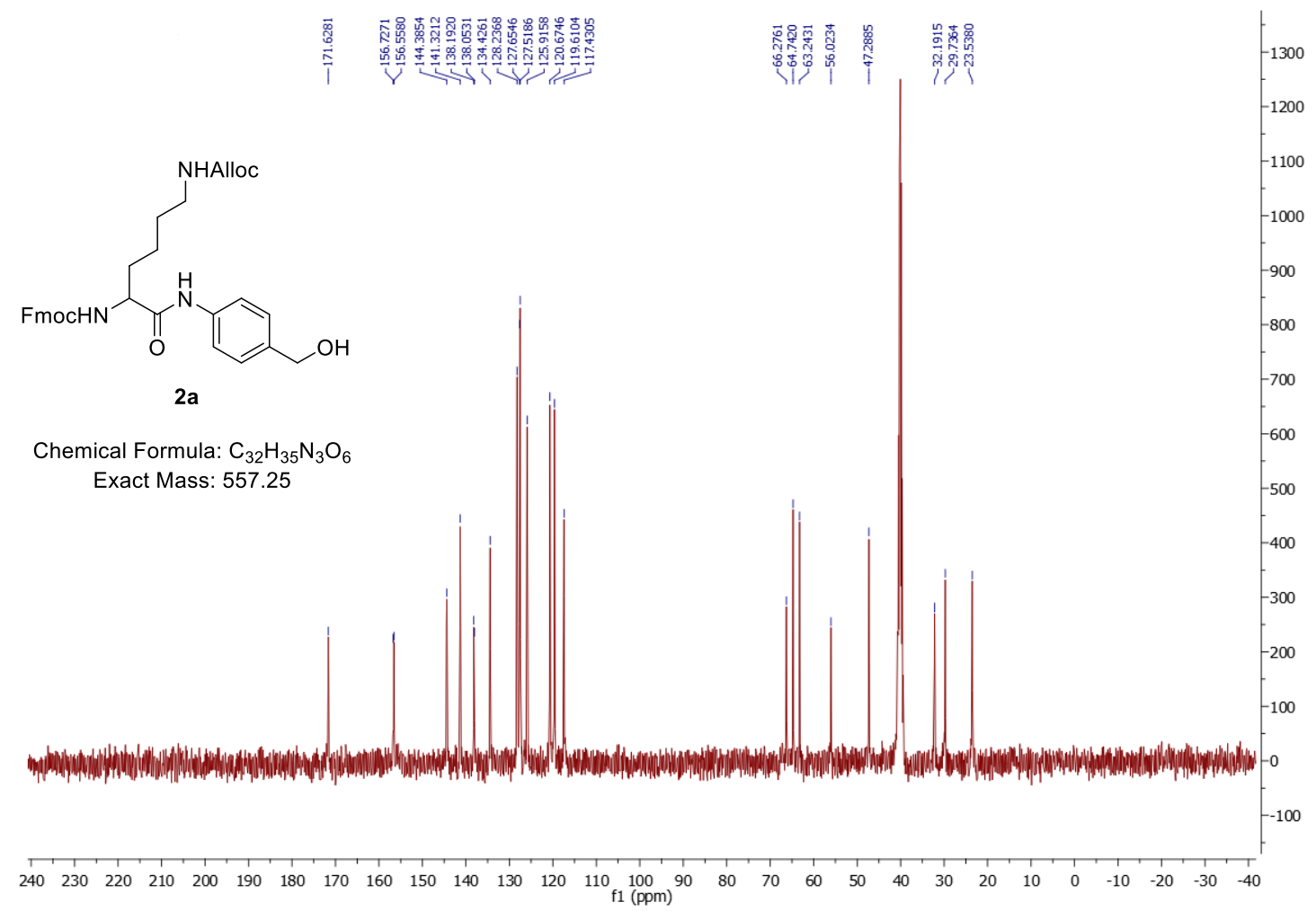

${ }^{13} \mathrm{CNMR}$ spectrum of compound $\mathbf{2 a}$ 


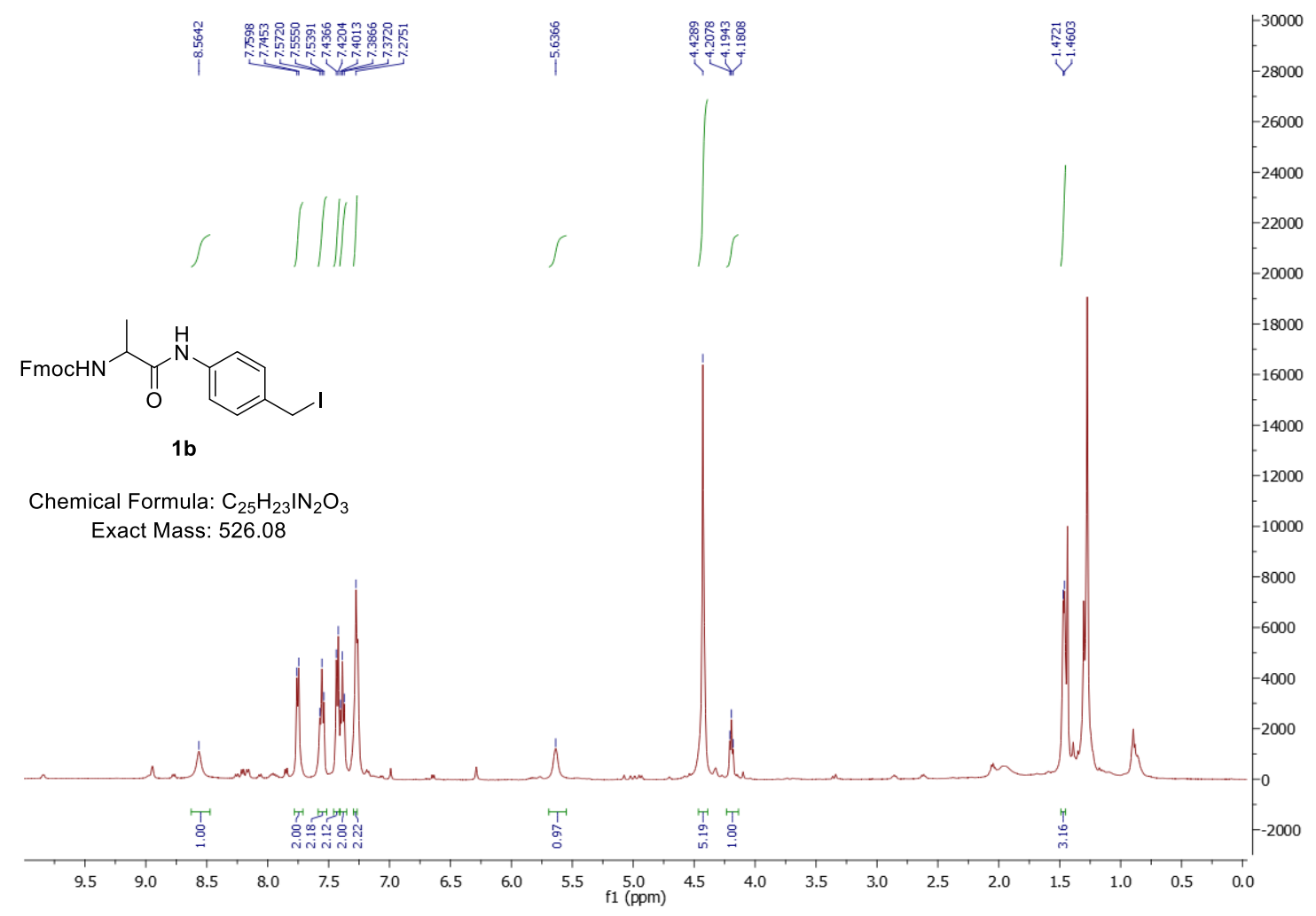

${ }^{1}$ HNMR spectrum of compound $\mathbf{1 b}$

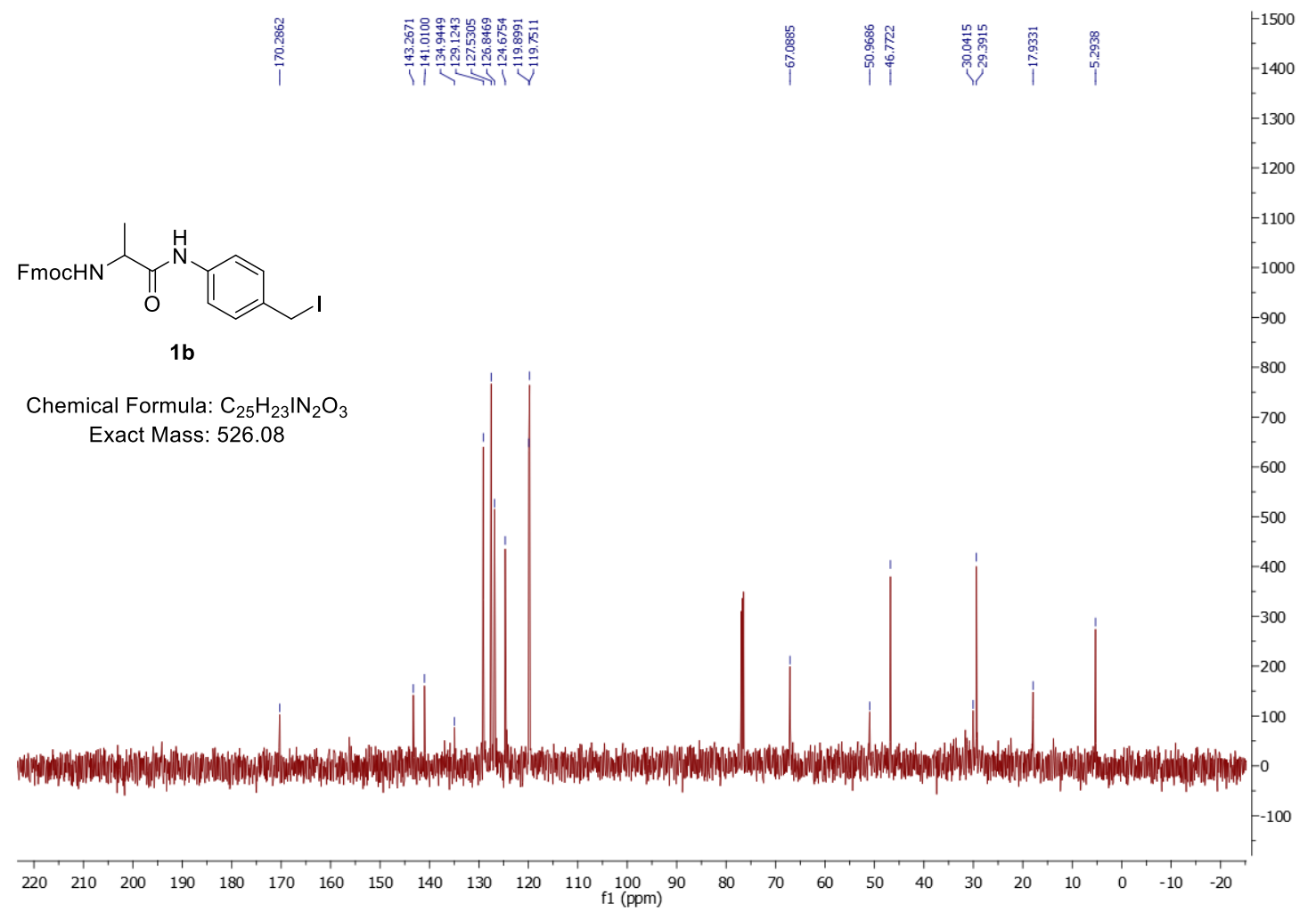

${ }^{13} \mathrm{CNMR}$ spectrum of compound $\mathbf{1} \mathbf{b}$ 


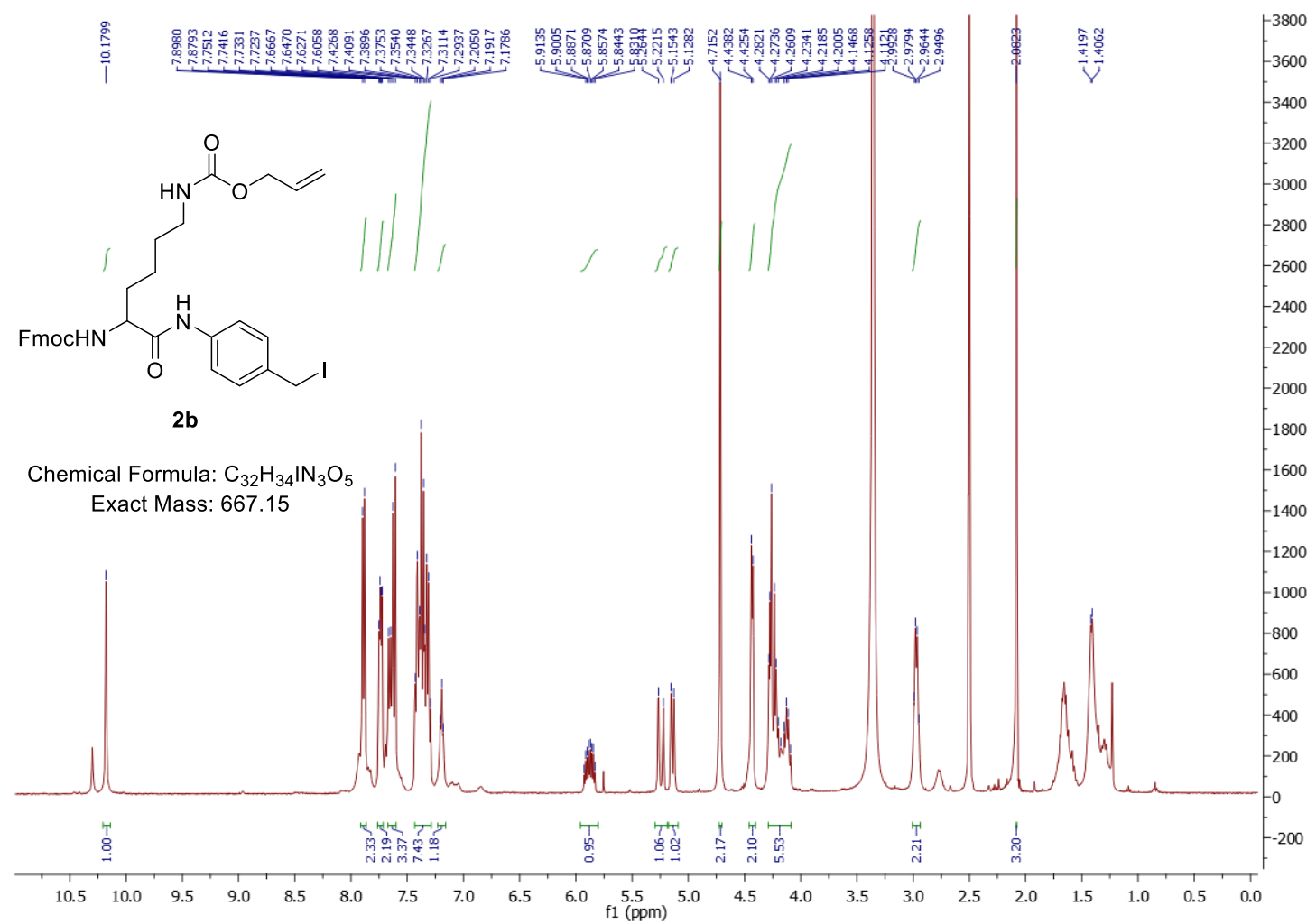

${ }^{1}$ HNMR spectrum of compound $\mathbf{2 b}$
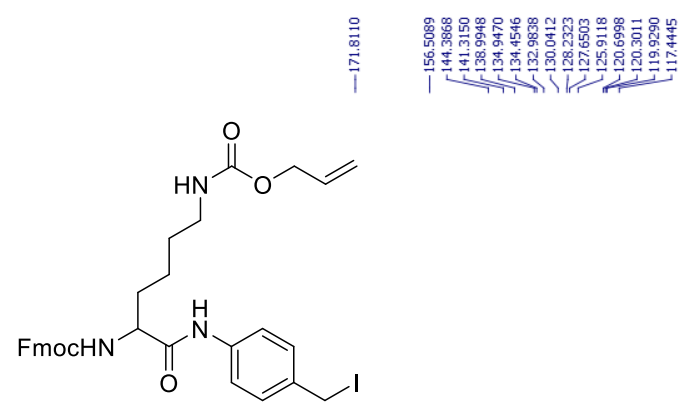

2b

Chemical Formula: $\mathrm{C}_{32} \mathrm{H}_{34} \mathrm{IN}_{3} \mathrm{O}_{5}$

Exact Mass: 667.15

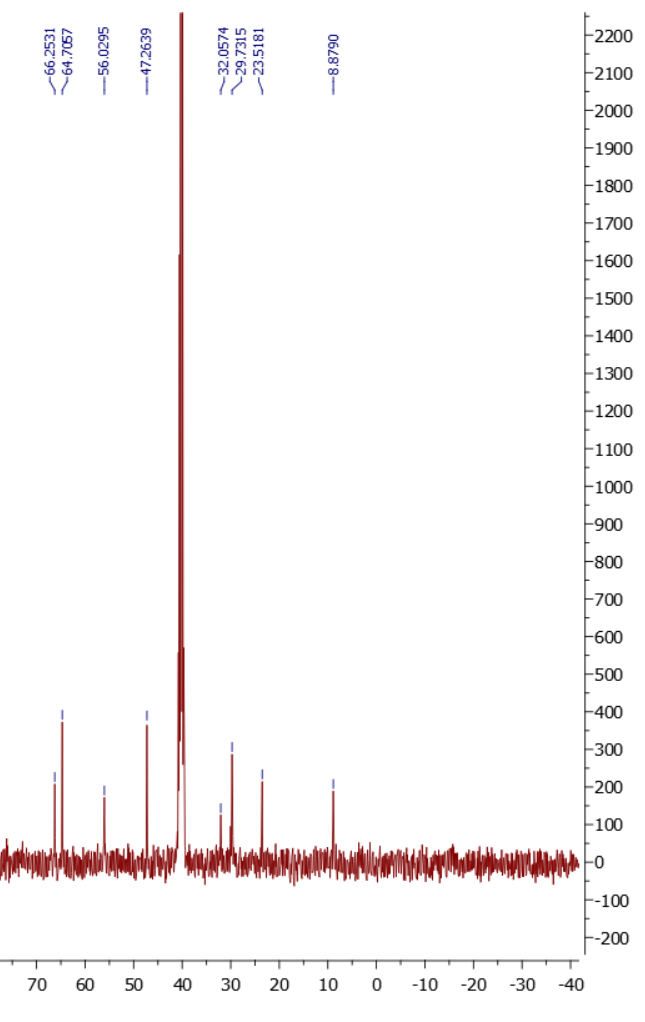

${ }^{13}$ CNMR spectrum of compound $\mathbf{2 b}$ 


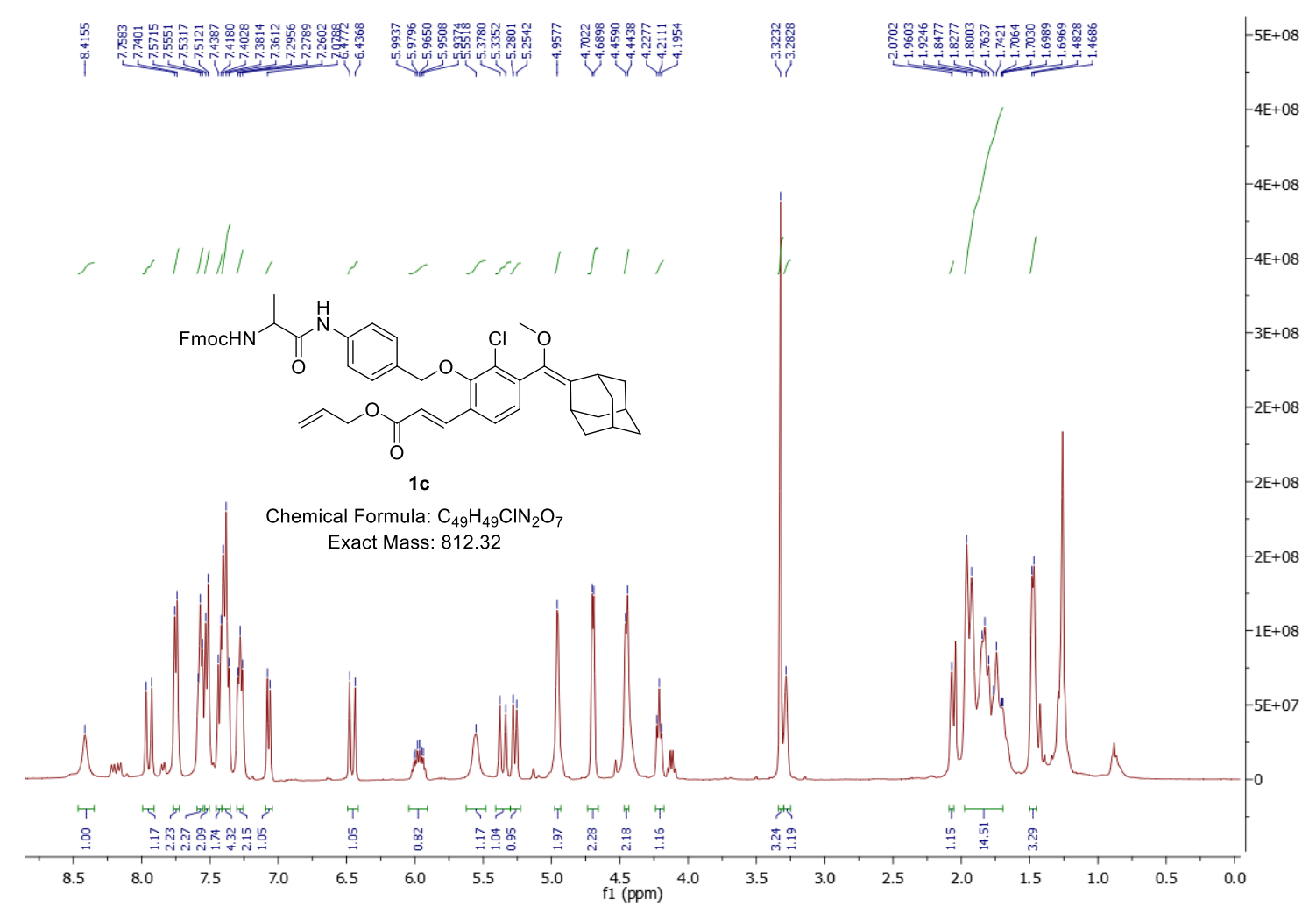

${ }^{1}$ HNMR spectrum of compound $\mathbf{1 c}$

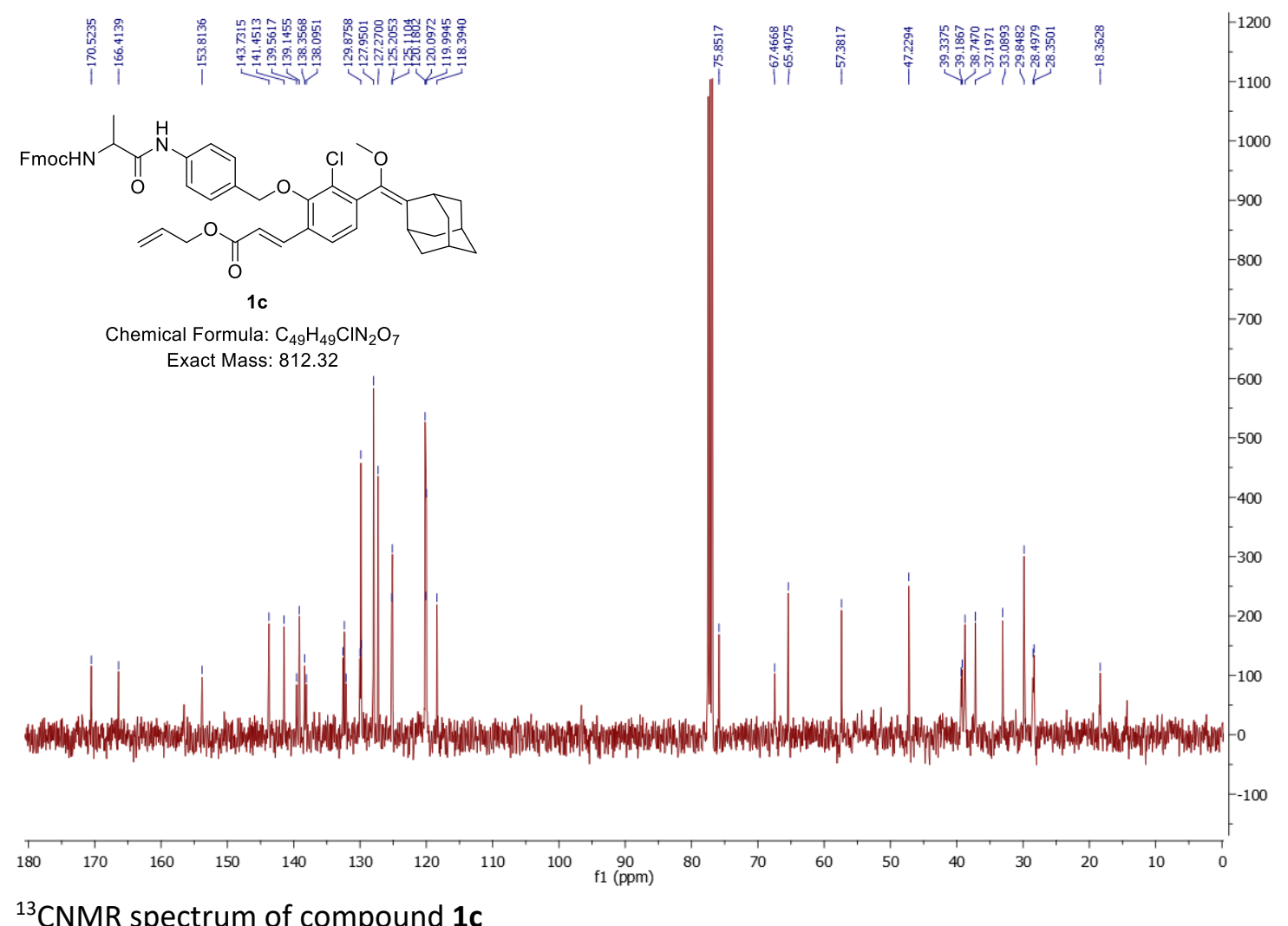

${ }^{13} \mathrm{CNMR}$ spectrum of compound $\mathbf{1 C}$ 
<smiles>C=CCOC(=O)NCC</smiles>
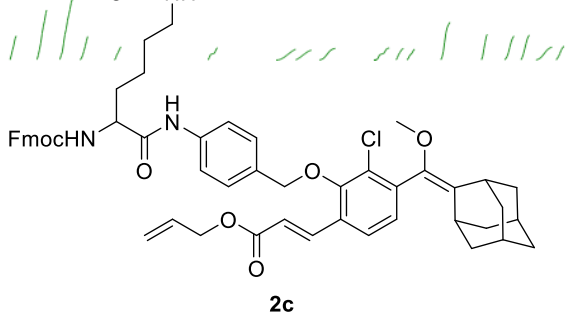

2c
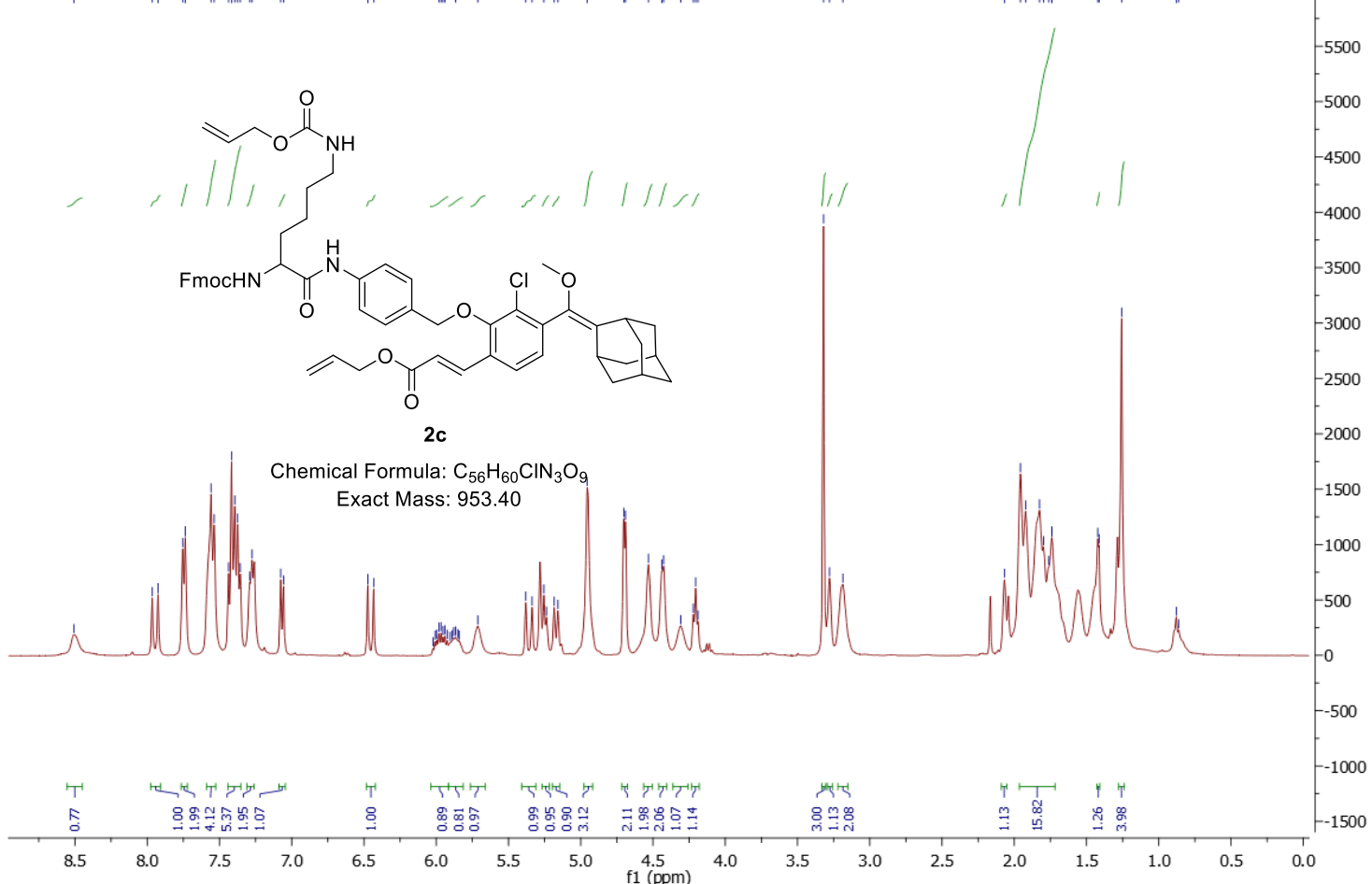

${ }^{1}$ HNMR spectrum of compound $\mathbf{2 c}$
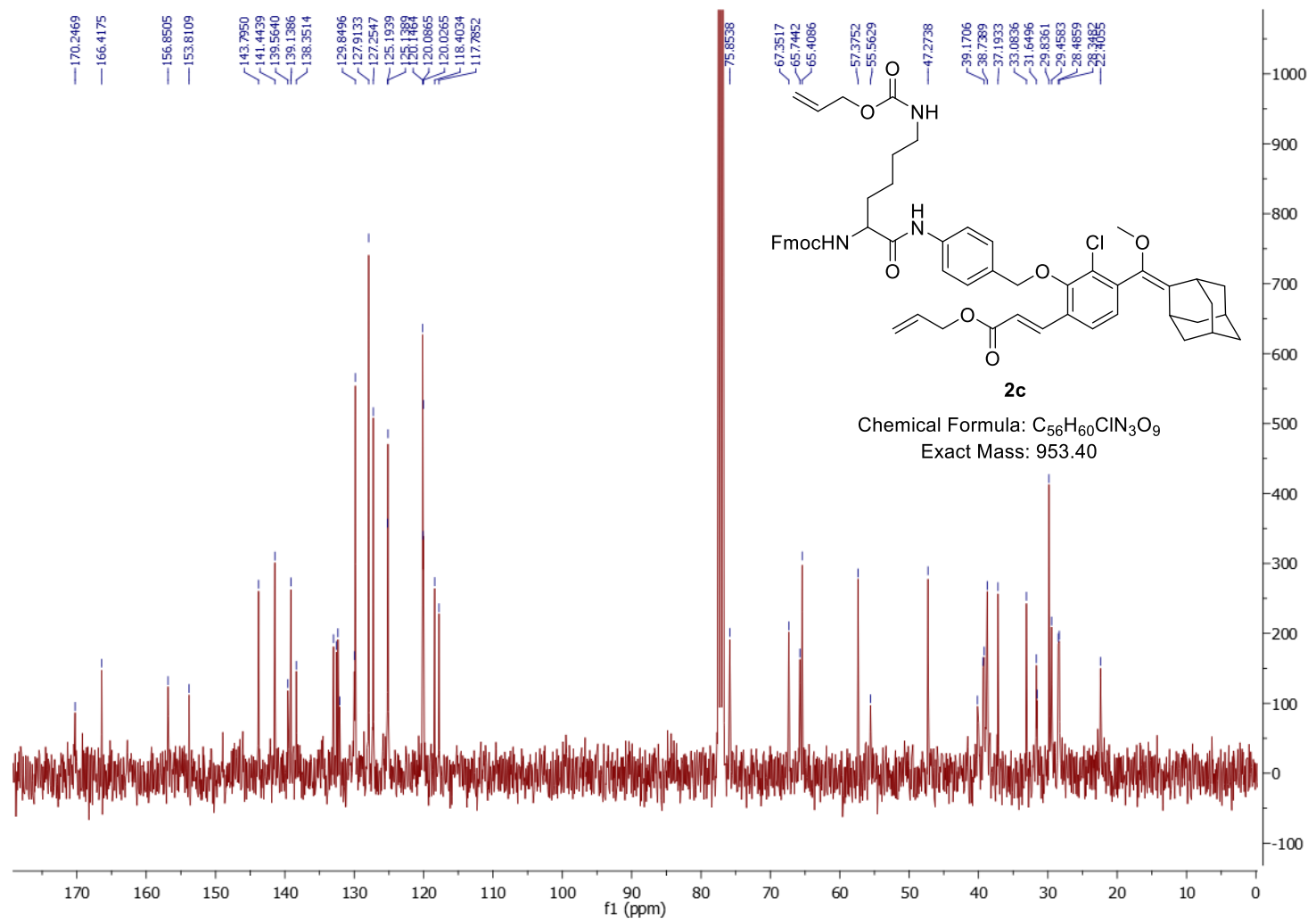

${ }^{13}$ CNMR spectrum of compound $\mathbf{2 c}$ 


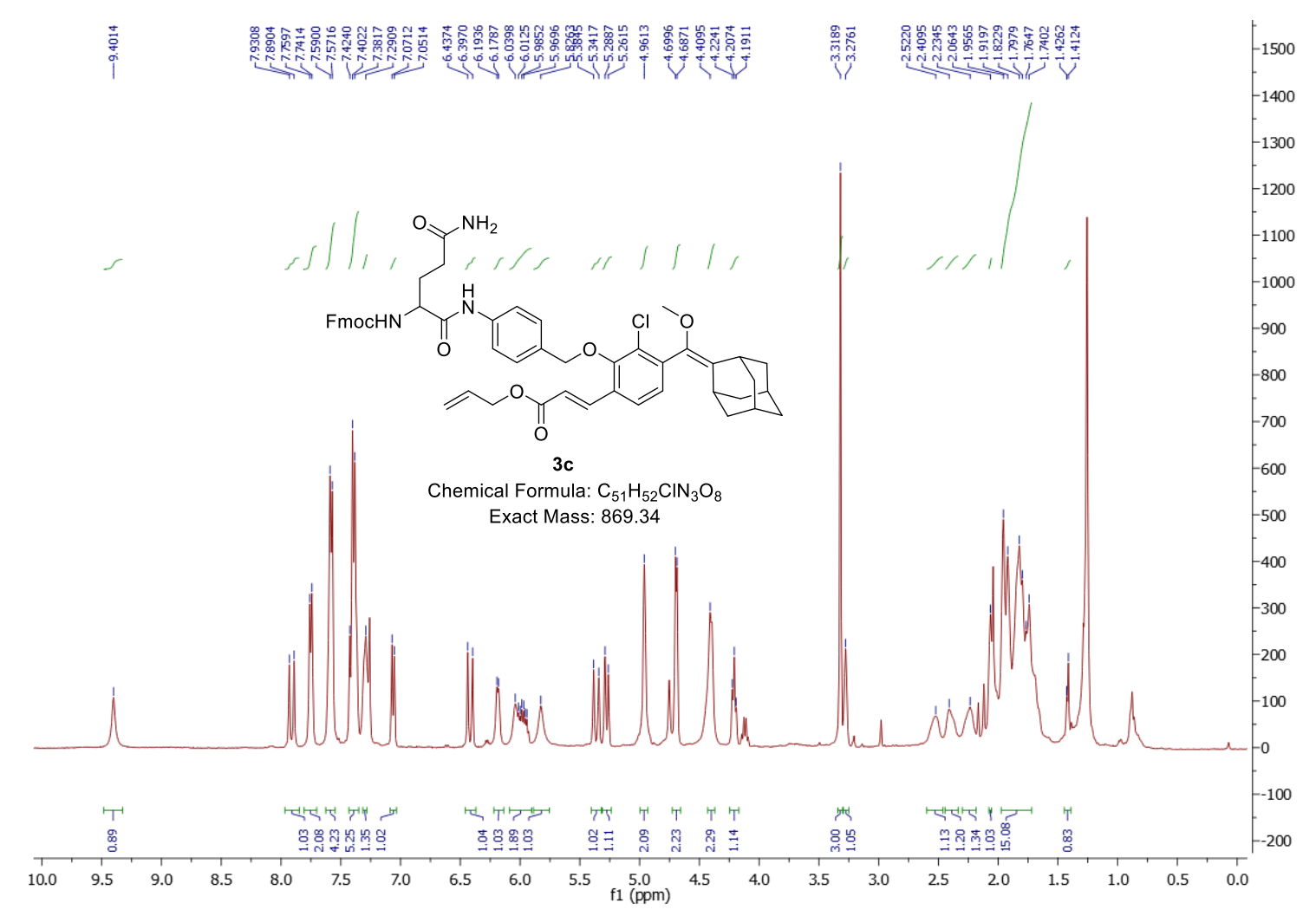

${ }^{1} \mathrm{HNMR}$ spectrum of compound $3 \mathrm{C}$
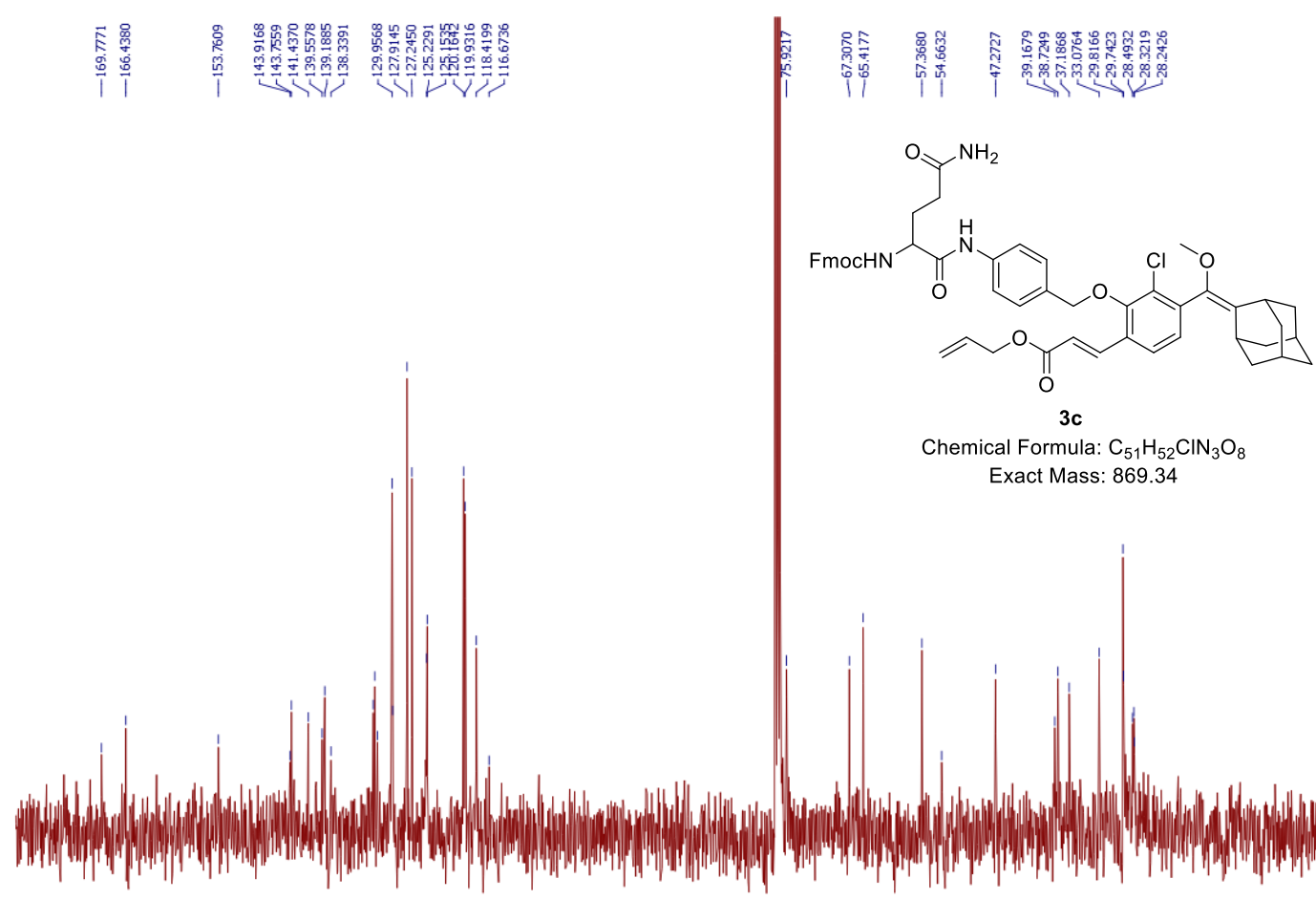

Chemical Formula: $\mathrm{C}_{51} \mathrm{H}_{52} \mathrm{CIN}_{3} \mathrm{O}_{8}$ Exact Mass: 869.34

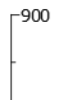

$-800$

$-700$

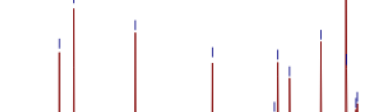

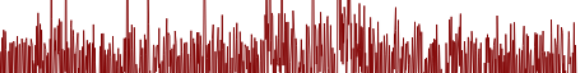

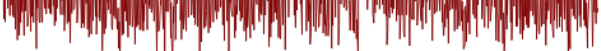

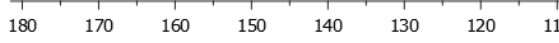

${ }^{13}$ CNMR spectrum of compound $3 \mathrm{c}$ 


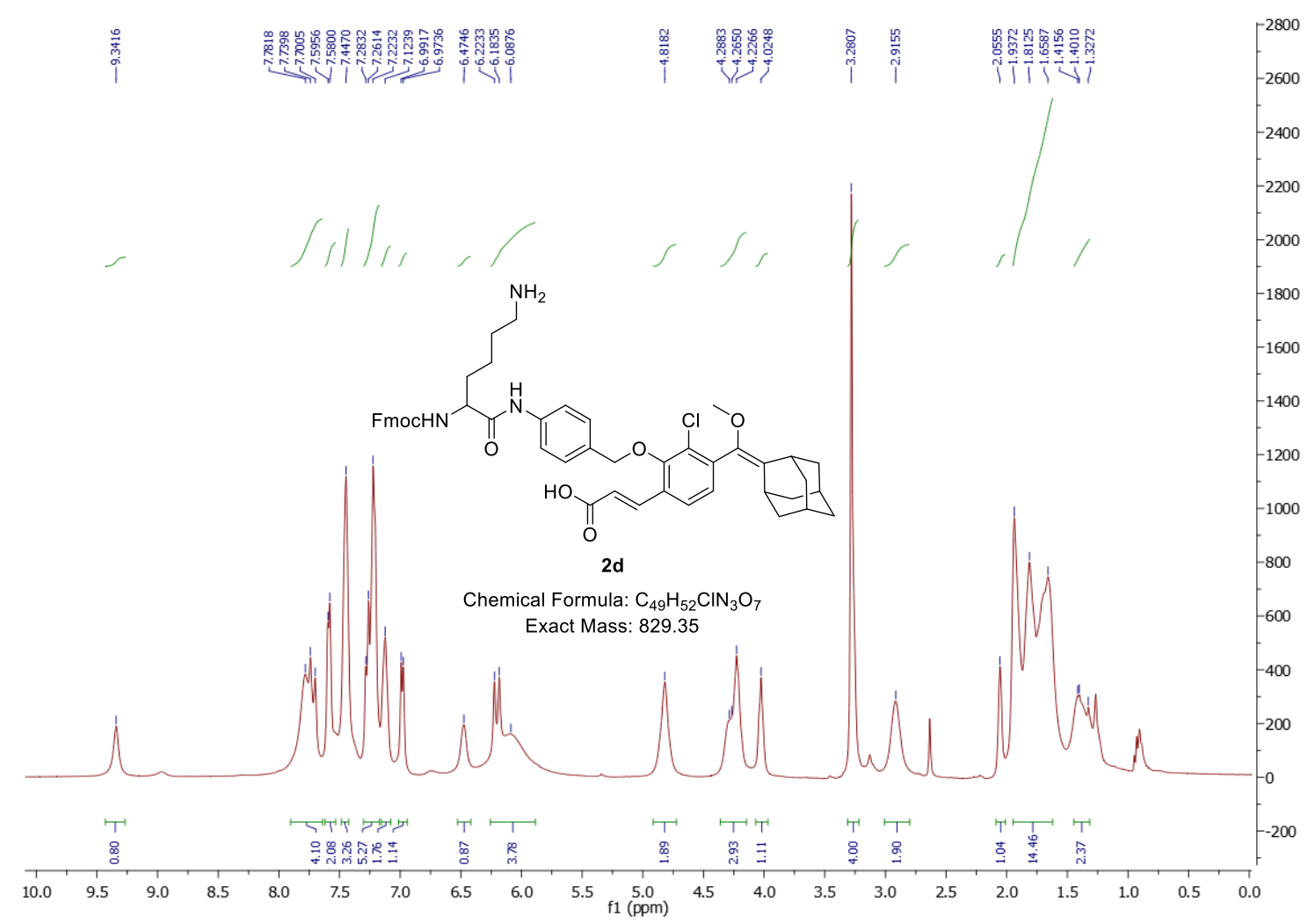

${ }^{1}$ HNMR spectrum of compound $\mathbf{2 d}$

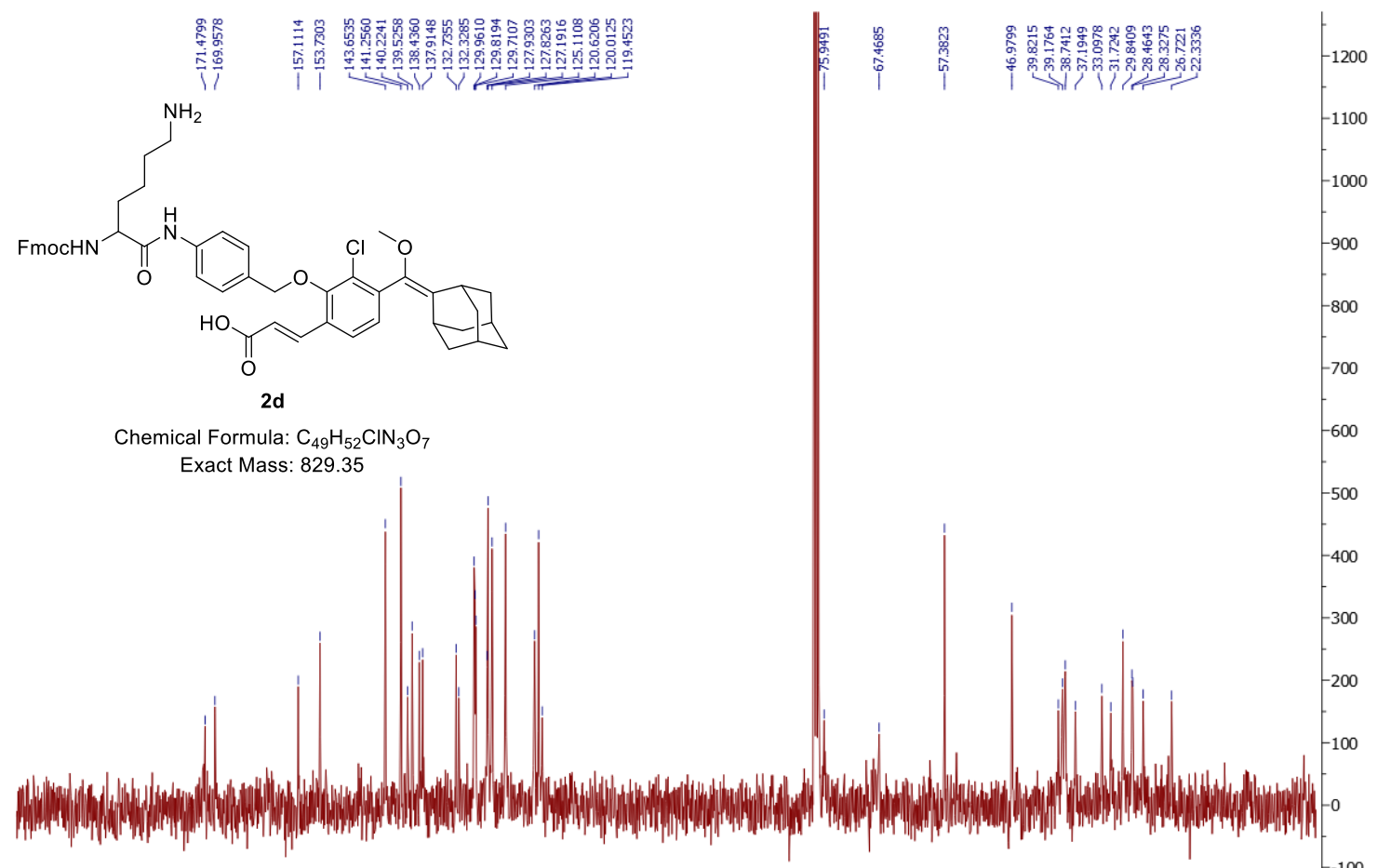

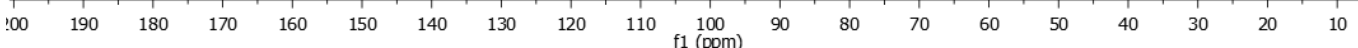

${ }^{13}$ CNMR spectrum of compound $\mathbf{2 d}$ 


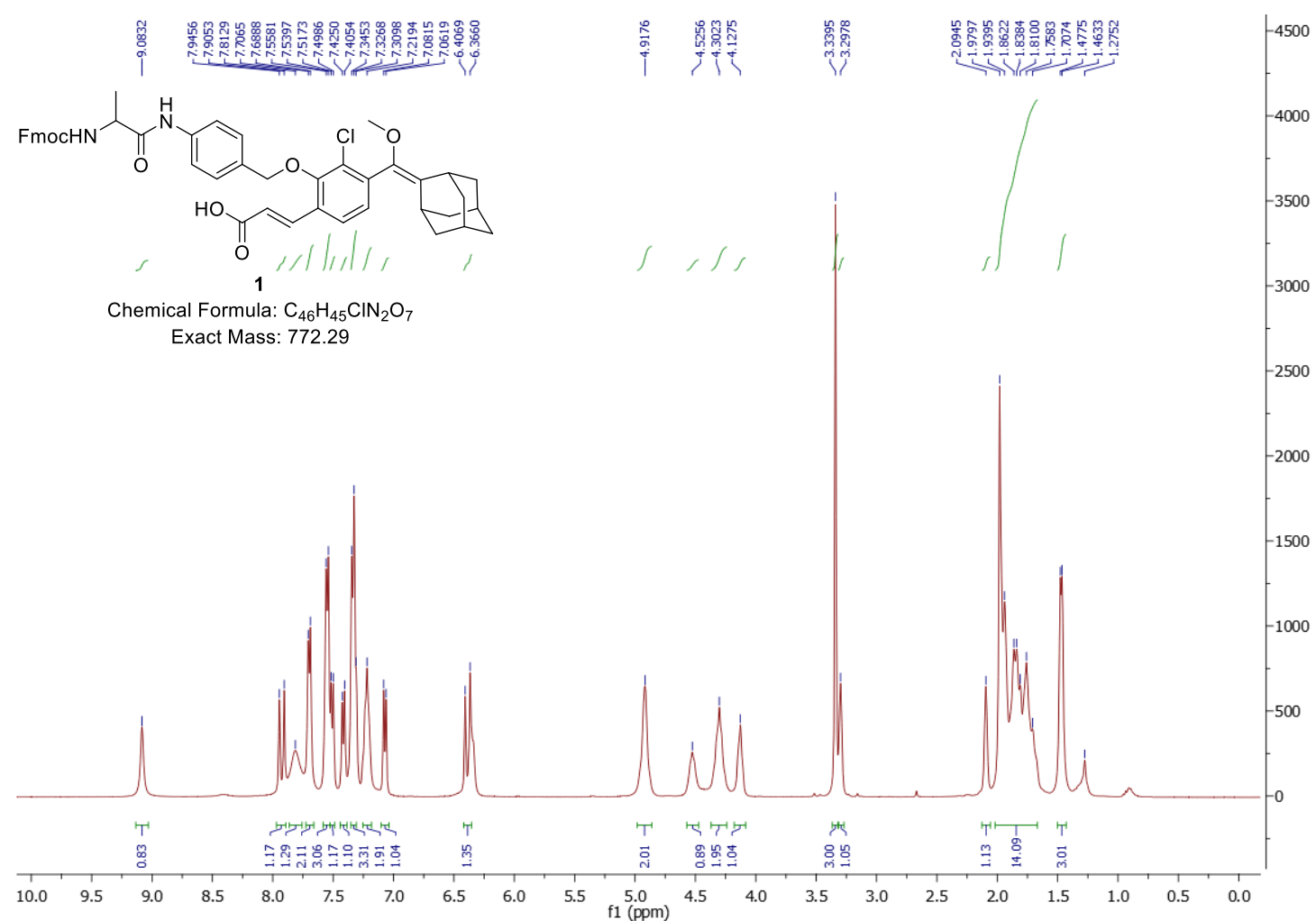

${ }^{1}$ HNMR spectrum of compound 1
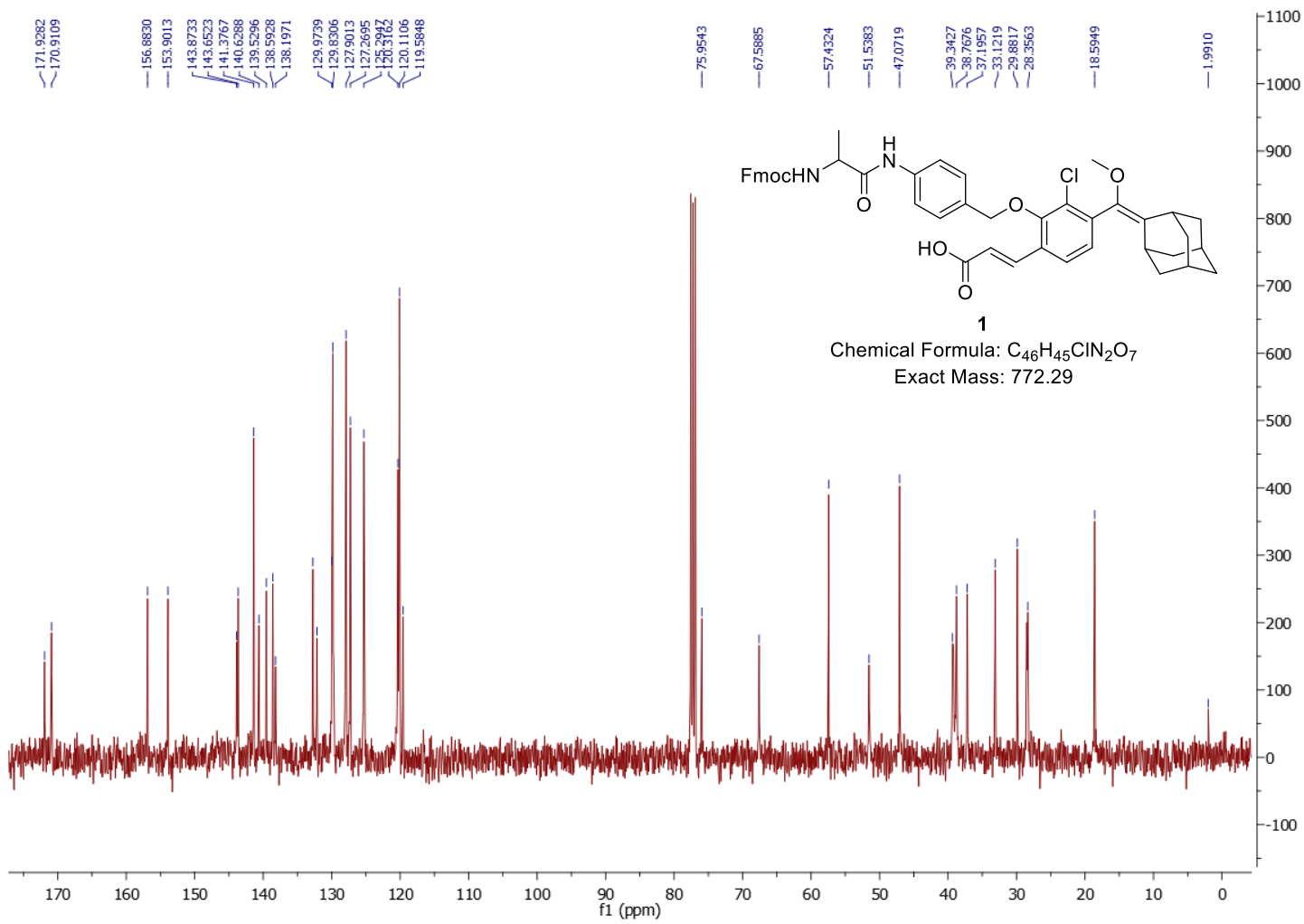

${ }^{13}$ CNMR spectrum of compound $\mathbf{1}$ 


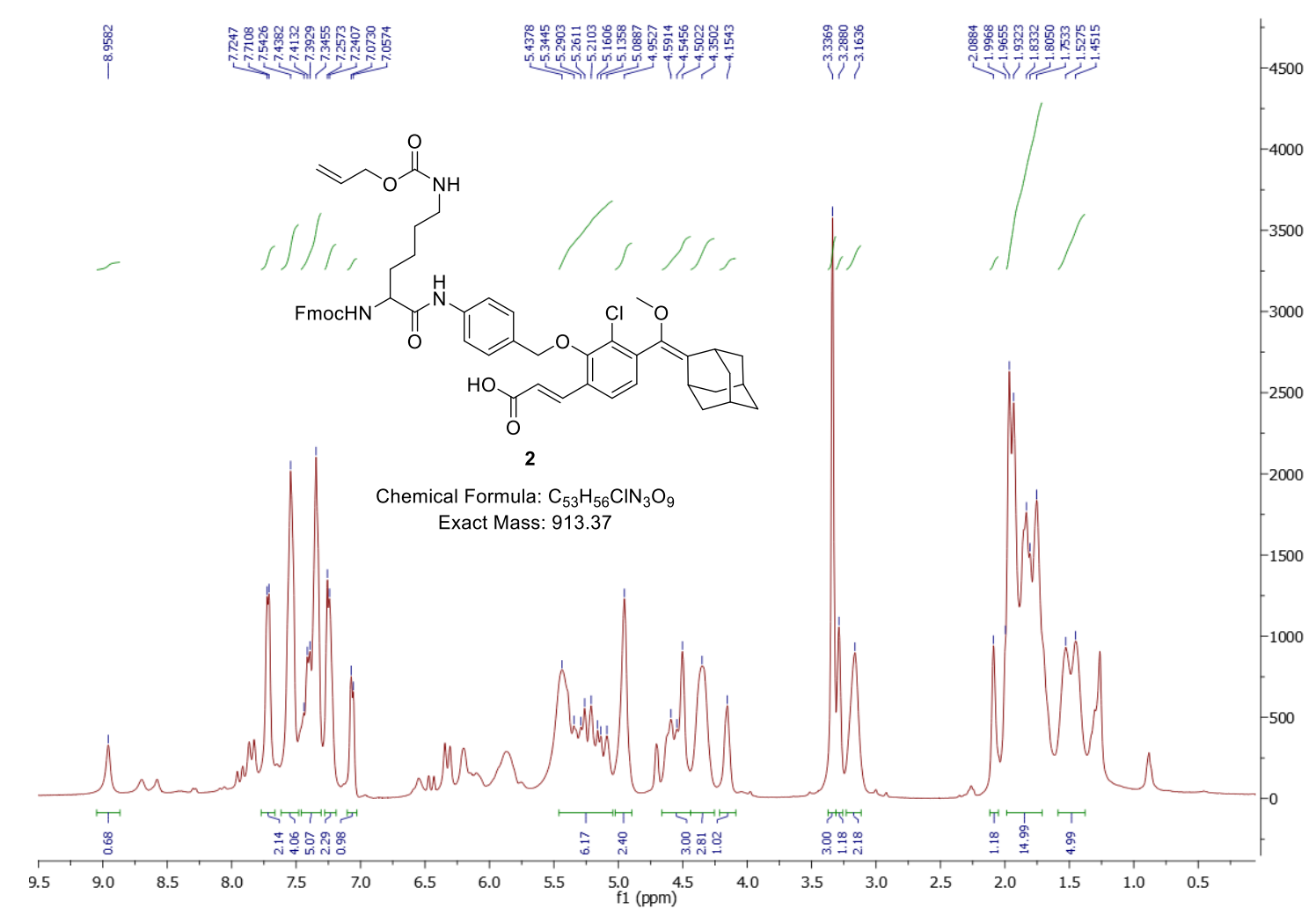

${ }^{1}$ HNMR spectrum of compound 2

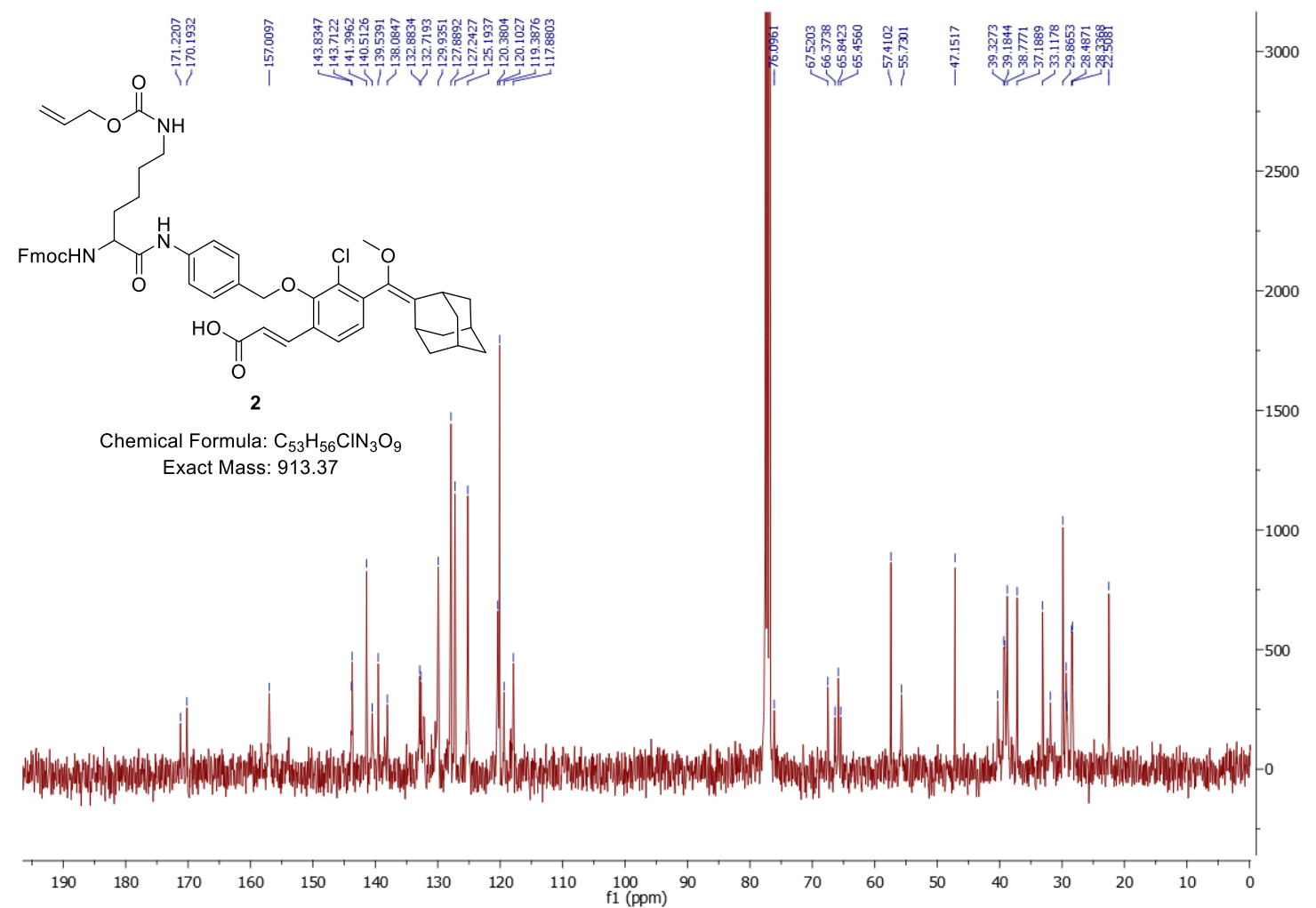

${ }^{13} \mathrm{CNMR}$ spectrum of compound 2 


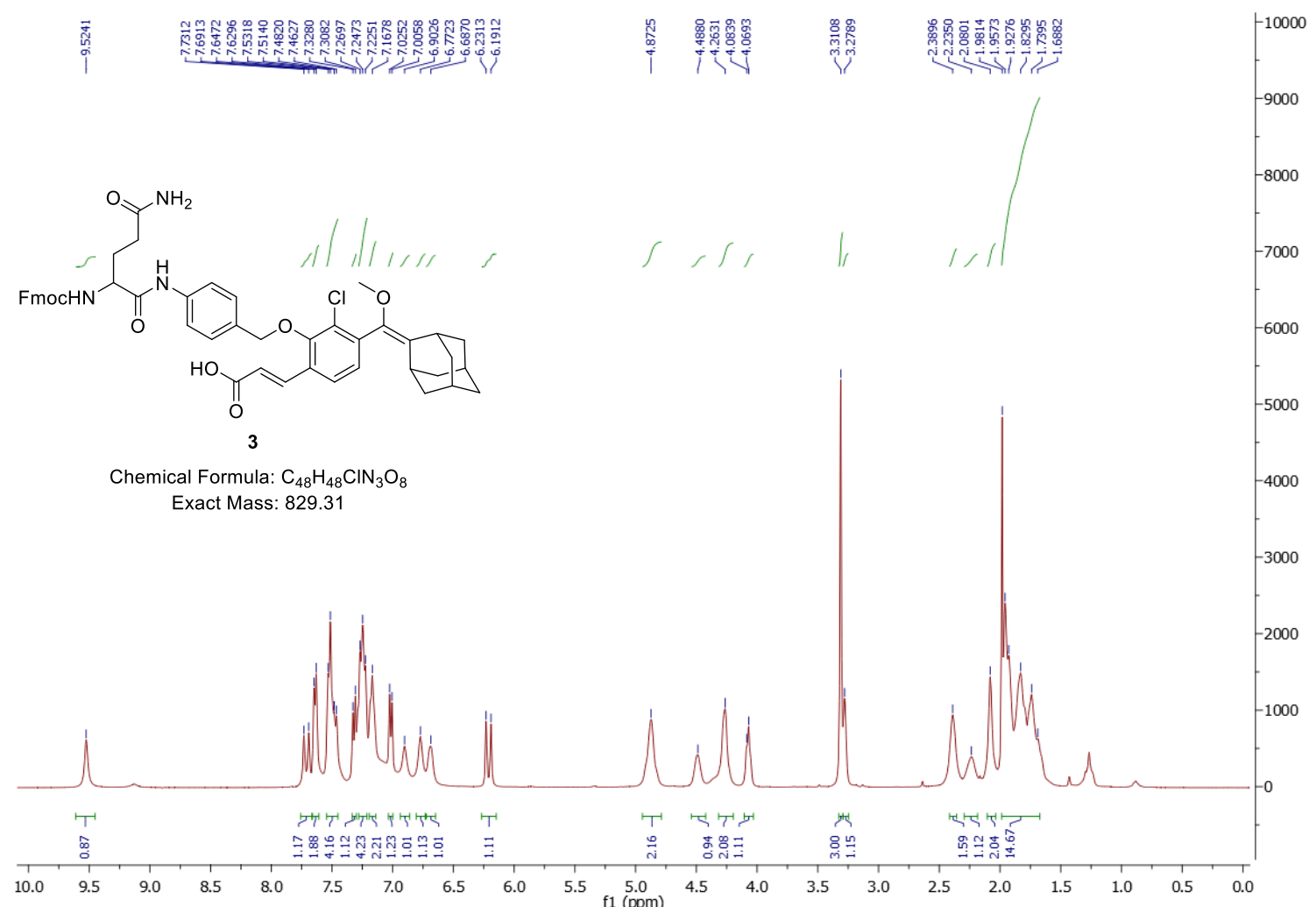

${ }^{1}$ HNMR spectrum of compound 3

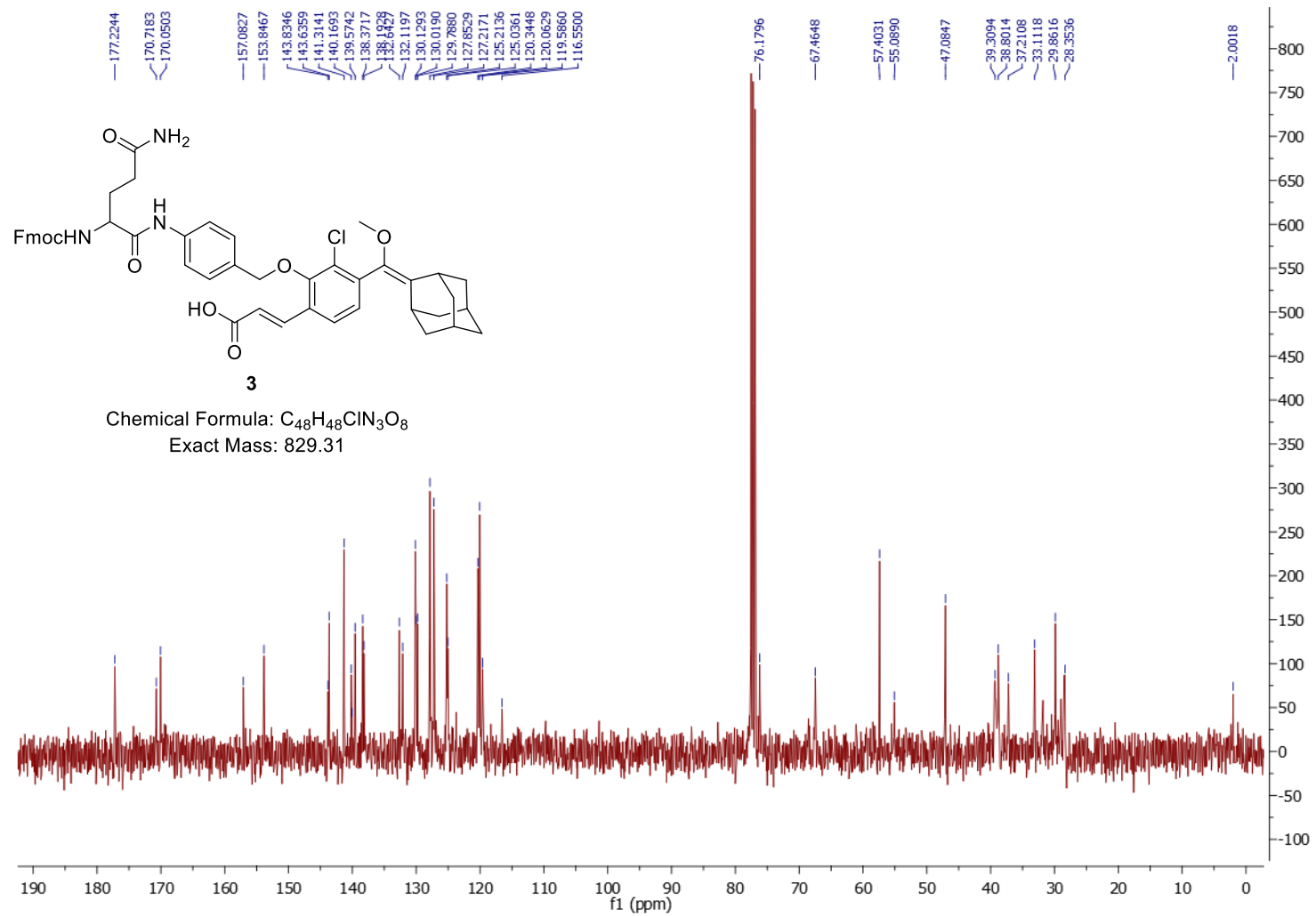

${ }^{13}$ CNMR spectrum of compound 3 


\section{References}

1. Hananya, N., Reid, J.P., Green, O., Sigman, M.S., and Shabat, D. (2019) Chem. Sci. 10, $1380-$ 1385.

2. Gutkin, S., Green, O., Raviv, G., Shabat, D., and Portnoy, O. (2020) Bioconjugate. Chem. 31, 2488-2493.

3. Roth-Konforti, M., Bauer, C., and Shabat, D. (2017) Angew. Chem. Int. Ed. 129, 1583915844.

4. Kisin-Finfer., Ferber, S., Blau, R., Satchi-Fainaro, R., and Shabat, D. (2014) Bioorg. Med. Chem. Lett. 24, 2453-2458. 